\title{
WestVirginiaUniversity
}

THE RESEARCH REPOSITORY @ WVU

Graduate Theses, Dissertations, and Problem Reports

2015

\section{Three Essays on the Economics of Agricultural and Energy Policy}

Christopher Shultz

Follow this and additional works at: https://researchrepository.wvu.edu/etd

\section{Recommended Citation}

Shultz, Christopher, "Three Essays on the Economics of Agricultural and Energy Policy" (2015). Graduate Theses, Dissertations, and Problem Reports. 6640.

https://researchrepository.wvu.edu/etd/6640

This Dissertation is protected by copyright and/or related rights. It has been brought to you by the The Research Repository @ WVU with permission from the rights-holder(s). You are free to use this Dissertation in any way that is permitted by the copyright and related rights legislation that applies to your use. For other uses you must obtain permission from the rights-holder(s) directly, unless additional rights are indicated by a Creative Commons license in the record and/ or on the work itself. This Dissertation has been accepted for inclusion in WVU Graduate Theses, Dissertations, and Problem Reports collection by an authorized administrator of The Research Repository @ WVU.

For more information, please contact researchrepository@mail.wvu.edu. 


\title{
Three Essays on the Economics of Agricultural and Energy Policy
}

\author{
Christopher Shultz
}

Dissertation submitted

to the Davis College of Agriculture, Natural Resources and Design at West Virginia University

in partial fulfillment of the requirements for the degree of

Doctor of Philosophy in

Natural Resource Economics

\author{
Gerard D'Souza, Ph.D., Chair \\ Joshua Hall, Ph.D. \\ Donald Lacombe, Ph.D. \\ Michael Strager, Ph.D. \\ Xiaoli Etienne, Ph.D. \\ Inocencio Rodriguez, Ph.D. \\ Division of Resource Management
}

\author{
Morgantown, West Virginia \\ 2015
}

Keywords: campaign finance, political action committees, logrolling, median-voter theorem, Farm Bill, wind energy, hedonic regression, agricultural productivity, spatial heterogeneity, land values, spillover effects.

Copyright 2015 Christopher Shultz 


\section{Abstract \\ Three Essays on the Economics of Energy and Agricultural Policy}

\section{Christopher Shultz}

This dissertation is a discussion on the dynamics of energy and agricultural policy in the United States. The landscape for policy creation, innovation, and the role of government is ever changing as a new energy mix emerges. This study contributes to the academic literature by providing three independent narratives on various aspects of the changing relationship. Each of the three studies provides a unique insight into a narrowly defined aspect of the economics and policy of energy and/or agriculture in the United States.

First, consideration is made into the process of policy creation. This is accomplished through a review and synthesis of the literature on the determinants of legislator voting behavior and an econometric regression model. Using a series of legislator-specific, constituent specific and agricultural finance indicators, voting behavior on the 2014 Farm Bill is analyzed through the use of a simple binary logit regression model. Results indicate (along with the results of many other studies) that policy makers do not always act in a way that supports the desires of their constituency, and are often influenced significantly by campaign finance and lobbying. To be more specific, legislators did vote in favor of their constituency, but campaign finance and the state of the agricultural sector played the largest role in their decision making. This has implications for energy policy in general, and the agricultural-energy nexus in particular. Results are compared to those from prior studies which analyze the Farm Bill and similarities are defined. 
The second study provides a unique look at one type of externality that may occur as a result of the changing energy mix. As a result of the push toward renewables, wind is the fastest growing energy source in the United States. However, wind energy development has faced multiple forms of resistance with opponents citing issues such as bird deaths, noise, and aesthetics. Many studies have been published which examine the potential impact of wind turbines on surrounding residential land values and show that wind turbines can significantly reduce the value of homes nearby. While the literature with regard to residential land is abundant, very little work has been done in regard to agricultural land values. Given that agricultural landowners' portfolios are comprised heavily of land assets (accounting for approx. $80 \%$ of farm asset values on average), a significant reduction in value due to wind energy development is of significant concern. Using a hedonic regression model on the relatively small study area of Somerset County, PA, this study compares assessed land value to a series of land characteristics and other variables which represent the proximity and intensity of surrounding wind turbines. Results indicate that no significant relationship exists between the value of agricultural land and the presence of wind turbines nearby. Thus, policy makers are free to pursue the wind energy option relatively unencumbered by its impact on agricultural land. Based on previous research, the same cannot be said for residential land.

Finally, the third study uses agricultural production statistics at the county level for the entire United States to consider the role of spatial heterogeneity in agricultural productivity levels across the U.S. This impact is analyzed by estimating a spatially explicit production function for U.S. agriculture. Results indicate that significant spatial heterogeneity is present which in turn impacts productivity in the form of reduced (and sometimes increased) return to inputs. Clustering of productivity areas is apparent, with high productivity areas concentrated in 
the Midwest and Southeast, and low productivity areas concentrated in the Northeast and Southwest. This is quite likely due to factors such as land use, geographic characteristics and water availability. No significant spillovers from one region's input use on the net income of neighboring regions are observed. Despite this, the presence of a spatial lag is clear. From a policy standpoint, consideration should be made toward the costs and benefits of subsidy activity given that productivity levels are not uniform across space. 


\section{Acknowledgments}

First, I would like thank my wife for her endless patience and understanding through countless long work days. Not only has she been patient, but she has been almost solely responsible for keeping our lives 'normal.' Her love and friendship has been my single largest source of support and happiness in both life and work. Also, both sides of our family have been completely supportive of all aspects of our personal and professional lives. Thanks to my parents, David and Melody Shultz, my sister, Ashlyn Shultz, and my in-laws, Mike and Shae Davis for all of their help and guidance.

Professionally, my biggest supporter has been my dissertation chair, Dr. Gerard D’Souza. He has made himself available even in the busiest of times and I could not have asked for a better mentor. From helping define my interests to simplifying the research process, he has been instrumental in my success both academically and professionally. Dr. D’Souza has achieved a great deal and is a role model for anyone interested in a career in academia. I am grateful for his support and look forward to keeping in touch for years to come.

Each of the members of my dissertation committee have provided a limitless amount of help both inside and outside of the classroom. Dr. Joshua Hall continues to act as an inspiration, mentor, as well as a colleague in the research process. Early on, I was inspired by his work ethic and philosophy regarding research. Soon after, we began working together on a variety of projects by which he helped me learn to link two separate interests - in this case, energy and public finance. He is also the absolute best teacher I have ever had. Dr. Hall genuinely views his students as equals and I am eternally thankful for his advice and mentorship. 
In addition, I am grateful for the remaining members of my committee. They always had an open door and exemplified professionalism and collegiality in helping me with research and coursework. Thanks to Dr. Donald Lacombe, Dr. Michael Strager, Dr. Xiaoli Etienne, and Dr. Inocencio Rodriguez. Having a large and diverse support system was essential in keeping my productivity high. Not on my committee, but likewise essential, are Dr. Jerry Fletcher, Dr. Peter Schaeffer, Dr. Alan Collins, and Dr. Mark Sperow. During the application process, I was admittedly not the strongest candidate. My academic track record showed progress, but no real commitment to excellence. Through some combination of hard work and luck, I managed to convince Dr. Fletcher and Dr. Schaeffer to take a chance on me. They conducted multiple private meetings with me to discuss my goals, interests, and motivations for entering the program, as well as introducing me to existing students. This process was vital in concreting my interest in the program and building relationships. I am eternally indebted to Dr. Fletcher and Dr. Schaeffer as, without their decision to admit me, I would not be writing this now. Admission to the program has undoubtedly changed my life, and they are partially responsible for that change.

Other members of the administration and faculty provided boundless support and advice. Dr. Alan Collins helped me through my first real attempt at academic research and provided guidance throughout my time in the program. Dr. Mark Sperow was the instructor for my first course in the program, and made himself available any time for long discussions on research and current events. Dr. Sperow also happens to be an all-around interesting person and his resume is enviable. Finally, Lisa Lewis was always available with not only professional but emotional support, and she really helped to make my time in the Division enjoyable. Thanks to Dr. Collins, Dr. Sperow, and Ms. Lewis. 
I would be careless if not to mention the friends I made through the program. Each of them played a role in shaping my experience and making it incredibly positive. Thanks to Sam Taylor for helping me grow not only professionally, but as a person. He is a constant force of positivity and liked by everyone he meets. He once peer-pressured me to lead climb a 100 foot cliff, which I safely accomplished despite my doubts. I believe that fear can be one of our greatest teachers and I appreciate his willingness in teaching me to safely harness it through climbing. I would also like to thank Elham Erfanian, Brianne Zimmerman, Caleb Stair, Kofi Nkansah, David Aratuo and Jennifer Dumevi for not only being supportive colleagues, but also friends. I look forward to seeing what you will all inevitably accomplish and I continue to root for your happiness and success. 


\section{Table of Contents}

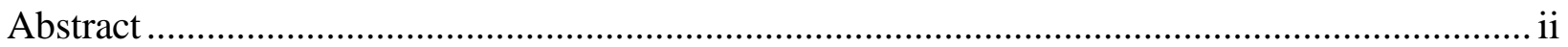

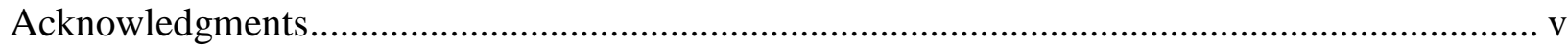

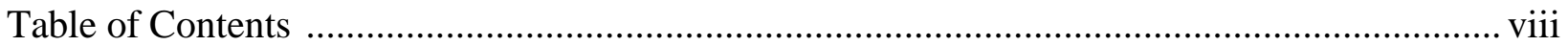

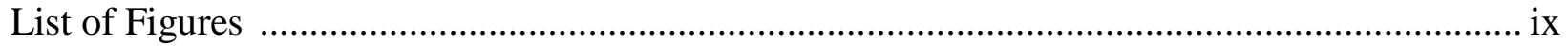

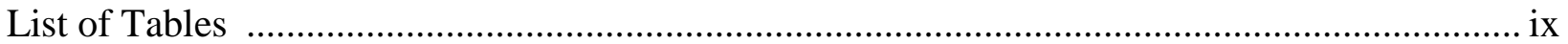

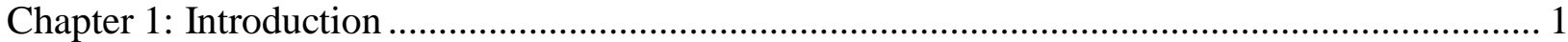

Chapter 2: Essay 1 - Congressional Voting on the 2014 Farm Bill and the Role of Campaign

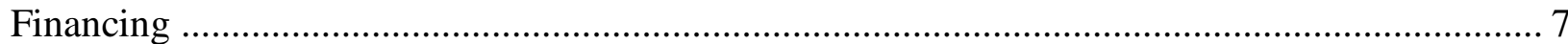

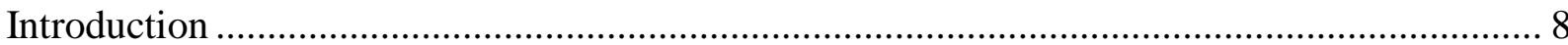

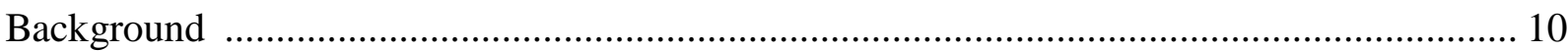

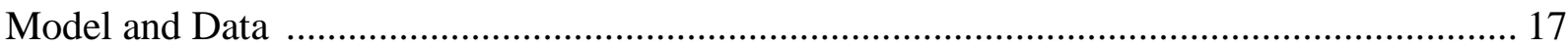

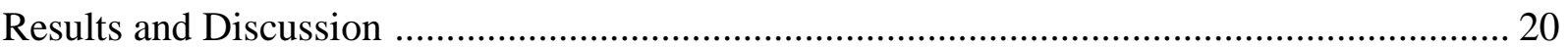

Chapter 3: Essay 2 - Production of Wind Energy and Agricultural Land Values: Evidence from

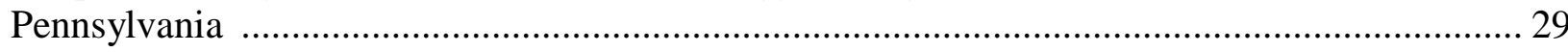

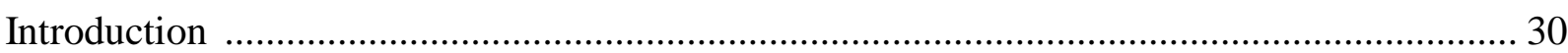

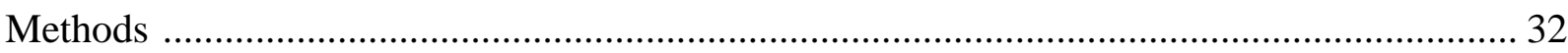

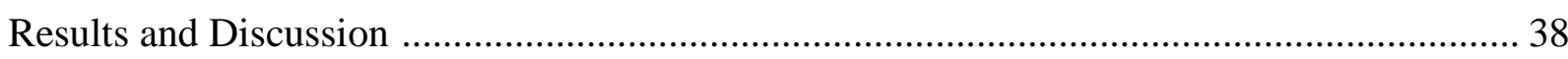

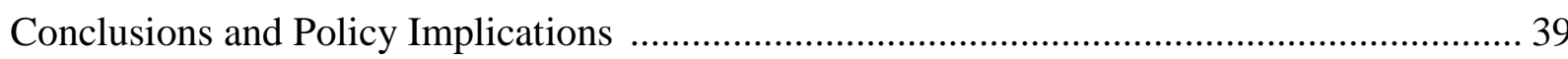

Chapter 4: Essay 3 - Estimating a Spatially Explicit Production Function for U.S. Agriculture 43

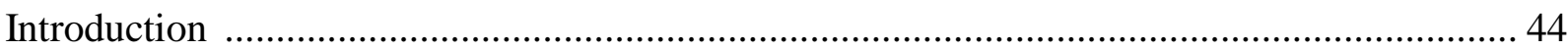

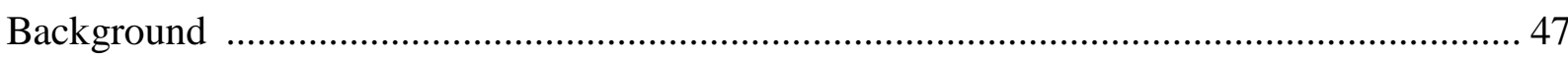

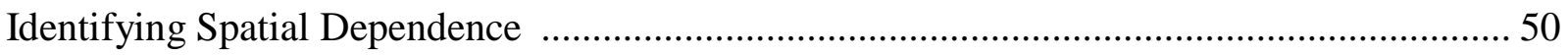

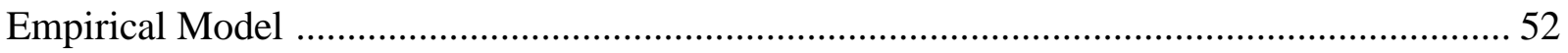

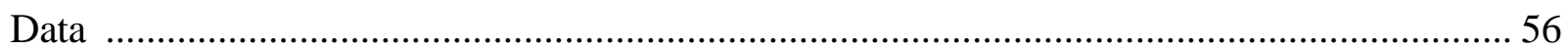

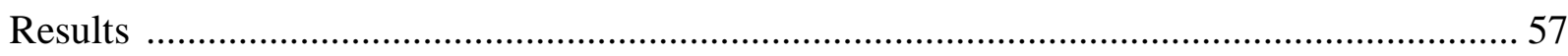

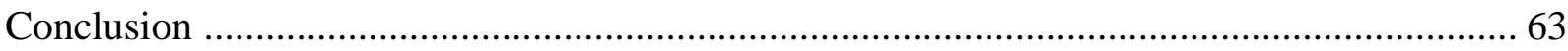

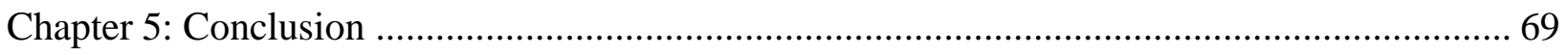

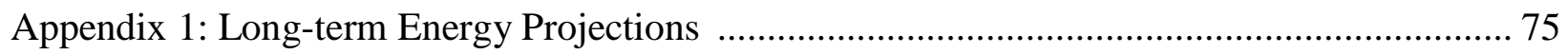

Appendix 2: Elhorst Testing Procedure ………………….................................................... 82

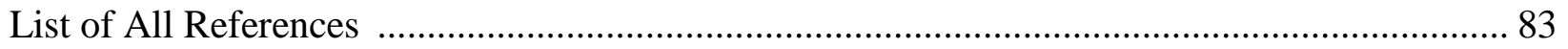




\section{List of Figures}

Figure 1: U.S. Corn Usage by Segment (2011) Source: NGGA 2012 World of Corn ................. 2

Figure 2: Components of the 2014 Farm Bill (Billions of US \$) ........................................... 9

Figure 3: Agricultural Land and Wind Turbines in Somerset County, PA................................ 35

Figure 4: Farms and land in U.S. Farms by Economic Sales Class (2012) ............................. 45

Figure 5: Bureau of Economic Analysis Regions ............................................................... 46

Figure 6: Change in Agricultural Productivity by State, percent, 1960-2004 .......................... 49

Figure 7: Local Indicators of Spatial Association (LISA) on U.S. Agricultural Data (2012) ...... 58

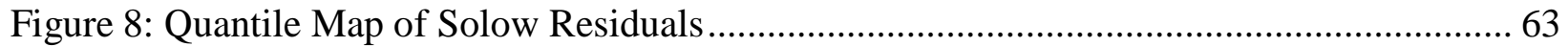

Figure 9: Total Energy Production Projections..................................................................... 75

Figure 10: Nuclear Energy Consumption Projections ...................................................... 77

Figure 11: Hydropower and Other Renewables............................................................. 78

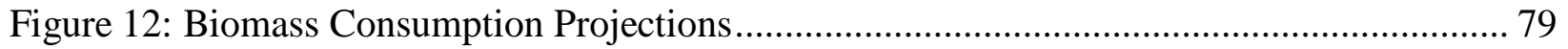

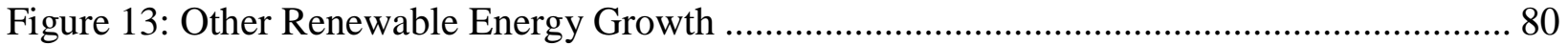

\section{List of Tables}

Table 1: Descriptive Statistics for Non-Binary Variables .................................................... 20

Table 2: Logit results on 2014 Farm Bill vote .................................................................. 21

Table 3: Marginal effects from logit regression........................................................... 21

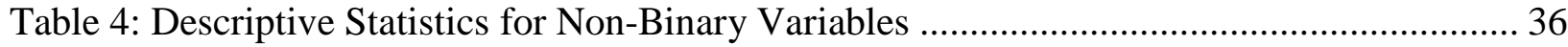

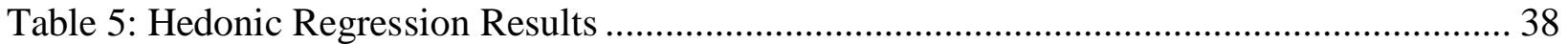

Table 6: Descriptive Statistics of U.S. Agricultural Data (2012) .......................................... 57

Table 7: Global Moran's I Statistics for U.S. Agriculture (2012) .......................................... 57

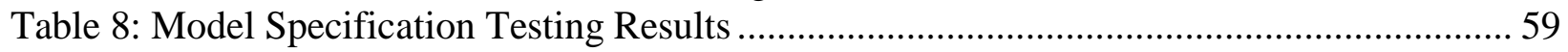

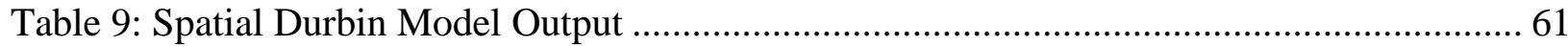

Table 10: Growth Rates of Energy Production by Source $(2015-2040)$.................................... 76 


\section{Chapter 1: Introduction}

Among many policy actions, the Energy Independence and Security Act of 2007 (subsequently revised in 2014) sets forth ambitious goals including the use of 35 billion gallons of ethanol-equivalent biofuels and 1 billion gallons of biomass based diesel in the United States by 2022 . The EISA also includes funding of other renewable technologies such as solar and wind power. Renewable sources of energy are regional and site-specific, so it is natural that each region of the nation will play its own role in the fulfillment of the mandates (Chel and Kaushik, 2011). Regardless of mandated figures, the EIA and EPA both forecast long term numbers far below the EISA requirements (Tyner et al., 2011). Projections reveal a changing climate in which coal will decline, and alternate sources such as natural gas and renewables such as wind and solar are expected to rise. Recently, President Obama released a Clean Power Plan which

includes a variety of similar provisions, most notably, a 32 percent reduction in 2030 (White House, 2015). As background on the general state of the industry, long-term energy projections are included in Appendix 1.

Before 2005, there was little correlation between energy and agricultural commodity prices (Tyner 2010). Given that the push towards renewables requires trade-offs in the form of land-use change and increased demand for agricultural commodities, energy and agricultural prices are becoming increasingly linked. For example, ethanol policy can have a significant impact on corn prices and often increase the inefficiency of farm subsidies (de Gorter and Just, 2010). By 2020, considering current investment plans, international prices could increase $26 \%$ for corn, 28\% for oilseeds, and $8 \%$ for wheat (Bessou et al., 2011). The United States is one of the largest agricultural producers in the world, and leads the world in corn. U.S. agricultural exports have been larger than U.S. agricultural imports since 1960, generating a surplus in 
agricultural trade (ERS, 2013). This results from a variety of factors, agricultural policy being one. In order to make informed agricultural policy decisions, empirical data and analysis is vital.

In the creation of policy moving forward, these changing dynamics must be considered. In the new energy mix, the energy and agricultural sectors are likely to compete for land and water use as well as commanding more policy attention. For example, corn is the most widely produced feed grain in the U.S., a mainstay of agricultural policy, as well as a multitude of food products for human consumption (ERS, 2013). As the energy mix changed, corn became increasingly demanded by ethanol producers; whether this will continue is less certain. Figure 1 shows a breakdown of corn usage by sector in 2011. It is clear that ethanol requires a significant amount of corn, and as dependence on biofuels increases, this number is likely to rise, unless switch grass and other feedstock rise in prominence.

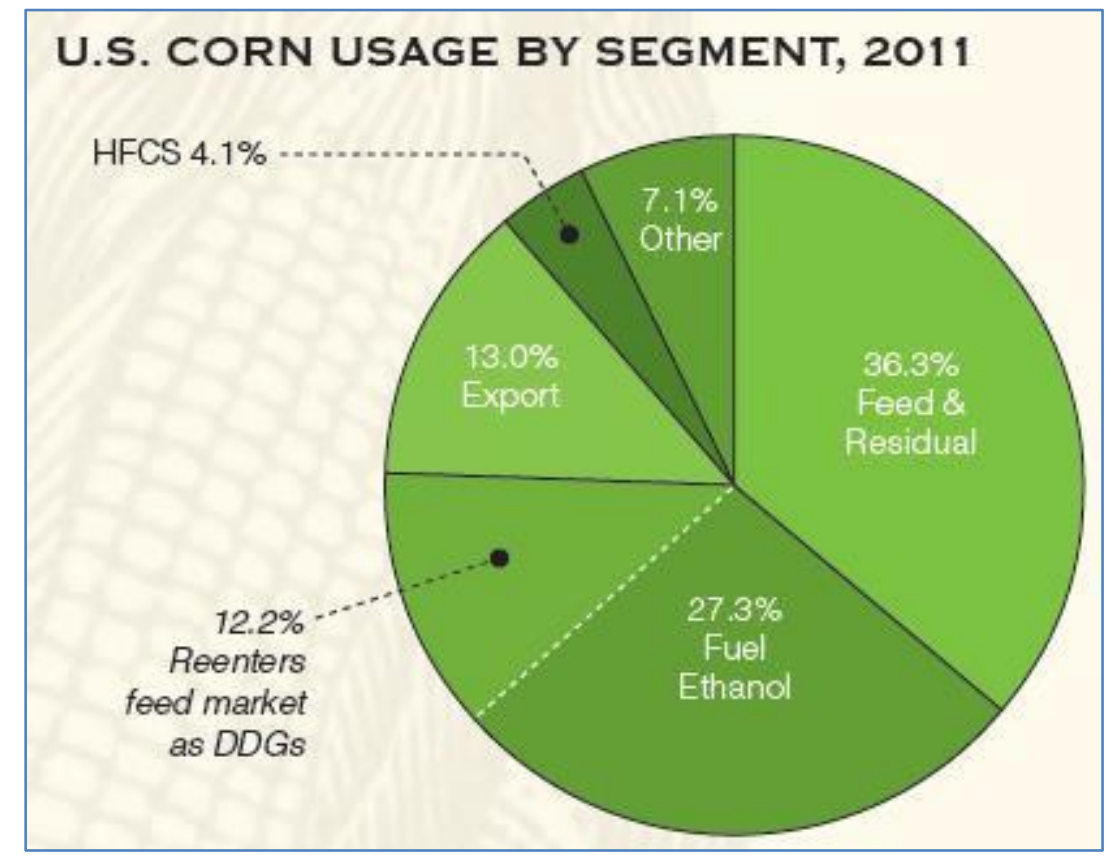

Figure 1: U.S. Corn Usage by Segment (2011) Source: NGGA 2012 World of Corn

Given that resources (land, food, water, etc.) are limited, competition for land between energy and agricultural producers leads to a new range of problems with regard to resource 
allocation. As demand for corn increases, so should its price. Alternatively, supply could rise in which more land would be needed for production. The emerging dynamics of the energyagriculture nexus are complex and a constant source of discussion in the literature. Corn for food and ethanol is only one example of the emerging energy mix. The discussion of all potential issues that could arise out of the changing market conditions for energy and agriculture would warrant its own paper. Rather than try to tackle that challenge, this study attempts to analyze three separate case studies in regard to energy and/or agricultural policy.

First, essay \#1 provides a review and synthesis on the determinants of legislative voting behavior on current and past Farm Bills. This is done through the implementation of a simple logit regression model over the legislative votes on the 2014 Farm Bill (Agricultural Act of 2014 ) in the $113^{\text {th }}$ Congress on January 29,2014 . The topic of money in politics is often discussed and is a commonly addressed topic in econometric modeling (Abler, 1991; Brooks, 1997; Ansolabehere et al., 2003; Abetti, 2008; etc.). This study adds value by isolating those studies which have focused on Farm Bill legislation. Lee and Tkachyk (1987) examine the farm bills of 1977, 1981, and 1985, while Yeung (2008) examines the Farm Bill of 1996 and various amendments. This study contributes to the literature by analyzing determinants of voting behavior on the Farm Bill of 2014 and subsequently providing a synthesis and discussion of common themes among the results in all three papers.

The second essay examines one scenario in which externalities may exist as a result of the changing energy mix. Wind is the fastest growing source of renewable electricity in the United States. However, this growth is not without opponents. Those against the development of wind energy cite bird deaths, noise, and aesthetics. Prior literature has shown that wind turbines can reduce the value of residential property (Heintzelman and Tuttle, 2012). No other studies 
have focused primarily on agricultural land. This study presents a case study of Somerset County, Pennsylvania. Somerset County, PA is a highly rural area with approximately 80 people per square mile. Despite its rural nature, the area is also in heavily utilization of its wind energy capacity with turbines spanning across many of the dominant ridge lines. A hedonic price model is implemented in comparing the assessed value of a given agricultural land parcel to a matrix of explanatory variables and property characteristics. This provides insight into the relationship between agricultural land and wind turbines by explaining how assessment values take surrounding property into consideration.

Finally, the third essay in this series examines the role of spatial heterogeneity in agricultural production and what role it may play in the productivity of various operations. For example, an apple farm in the Arizona desert is likely to exhibit different productivity characteristics than apple farms in West Virginia. This study employs a spatial econometric model specification to estimate an agricultural production function at the county-level and then quantify this spatial variation in productivity that results from spatial heterogeneity. 


\section{References}

Abetti, P. (2008) "Congressional Voting on DR-CAFTA: Ineffectiveness of Environmental Lobbying." Journal of Economic Policy Reform. 11:11-20.

Abler, D. (1991) "Campaign Contributions and House Voting on Sugar and Dairy Legislation." American Journal of Agricultural Economics. 73: 11-17.

Ansolabehere, S., de Figueiredo, J., and Snyder, J. (2003) "Why is There So Little Money in U.S. Politics?” Journal of Economic Perspectives. 17(1): 105-130.

Bessou, C., Ferchaud, F., Gabrielle, B. and Mary, B. (2011) "Biofuels, Greenhouse Gases and Climate Change. A Review.” Agronomy for Sustainable Development. 31(1):1-79.

Brooks, J. (1997) “Congressional Voting on Farm Payment Limitations: Political Pressure or Ideological Conviction?” Journal of Agricultural and Resource Economics. 22(2): 281-295.

Chel, A. and Kaushik, G. (2011) "Renewable Energy for Sustainable Agriculture." Agronomy for Sustainable Development. 31(1): 91-118.

De Gorter, H. and Just, D. (2010) "The Social Costs and Benefits of Biofuels: The Intersection of Environmental, Energy and Agricultural Policy." Applied Economic Perspectives and Policy. 31(1): 4-32.

ERS (Economic Research Service). (2013) “Corn Overview." USDA Economic Research Service. http://www.ers.usda.gov/topics/crops/corn.aspx

ERS (Economic Research Service). (2013). “U.S. Agricultural Trade Overview.” USDA Economic Research Service. http://www.ers.usda.gov/topics/international-markets-trade/usagricultural-trade.aspx\#.U5h_IyiPW71

Heintzelman, M. and Tuttle, C. (2012) "Values in the Wind: A Hedonic Analysis of Wind Power Facilities." Land Economics. 88(3): 571-588.

Lee, D. and Tkachyk, S. (1987) "An Empirical Analysis of Congressional Voting on Farm Bill Legislation." Cornell Agricultural Economics Staff Paper. 87(21)

Tyner, W. (2010) “The Integration of Energy and Agricultural Markets.” Agricultural Economics. 41(6): 193-201.

Tyner, W., Dooley, F. and Viteri, D. (2011) "Alternative Pathways for Fulfilling the RFS Mandate.” American Journal of Agricultural Economics. 93(2): 465-472. 
The White House. (2015) "Fact Sheet: President Obama to Announce Historic Carbon Pollution Standards for Power Plants." The White House. Office of the Press Secretary.

https://www.whitehouse.gov/the-press-office/2015/08/03/fact-sheet-president-obama-announcehistoric-carbon-pollution-standards

Yeung, I. (2008) "The Influence of Campaign Contributions on Legislative Voting: A Case Study of the 1996 Farm Bill.” Thesis. Department of Economics, Amherst College. 


\title{
Chapter 2: Essay 1 - Congressional Voting on the 2014 Farm Bill and the Role of Campaign Financing
}

\begin{abstract}
This paper is a review and synthesis on the determinants of legislative voting behavior on current and past Farm Bills. A detailed overview of the 2014 Farm Bill and supporting literature are discussed. Using a series of legislator-specific, constituent-specific, and agricultural finance indicators, this paper utilizes a simple binary logit regression model which provides insight into the role of campaign finance, demographics, and constituent interests in the voting decisions of legislators. Results indicate that while legislators did vote in favor of their constituency, campaign finance and the state of the agricultural sector played a larger role in decision making. In addition, results of prior studies on Farm Bills are discussed and compared.
\end{abstract}

Keywords: campaign finance, political action committees, logrolling, median-voter theorem, Farm Bill

JEL Classification: D72, D73 


\section{Introduction}

The Agriculture Act of 2014 — commonly referred to as the 2014 Farm Bill— was passed by the U.S. House of Representatives 251 to 166 on January 29th, 2014. The U.S. Senate passed the bill with a tally of 68 to 32 on February 3rd (U.S. Senate, 2014). According to U.S. Senator Debbie Stabenow, the main purpose of the Farm Bill is to "reform, eliminate, and streamline numerous programs, saving taxpayers \$23 billion.” The 2014 Farm Bill provides legislation to deal with the constantly changing challenges involved with agricultural production in the United States. A few ways the bill does this are ending direct payments, strengthening crop insurance, and innovating in regard to risk management strategies (Stabenow, 2014). The bill also provides programs for conservation, rural development, trade promotion, and countless others (U.S.D.A., 2014).

Despite these seemingly positive changes for the agricultural sector, many researchers argue that the economic welfare implications of the 2014 Farm Bill are unjust. In a 2014 article, Goodwin and Smith argue that the bills' main action is the transfer of income to relatively wealthy farm families at the expense of taxpayers. In their study, which is essentially a summary of prior literature, they conclude that the long run productivity of the agricultural sector is at stake as a result. In addition to transfers for farm-related concerns, SNAP and nutrition funding in the 2014 Farm Bill is dominant (see Figure 1). The magnitude of the proportion of the total budget allocated to SNAP and nutrition is worth consideration.

In the passing of such a bill, a wide variety of costs and benefits must be considered. Hamilton (2014) provides an extensive overview of the difficulties faced in the legislative process for the 2014 Farm Bill and identifies what he refers to as "eight stages of frustration." The Farm Bill was supposed to be renewed in 2012, but due to a variety of 
complications including inactivity from the House and division among Republicans, it took roughly two years before its final passage. Hamilton points out that this lengthy process (due to bureaucratic inefficiency) had significant costs and impacts on farmers and ranchers across the country. However, he also argues that the final bill is a demonstration that local governments still have a voice and role to play in the Farm Bill and other major legislative action.

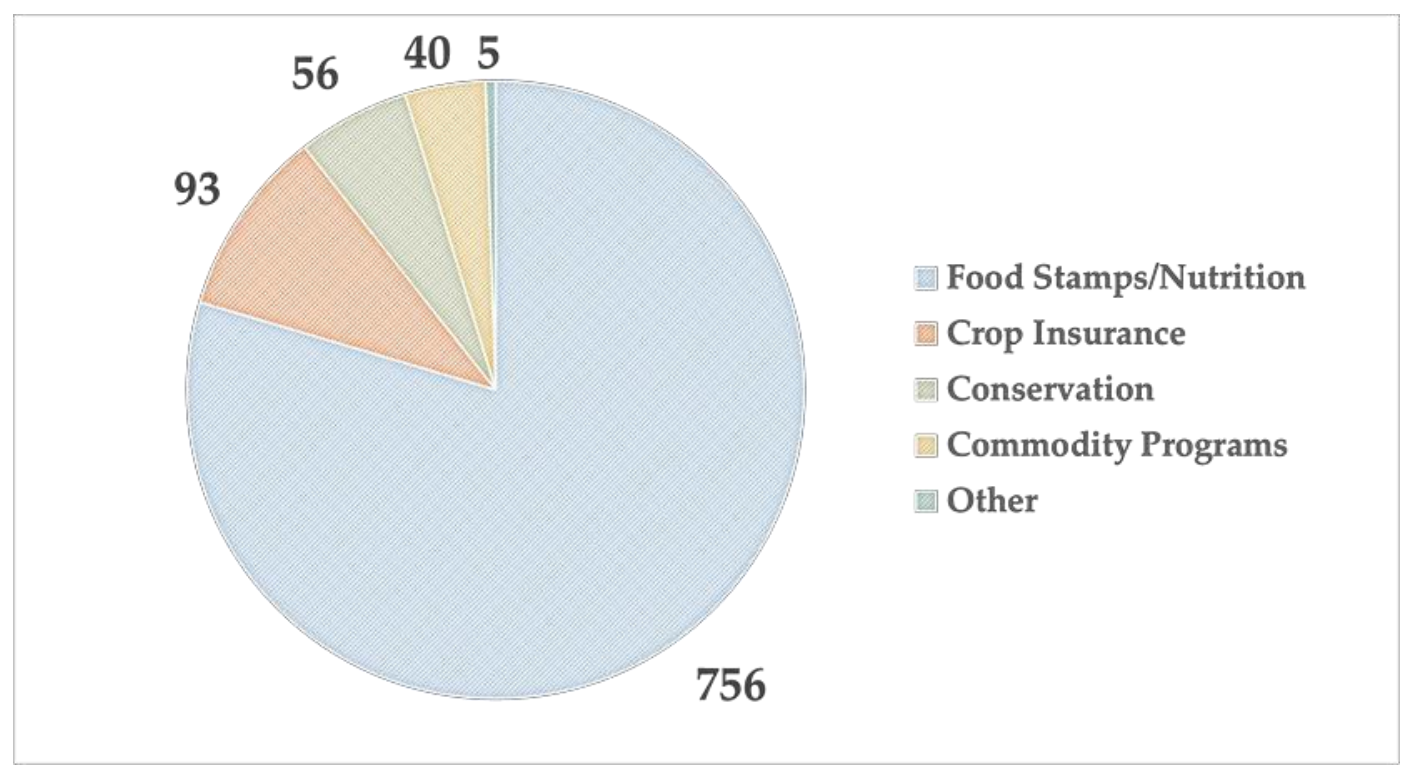

Figure 2: Components of the 2014 Farm Bill (Billions of US \$)

Multiple studies have shown that legislators don't always vote in the best interest of their constituents. For example, Brooks et al. (1998) find that the effectiveness of Political Action Committee (PAC) contributiosn reflects the dominance of political pressure over ideological concerns. Voting behavior can also be influenced by other factors such as campaign funding, logrolling, and political pressure. However, measuring these influences has proven difficult. The influence of donors is often likely to occur early in the legislative process, especially in committees where the results of such action are not easily quantifiable. Individuals who wish to have influence on legislative action are not limited to individual contribution, but may also pursue other strategies such as lobbying or favor trading. Thus, researchers who wish to examine 
the role of money in politics must consider the impact of both interest groups, PACs and individual donors (Powell, 2014).

This study investigates the determinants of legislator voting on the recent 2014 Farm Bill with a specific focus on campaign contributions from the agricultural sector. Many of the developments in the agricultural sector since the 1950s have been sudden and transformational, while others have been gradual, but present (Anderson et al., 2013). As stated by Yeung (2008), the Farm Bill provides an interesting case study "because the benefits are concentrated on a small group and the costs are spread throughout the public." In examining the way agricultural policy is made, it is important to understand why legislators vote in a particular way. More importantly, The Farm Bill is a very expensive program, costing taxpayers over $\$ 900$ billion. Given that roughly 85 million tax units (including single, married filing individually and married filing jointly) paid federal income tax in 2010, this implies that each tax unit will pay roughly $\$ 10,000$ for the 2014 Farm Bill. In addition to this important consideration, Lopez (2001) finds that eliminating campaign contributions would significantly decrease agricultural subsidies, benefit consumers and taxpayers, and increase social welfare by approximately $\$ 5.5$ billion.

The remainder of this paper is structured as follows: Section 2 provides a brief overview of the relevant literature with a theoretical discussion, an examination of previous studies, and finally, an overview of analyses on the influence of campaign contributions on prior Farm Bills; Section 3 presents a comprehensive overview of the data and methodology used for the empirical analysis; Section 4 provides an in depth examination of the empirical findings and concludes the study and compares results to other studies on previous Farm Bill legislation.

\section{Background}


In a 1997 paper on congressional voting on farm payment limitations, Jonathan Brooks addresses the complex nature of the relationship between constituency desires, ideological beliefs, and the pressure to tow the party line. Citing various studies (Kau, Kennan, and Rubin, 1982; Welch, 1982; Vesenka, 1989; Abler, 1991) he identifies three main categories which have been shown to impact legislative decision making: (1) a response to lobbying, measured by campaign contributions; (2) a response to the concerns of the constituency; and (3) ideological factors specific to the legislator. As previously mentioned, campaign financing from lobbying can serve as a proxy, but it is also important for a researcher to consider all funding sources ranging from lobbyists to PACs to individuals. The role of lobbying can even change an entire industry as a result of policy manipulation. For example, the U.S. sweetener industry has been heavily impacted by federal legislative protection, resulting in prices that are relatively stable, but much higher than the rest of the world. The three major factors behind that protective status are: (1) the economic importance of the industry; (2) the large representation of sweetener producing states in the U.S. congress; and (3) a powerful and successful lobby (Alvarez, 2005).

The economic theory of regulation is often used as a starting point in the analysis of the determinants of voting decisions. Originally discussed by Stigler (1971) and later modified by Peltzman (1976), the theory provides a framework of economic and political regulation using the concepts of supply and demand. A state can provide benefits to industry through coercion and manipulation of the market. Market manipulation can take various forms including direct subsidies, control over market entry, control of substitutes and complements, and price-fixing. The actualization of such policies requires a cost. For example, costs that political parties face include operational, organizational, and campaign costs. Industries wishing to influence a political party must be prepared to pay with either votes or resources. Resources can take the 
form of campaign contributions, services, favor trading, etc. Thus, in the traditional supply and demand framework, political parties supply the potential for market manipulation and demand votes and resources. Industries supply votes and resources and demand market manipulation Inherent in this theory is that lawmakers are motivated primarily by the possibility of reelection and thus, aim to enact policy at the level that equates marginal cost to marginal benefit. Costs in this case are defined as the potential loss of political support from 'losers' within the constituency whose policies did not win out. Benefits are the potential gain of political support of 'winners.' (Brooks, 1997). In one application of this idea, Abler (1991) examines PAC contributions by sugar and dairy producers and their role on sugar and dairy legislation in the U.S. House of Representatives. Results indicate that while groups may buy votes from legislators who would not otherwise support them, the most common occurrence is that groups help elect legislators who are ideologically predisposed to supporting their goals. While the Economic Theory of Regulation provides a useful framework, a narrowly defined model based on this theory does not perform well in explaining voting behavior compared to an expanded model which includes some proxy for legislator ideology (Vesenka, 1989).

The traditional median-voter model was first brought forth by Duncan Black (1948) and then in a 1957 paper by Anthony Downs, titled "An Economic Theory of Political Action in a Democracy." In its simplest form, the Downsian model makes two assumptions regarding the behavior of constituents and legislators. Voters are assumed to act in a way which maximizes their utilities. Conversely, legislators are assumed to act in a way which maximizes their chance of reelection. This results in an equilibrium when the lawmaker matches his or her position to that of the median voter in the constituency. Congleton (2002) provides a comprehensive overview and update of the median voter model and describes it as perhaps the simplest model of 
majoritarian decision making. Inherent in the median voter model is the assumption that the median voters' age, sex, income, information, ideology, and expectations should all affect public policy outcomes. Weak form median voter theorem is the case in which the median voter always casts his or her vote for the policy which is adopted. Strong form median voter theorem is the case in which the median voter will always get his or her most preferred policy.

It should be noted that lawmakers - while representatives of a constituency — are motivated by their own self-interest. Despite the presence of incentives such as reelection, it is possible that legislators act in ways that reflect their independent ideological characteristics. However, it is also possible that these independent ideological characteristics reflect that of their constituency. This makes sense given that Downs argued rational ignorance among voters can lead them to elect lawmakers who they believe will represent them on a broad range of issues (Brooks, 1997).

In a largely comprehensive overview, Ansolabehere, de Figuieredo and Snyder (2003) examine 35 prior studies of the impact of campaign contributions on legislative voting behavior. The issues covered within the surveyed papers range from minimum wage to agricultural policy to aircraft carriers and indicate a highly mixed result. In their examination of the determinants of campaign contributions, some studies show high significance of campaign financing variables, while others do not. Out of 35 studies surveyed, 472 variables related to campaign donations were considered and only 124 (roughly 26\%) were significant at the $95 \%$ level. However, 34 of the 35 studies showed at least one significant ideological variable. Despite these interesting results, only four of the studies surveyed were directly related to agriculture. One interesting point made by the authors is that campaign contributions seem to be viewed as an investment in a political market place, and a return on investment is expected. Roscoe and Jenkins (2005) 
provide a similar study in which they conduct a meta-analysis on more than 30 previously published papers. Using logit meta-regression, they provide a summary of the literature on the link between contributions to political campaigns and the outcome of roll call voting. They conclude that roughly one-third of roll call votes display evidence of influence from campaign funding.

Abetti (2008) tested the effect of environmental lobbying on vote determination in regard to DR-CAFTA (Dominican Republic and Central American Free Trade Act), the first free trade agreement between the United States and a group of smaller developing economies. Despite the strong opposition from environmentalists, the authors found no significance between the lobbying efforts of environmental groups and the outcome of the vote. The strongest significance was found in regard to demographic and labor variables such as lobbying against the agreement from situational 'losers' such as the sugar and textiles industry. Results indicate that campaign contributions from labor and business were such an important factor, without them, CAFTA would not have passed. In a similar study, Devault (2010) concludes that interest groups had at best a 'modest' effect on political action in regard to CAFTA. Many other indirectly related studies have been completed (Tosini and Tower, 1987; Stratmann, 1991; McArther and Marks, 1998; Kahane, 1996; de Gorter and Swinnen, 2002; Fordham and McKeown, 2003; Constant, 2006; Chupp, 2011) and results are significantly mixed.

In 1982, Henry Chappell brought forth the idea that if contributions are endogenous, then single equation systems of estimation are subject to a possible bias based on the assumption that legislators with more 'power' are likely to receive more contributions, which is the source of endogeneity. As an alternative to single equation methods which may be subject to this bias, he proposes a 'simultaneous probit-tobit' model, which is composed of five equations: 

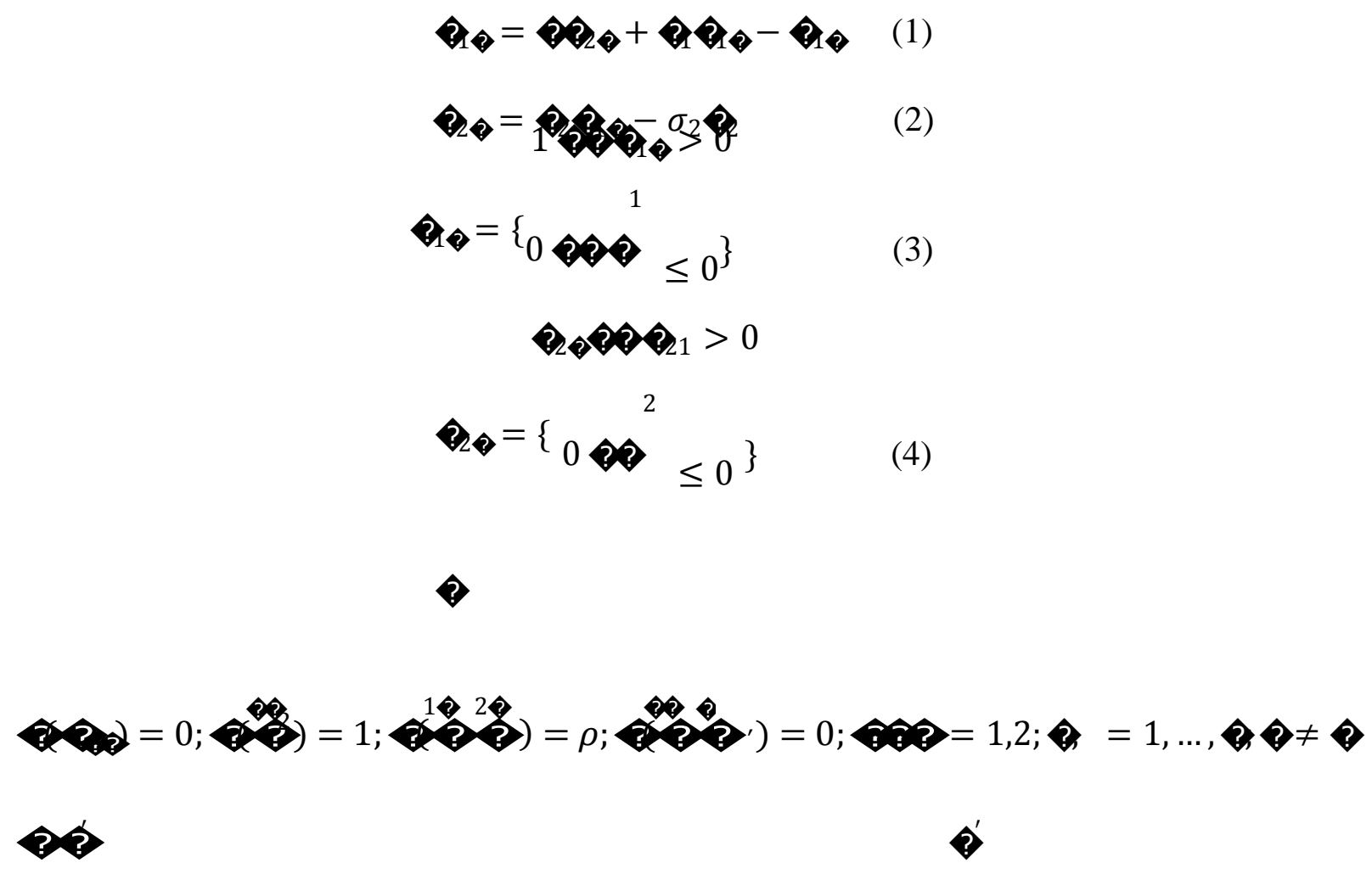

(5)

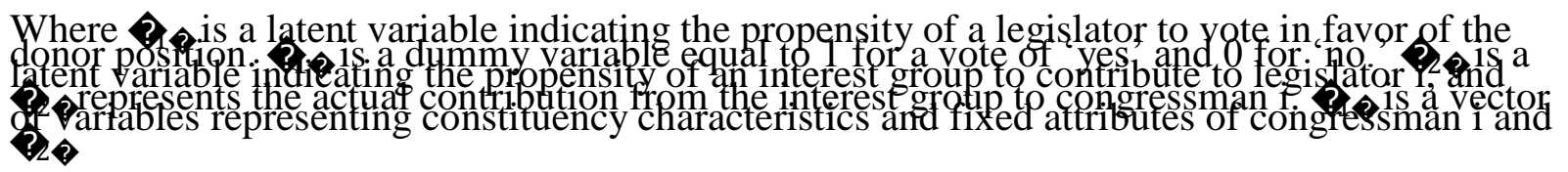
is a vector of variables indicating the legislative power of congressman $i$, his probability of election, and his position on the issue. The SPT model differs from traditional probit and Tobit models only within the correlation coefficient of the errors, $\rho$. Chappell describes the potential for a bias such that if $\rho=0$, no bias exists and single equation techniques will be accurate.

However, if $\rho \neq 0$, the error terms will generally be correlated with the endogenous variable explaining the amount of campaign contributions from an interest group which creates a bias.

See Chappell (1982) for a more thorough overview of the model and its theoretical background and applications. 
In consideration of the effects of logrolling and unobserved ideology on the behavior of voters, Stratmann (1992) finds a reflection of the presence of vote trading coalitions on some votes but not others and ultimately doubts the importance of the personal ideology of legislators. Chupp (2014) provides a unique 'spatial' analysis of strategic voting behavior and ultimately finds that political interest groups tend to target their donations toward legislators with the most influence, supporting the concerns of Chappell (1982). He does this by developing a spatial econometric approach to analyzing the relationships among voters which has at its core a spatial weights matrix representing the interactions that may exist due to logrolling, favor-trading, or yardstick competition. The literature in regard to logrolling and unobservable influences is dense and thorough (Kalt and Zupan, 1984, 1990; Bender 1991; Chressanthis et al. 1991; Ladha, 1994; Stratmann, 1995). Maniadis (2009) uses a probabilistic voting model to explore the idea that the influence of donors may actually have positive economic effects. At the core of his argument is the view that firms drive economic growth through investment, and this provides a common interest for voters to encourage private investments. Given that governments may default on promises for economic stability and choose leftist policies, campaign contributions by firms can be viewed as a 'commitment device' for policy action.

The agricultural sector is one of the most protected industries in today's global market. Bellemare and Carnes (2015) define agricultural protection as "the broad array of subsidies to farmers and taxes and quotas imposed on agricultural imports." Dutt and Mitra (2009) provide a narrative on the political economy of agricultural protection and find that both the government ideology and the degree of income inequality are important determinants of the degree by which the agricultural sector is protected. Bellemare and Carnes (2015) find that electoral incentives explain a large degree of variation in support for agricultural protection, but ideology and a 
response to lobbying are also likely to play a role. Beghin and Kherallah (1994) find that pluralistic systems are associated with higher levels of agricultural protection.

Prior studies have attempted to quantify the influence of campaign contributions on Farm Bill legislation (Lee and Tkachyk, 1987; Yeung, 2008). Using a simple probit analysis, Lee and Tkachyk (1987) examine the determinants of voting behavior on multiple Farm Bills and present a few notable indicators of a legislator voting: (1) legislators whose constituent state was more dependent on farm transfer programs were more likely to vote for Farm Bills; (2) legislators whose constituent state's farms had a higher debt-to-asset ratio were more likely to vote for Farm Bills; and (3) legislators whose state's farm income is lower relative to non-farm income. They also find that ideological variables play a crucial role in the determination of voting patterns on farm bills. Focusing on a series of amendments to the 1996 Farm Bill, Yeung (2008) uses Chappell's Simultaneous Probit-Tobit Model and finds a statistically significant relationship between campaign contributions and voting behavior. This extends to the case of anti-legislation funding as well, i.e. funds from those who were generally against the legislation were shown to decrease the likelihood of a 'yea' vote. In addition to campaign contributions, Yeung also shows that constituent interests and legislator ideology are of significant importance.

\section{Model and Data}

Rather than a simultaneous-equations system, this study attempts to simplify the problem. In order to examine the determinants of congressional voting behavior on the 2014 Farm Bill, a simple logit binary choice model is fitted to the "Yea" and "Nay" decisions of senators who voted on its passage. The dependent variable in this study is a binary value equal to 1 if the legislator in question voted "Yea" and equal to 0 if the legislator voted "Nay." This paper takes only the Senate vote into account due to the simplicity of mapping state-level constituency data 
to Senators. The main difference between this study and those which rely on a simultaneousequations system is in that of an important explanatory variable. Rather than using the actual funding amount from an interest group, this paper focuses on the proportion of total funding from a particular interest group to total campaign finance, which gives insight into the relative importance of the particular source of funding. This is justified through the idea that while the agricultural sector may be more likely to direct funds toward more 'powerful' legislators, the same can be said for any sector. Thus, the use of a ratio eliminates the effect of scaling and gives insight into the magnitude of importance for funding from the agricultural sector alone. In addition, Yeung (2008) showed that the difference between estimates from SPT and single equation models is negligible.

Independent variables consist of: (1) legislator-specific information, (2) constituent specific information, and (3) economic indicators. The main variable of interest is the proportion of campaign funding from the agricultural sector to total campaign funding for each legislator. ADA is a variable constructed by the Americans for Democratic Action and its value can be interpreted as a ratio of the amount of 'Democratic action' taken by each senator in their voting history. For example, an ADA score of 56 means the Senator has voted 'Democratically' in approximately 56 of past roll calls. TENURE represents the number of years that each legislator has been in office and is meant to act as a proxy for experience. In examining agricultural policy actions, it is important to consider membership in the United States Senate Committee on Agriculture, Nutrition, \& Forestry. Given that this group is largely responsible for drafting the Farm Bill legislation, this variable is likely to play a key role. In fact, of the 16 members on the committee, only four voted against the legislation (roughly 30 percent). Parlberg (2010) provides a detailed description of the important role of these committees: "The secret to every farm bill's 
success in Congress is the lead role played by the House and Senate Agriculture Committees, where members from farm states and farm districts enjoy a dominant presence and are rewarded for their legislative efforts with generous campaign contributions from the farm lobby, which is built around organizations representing the farmers who get the subsidies. The Agriculture Committees draft the legislation that goes to the floor for a final vote, and in the drafting process they take care to satisfy the minimum needs of both Republican and Democratic members to ensure bipartisan support....The final package is what students of legislative politics call a committee-based logroll."

In examining information about the constituency, information availability is affected due to multicollinearity. For example, a 'political climate' variable was constructed which is equal to the percent of each state's population that voted Republican in the 2012 presidential election. This variable is highly correlated with legislator ADA scores, and thus, cannot be used in modeling. This result is intuitive, however, given the idea that rational ignorance results in individuals voting for a legislator who will represent them on a wide range of issues. As the main indicator for constituent characteristics, SNAP participation rates are used to indicate the level of poverty in the region. This is also an important consideration given that SNAP and nutrition programs are a large component of the 2014 Farm Bill. We examined education levels, poverty rates, etc., but they had a small degree of correlation with other important variables and lack statistical significance.

Finally, economic variables were examined to represent the state of the constituency and its agricultural sector. State GDP values are produced in order to provide a proxy for the relative wealth in each state. Additionally, a variable was created to reflect the 'relative agricultural income,' which provides information about the importance of agriculture in each constituency. 
Relative agricultural income is calculated as the ratio of per capita personal income to average farm net income. This is included to account for the idea that legislators may be more likely to support Farm Bill legislation in the event that their constituents have relatively lower levels of farm income (Lee and Tkachyk, 1987). As this variable gets larger, the relative income level of the state's agricultural sector is reduced. In three cases, this variable was negative as a result of negative gross agricultural income. These three observations were removed to maintain continuity. Also included is the CCC Ratio which is defined as farm program benefits as a proportion of total farm gross income. Both agricultural finance indicators were retrieved from the USDA. Descriptive statistics for all non-binary variables can be found in Table 1.

Table 1: Descriptive Statistics for Non-Binary Variables

\begin{tabular}{|c|cccc|}
\hline & Mean & $\begin{array}{c}\text { Standard } \\
\text { Deviation }\end{array}$ & Minimum & Maximum \\
\hline Vote & 0.68 & 0.47 & 0.00 & 1.00 \\
Ag. Committee Mem. & 0.16 & 0.37 & 0.00 & 1.00 \\
Tenure & 10.67 & 9.89 & 1.00 & 39.00 \\
Ag. Funding Ratio & 3.05 & 3.04 & 0.18 & 16.68 \\
ADA & 50.61 & 41.07 & 0.00 & 100.00 \\
CCC Ratio & 1.56 & 1.39 & 0.13 & 5.50 \\
Relative Ag. Income & 1.50 & 1.85 & 0.20 & 8.86 \\
SNAP Participation & 14.88 & 3.84 & 6.53 & 22.35 \\
State GDP & 266751.74 & 320512.81 & 23912.00 & 1751002.00 \\
\hline
\end{tabular}

\section{Results and Discussion}

Three separate specifications were examined in order to provide a robust estimate. The first specification examines only variables that are specific to the legislator. ADA scores provide a measure of legislator ideology, tenure and committee membership provide a proxy for political influence, and the agricultural funding ratio provides a quantification of the potential for lobbying pressure. The second regression is a full specification which includes both constituent- 
related and economic variables. The third and final specification is a condensed regression which removes insignificant variables. A detailed overview of regression results is provided in Table 2 with marginal effects in Table 3.

Table 2: Logit results on 2014 Farm Bill vote

\begin{tabular}{|c|c|c|c|}
\hline & Legis. & Full & Condensed \\
\hline \multirow{2}{*}{ ADA } & $\begin{array}{c}0.0353^{* * *} \\
(0.0000)\end{array}$ & $\begin{array}{c}0.0735^{* * *} \\
(0.0002)\end{array}$ & $\begin{array}{c}0.0697 * * * \\
(0.0000)\end{array}$ \\
\hline \multirow{2}{*}{ Tenure } & $\begin{array}{c}0.0118 \\
(0.6802)\end{array}$ & $\begin{array}{c}-0.0201 \\
(0.6501)\end{array}$ & \\
\hline \multirow{2}{*}{ Ag. Committee Mem. } & 0.3293 & $1.898^{*}$ & $1.735^{*}$ \\
& $(0.6476)$ & $(0.0812)$ & $(0.0894)$ \\
\hline \multirow{2}{*}{ Ag. Funding Ratio } & $0.3915^{* *}$ & $0.3410^{* *}$ & $0.3462^{* *}$ \\
& $(0.0143)$ & $(0.0471)$ & $(0.0419)$ \\
\hline \multirow{2}{*}{ State GDP } & & $-0.00004 * *$ & $-0.00004 * *$ \\
& & $(0.0115)$ & $(0.0100)$ \\
\hline \multirow{2}{*}{ SNAP Participation } & & -0.188 & $-0.1980 *$ \\
& & $(0.1113)$ & $(0.0899)$ \\
\hline \multirow{2}{*}{ Relative Ag. Income } & & -0.325 & \\
\hline \multirow{2}{*}{ CCC Ratio } & & $(0.3379)$ & \\
\hline R-squared & 0.325 & $0.8241^{* *}$ & $0.8089^{* *}$ \\
& & $(0.0148)$ & $(0.0138)$ \\
\hline
\end{tabular}

Table 3: Marginal effects from logit regression

\begin{tabular}{|c|c|c|}
\hline Variable & Condensed & P-Values \\
\hline ADA & $0.0067^{* *} *$ & 0.0000 \\
\hline HSAC & $0.1661^{*}$ & 0.0894 \\
\hline AGPACRATIO & $0.0033^{*}$ & 0.0419 \\
\hline STGDP & $-0.00000035^{* *}$ & 0.0100 \\
\hline SNAP & $-0.0019^{*}$ & 0.0899 \\
\hline CCCRATIO & $0.00774^{*}$ & 0.0138 \\
\hline
\end{tabular}

Significant variables include ADA score, committee membership, campaign financing from the agricultural sector, the GDP of each state, SNAP participation rates, and the CCC Ratio (level of participation in farm program benefits). The single most important indicator of voting 
behavior is membership on the United States Senate Committee on Agriculture, Nutrition, \& Forestry. This result is less interesting than the others, as it is easily expected that those who spearhead the drafting and development of a policy are likely to vote in its favor. With regard to the remaining variables, results indicate that three major factors came into play in voting for the 2014 Farm Bill:

(1) Legislator Ideology and Politics: the significance of the ADA coefficient indicates that legislators are likely to be influenced by their past behavior and party affiliation. In this case, legislators who have previously participated in a high level of "Democratic Action" were likely to repeat that trend on this particular policy, which some may refer to as "Democratic" due to its high concentration of transfer programs. Additionally, the amount and source of campaign funding had a positive and statistically significant impact on voting behavior. This indicates that agricultural interest groups who approached legislators in an attempt to manipulate the market very likely succeeded in doing so.

(2) Constituent Characteristics: the SNAP participation rate in each state revealed a negative effect on Farm Bill voting. This may come as a surprise given that SNAP and nutrition programs are such a high priority in the Farm Bill. Despite this negative (and statistically significant) effect, the magnitude is negligibly small. The table of marginal effects (Table 3) shows that the effect is roughly one-fifth of a percent marginal change.

(3) Economic Indicators: In this regard, the states' dependence on agricultural transfer payments as well as its GDP are important for determining voting behavior.

This is an important result because it goes to show that each of the three previously mentioned types of variables (legislator specific, constituent specific, and agricultural finance indicators) do in fact influence voting and supports the conclusions brought forth by Brooks (1997). While each 
of the three types of variables show significance, the dominant effects are those of a political and ideological nature. While the significance of the ADA value and state agricultural finance variables is expected, the magnitude of marginal effects for campaign finance from the agricultural sector is of concern. This indicates that efficient outcomes could be significantly missed due to the influence of powerful industries.

These results align closely with those found in the prior two studies on Farm Bill legislation. Lee and Tkachyk (1987) examine the Farm Bills of 1977, 1981 and 1985 and Yeung (2008) examines the Farm Bill and various amendments of 1996. Finally, this study examines the Farm Bill of 2014, providing a high level overview of Farm Bill voting for five different passages over the past 30 years. Common themes among the three papers are apparent. First, economic variables — specifically those with regard to the agricultural sector-are demonstrated to significantly impact voting behavior. States which display the highest dependence on farm payments are likely to have their representative vote in favor of Farm Bill legislation. Second, ideological variables are important in determining voting behavior on Farm Bills. ADA score has a positive relationship with voting behavior, which can be interpreted such that the 'more' democratic a legislator, the more likely he/she is to vote in favor of Farm Bill legislation. There is a clear party divide in this regard, as Republican voters are less likely to support legislation. Finally, and most importantly, campaign contributions are shown to play a consistent and significant role in the determination of voting behavior. All three studies show that funding from the agricultural sector has a positive relationship with voting behavior. In addition, Yeung (2008) showed that funding from sources which are against the bill has a significant negative relationship. 
With such strong support for the role of money in politics, it is vital to continue a discussion on campaign finance reform (CFR). The first major event in CFR was the passage of the Federal Election Campaign Act in 1972 which requires disclosure of funding and sources. Subsequently, the Federal Election Commission was created in 1974 to monitor and limit the role of money in politics. The most recent action on CFR is the Bipartisan Campaign Reform Act of 2002, which revised contribution limits, prohibited unregulated contributions, and more. Despite these continuing actions, this study—and multiple others--shows that money continues to play a significant role in politics and can skew the implementation of policies which are truly representative of the constituency.

It should be noted that while this study adds to a mixed literature on the impact of campaign financing on legislator behavior, it is not all encompassing. The empirical analysis focuses on a single case study of voting on the 2014 Farm Bill and thus, the results do not necessarily extend to other similar legislation. Also, this model does not take into account the influence of logrolling and other ideological influences that are not as readily quantifiable. Future studies could add value through the careful consideration of the influence of "behind the scenes' activity as discussed by Powell (2014). It has clearly been shown in the literature that campaign contributions are a significant force in legislative decision making. Politicians are individuals who serve to represent their constituencies. Despite this overall purpose, they also act in their own self-interest, as any rational economic agent is assumed to. This conclusion implies that further research on the impacts of campaign financing on legislative decision making is warranted and important. 


\section{References}

Abetti, P. (2008) "Congressional Voting on DR-CAFTA: Ineffectiveness of Environmental Lobbying." Journal of Economic Policy Reform, 11:11-20.

Abler, D. (1991) "Campaign Contributions and House Voting on Sugar and Dairy Legislation." American Journal of Agricultural Economics. 73:11-17.

Alvarez, J. (2005) "Sweetening the U.S. Legislature: The Remarkable Success of the Sugar Lobby." Political Quarterly. 76: 92-99.

Anderson, K., Rausser, G. and J. Swinnen. (2013) "Political Economy of Public Policies: Insights from Distortions to Agricultural and Food Markets." Journal of Economic Literature. 51(2): 423-477.

Ansolabehere, S., de Figueiredo, J., and Snyder, J. (2003) "Why is There So Little Money in U.S. Politics?” Journal of Economic Perspectives. 17(1):105-130.

Beghin, J. and M. Kherallah. (1994) "Political Institutions and International Patterns of Agricultural Protection.” Review of Economics and Statistics. 76: 482-489.

Bellemare, M. and N. Carnes. (2015) "Why Do Members of Congress Support Agricultural Protection?” Food Policy. 50: 20-34.

Bender, B. (1991) “The Influence of Ideology on Congressional Voting." Economic Inquiry. 29:416-428.

Brooks, J. (1997) “Congressional Voting on Farm Payment Limitations: Political Pressure or Ideological Conviction?” Journal of Agriculture and Resource Economics. 22(2):281-295.

Brooks, J., Cameron, A. and C. Carter. (1998) "Political Action Committee Contributions and U.S. Congressional Voting on Sugar Legislation." American Journal of Agricultural Economics. 80(3): 441-454.

Chappell, H. (1982) "Campaign Contributions and Congressional Voting: A Simultaneous ProbitTobit Model." Review of Economics and Statistics. 64:77-83.

Chupp, B. (2011) "Environmental Constituent Interest, Green Electricity Policies, and Legislative Voting." Journal of Environmental Economics and Management. 62:254-266.

Chupp, B. (2014) "Political Interaction in the Senate: Estimating A Political 'Spatial' Weights Matrix And An Application To Lobbying Behavior." Public Choice. 160(3):521-538.

Chressanthis, G., Gilbert, K. and Grimes, P. (1991) "Ideology, Constituent Interests, and Senatorial Voting: The Case of Abortion.” Social Science Quarterly. 72:588-600. 
Congleton, R. (2002) “The Median Voter Model.” In C.K. Rowley and F. Schneider, The Encyclopedia of Public Choice. Kluwer Academic Press.

Constant, L. (2006) "When Money Matters: Campaign Contributions, Roll Call Votes, and School Choice in Florida.” State Politics \& Policy Quarterly. 6(2):195-219.

De Gorter, H. and J. Swinnen. (2002) "Political Economy of Agricultural Policy." In: Gardner, B. and G. Rausser, Handbook of Agricultural Economics. 2(B): 1893-1943.

Devault, J. (2010) "CAFTA, Campaign Contributions, and the Role of Special Interests." Economics \& Politics. 22(3):282-297.

Downs, A. (1957) An Economic Theory of Democracy. New York: Harper and Row.

Dutt, P. and D. Mitra. (2009) "Explaining Agricultural Distortion Patterns: The Roles of Ideology, Inequality, Lobbying, and Public Finance.” The World Bank. Working Paper 84.

Ellison, S. and Mullin, W. (1995) "Economics and Politics - the Case of Sugar Tariff Reform." Journal of Law and Economics. 38(2):335-366.

FEC (Federal Elections Commission). (2012) "Federal Elections 2012: Election Results for the U.S. President, the U.S. Senate, and the U.S. House of Representatives." http://www.fec.gov/pubrec/fe2012/federalelections2012.shtml

Fordham, B. and McKeown, T. (2003) "Selection and Influence: Interest Groups and Congressional Voting on Trade Policy." International Organization. 57:519-549.

Gawandde, K. and Hoekman, B. (2006) "Lobbying and Agricultural Trade Policy in the United States.” International Organization. 60(3):527-561.

Goodwin, B. and Smith, V. (2014) "Theme Overview: The 2014 Farm Bill—An Economic Welfare Disaster or Triumph?” Choices: The Magazine of Food, Farm \& Resource Issues. 29(3):1.

Hamilton, N. (2014) "The 2014 Farm Bill: Lessons in Patience, Politics, and Persuasion." Drake Journal of Agricultural Law 19.1:1-37.

Kahane, L. (1996) "Congressional Voting Patterns on NAFTA.” American Journal of Economics and Sociology. 55:4.

Kalt, J. and Zupan, M. (1984) "Capture and Ideology in the Economic Theory of Politics." The American Economic Review. 74:279-300.

Kalt, J. and Zupan, M. (1990) "The Apparent Ideological Behavior of Legislators: Testing for Principal-Agent Slack in Political Institutions." The Journal of Law \& Economics. 33:103-131. 
Kau, J., Kennan, D., and Rubin, P. (1982) “A General Equilibrium Model of Congressional Voting." Quarterly Journal of Economics. 97:271-293.

Ladha, K. (1994) “Coalitions in Congressional Voting.” Public Choice. 76:43-63.

Lee, D. and Tkachyk, S. (1987) “An Empirical Analysis of Congressional Voting on Farm Bill Legislation.” Cornell Agricultural Economics Staff Paper. 87(21).

Lopez, R. (2001) “Campaign Contributions and Agricultural Subsidies.” Economics \& Politics. 13(3): 257-279.

Maniadis, Z. (2009) "Campaign Contributions as a Commitment Device.” Public Choice. 139:301-315.

McArther, J. and Marks, S. (1988) "Constituent Interest vs. Legislator Ideology: The Role of Political Opportunity Cost.” Economic Inquiry. 26(3):461-470.

Peltzman, S. (1976) “Toward a More General Theory of Regulation.” Journal of Law and Economics. 19:211-240.

Powell, L. (2014) “The Influence of Campaign Contributions on the Legislative Process.” Duke Journal of Constitutional Law \& Public Policy. 9(1):75-101.

Roscoe, D. and Jenkins, S. (2005) “A Meta-Analysis of Campaign Contributions' Impact on Roll Call Voting.” Social Science Quarterly. 86(1):52-68.

Stabenow, D. (2014) “Agriculture Reform, Food and Jobs Act of 2013." United States Senate Committee on Agriculture, Nutrition, and Forestry.

http://www.ag.senate.gov/download/?id=dfe429ca-4069-4119-a8ee-359dfb29e9c3

Stigler, G. (1971) “The Theory of Economic Regulation.” Bell Journal of Economics. 2:3-21.

Stratmann, T. (1991) "What Do Campaign Contributions Buy? Deciphering Causal Effects of Money and Votes.” Southern Economic Journal. 57(3):606-620.

Stratmann, T. (1992) "The Effects of Logrolling on Congressional Voting." The American Economic Review. 82:1162-1176.

Stratmann, T. (1995) "Logrolling in the U.S. Congress.” Economic Inquiry, 33:441-456.

Tosini, S. and Tower, E. (1987) "The Textile Bill of 1985: The Determinants of Congressional Voting Patterns.” Public Choice. 54:19-25.

U.S. Senate. (2014) “2014 Farm Bill.” United States Senate Committee on Agriculture, Nutrition, and Forestry. http://www.ag.senate.gov/issues/farm-bill 
U.S.D.A. (United States Department of Agriculture). (2014) "Farm Bill Highlights." http://www.usda.gov/documents/usda-2014-farm-bill-highlights.pdf

Vesenka, M. (1989) "Economic Interests and Ideological Conviction: A Note on PACs and Agricultural Acts." Journal of Economic Behavior and Organization. 12:259-263.

Welch, W. (1982) "Campaign Contributions and Legislative Voting: Milk Money and Dairy Price Supports.” Western Political Quarterly. 35:478-495.

Yeung, I. (2008) "The Influence of Campaign Contributions on Legislative Voting: A Case Study of the 1996 Farm Bill.” Thesis. Department of Economics, Amherst College. 


\title{
Chapter 3: Essay 2 - Production of Wind Energy and Agricultural Land Values: Evidence from Pennsylvania
}

\begin{abstract}
Given the push toward renewable and alternative energy, a new energy mix is emerging. Wind is the fastest growing source of renewable electricity in the United States. The siting of wind turbines has proven controversial with multiple operations facing local resistance. Opponents cite issues such as noise, bird deaths, and aesthetics. Given that farmer portfolios are heavily comprised of land assets, the possibility that surrounding wind energy operations may reduce agricultural land value is of concern. This study examines that possibility using a hedonic regression analysis comparing assessed land value to a series of land characteristics and distance variables for Somerset County, PA. Results indicate no significant relationship between the presence of wind turbines and the value of agricultural land. This confirms the findings of similar studies which have examined the same relationship.
\end{abstract}

Keywords: wind energy, hedonic regression, land values

JEL Codes: Q14, Q15, Q18, Q420, Q43 


\section{Introduction}

Renewable energy sources have become more common in the United States in recent years, driven by innovation in the energy sector and the desire among policymakers and the general public to diversify the energy supply of the U.S. and reduce the country's dependence on foreign oil (Velasco, 2008). Emerging sources of renewable energy include biofuels, solar, and wind, with wind being the fastest growing source of electricity in the United States (Bohn and Lant, 2009). While wind energy has been harnessed through windmills for much of recorded history, turbines for electricity were first developed for commercial use in Vermont in 1941 (Pralle and Boscarino, 2011) and really took off in 1992 when the federal government provided a production tax credit for renewable energy (Peek, 2014). According to Peek (2014), the tax credit led to the number of U.S. turbines increasing seven-fold over the next two decades. In addition to the incentive provided by tax credits and physical wind energy potential, Bohn and Lant (2009) argue that the development of wind energy is determined by factors dependent on human beliefs and actions, such as population size, public policies, renewable portfolio standards, and procedures and regulations for the siting and permitting of wind farms.

The role that human beliefs and actions play is important to consider because wind turbines bring forth an array of positive and negative impacts. Benefits include very low cost energy after installation, income to rural areas, reduction in greenhouse gases and increased energy independence. Wind energy can provide clean energy which does not contribute to air or groundwater pollution, especially relative to conventional generation, and therefore can be useful and important to regional environmental efforts. Siler-Evans (2013), for example, finds that a wind turbine in West Virginia displaces twice as much carbon dioxide as the same turbine in California. 
Opponents to wind-energy development have concerns both aesthetic and practical. A frequent concern that has been discussed in the ecological and environmental literature is that wind turbines ruin the natural beauty of a landscape (Brisman, 2005; Good, 2006). Other concerns revolve around turbine noise, shadow flicker and bird deaths (Pralle and Boscarino, 2011). Coleby et al. (2009) found using a survey-based approach that aesthetic impact remains the root cause of objection, at least at the local level. These objections mean that wind turbine operations are often subject to significant local resistance (Heintzelman and Tuttle, 2012). A short, but by no means exhaustive list of prominent communities that have seen resistance to wind energy operations include Glebe Mountain, VT; Hoosac, ME; Redington, ME; and most notably, Cape Wind, MA (Bohn and Lant, 2009).

As first noted by Devine-Wright (2005), the literature on public perceptions about renewable energy sources such as wind shows a strong degree of "Not In My Back Yard" (NIMBY) attitude. Individuals are very much in favor of wind energy generally (Swofford and Slattery, 2010), but not when the proposed siting is near their home. As argued by Fischel (2001), NIMBYs are often homeowners who cannot adequately insure their home value against decline from neighborhood effects, such as noise from a wind farm. This concern is not unfounded, given that proximity to wind facilities has been shown in some cases to reduce home values (Heintzelman and Tuttle, 2012), although other recent papers find no significant effect (Sims, Dent, and Oskrochi (2008); Sims and Dent (2007)).

In this paper we examine whether the presence of wind turbines has affected the value of nearby agricultural land in Somerset County, Pennsylvania. In doing so we build off an important recent paper by Vyn and McCullough (2014). While the literature on wind turbines has focused primarily on residential home sales, Vyn and McCullough (2014) also look at 
farmland sales and find no effect of wind turbine proximity on the value of farmland. Our paper adds to their contribution in two ways. First, to our knowledge we are the first to look at the effect of wind turbines on agricultural land in the United States, a country with a very different housing and mortgage market. Second, our focus area is primarily rural and agricultural, with a population density of fewer than 80 people per square mile.

Having a better understanding of the relationship between wind facilities and agricultural land in areas like Somerset County is important for two reasons. First, if wind power facilities continue to emerge in the United States they will likely be located in agricultural and rural areas in order to overcome the most stringent of NIMBY opposition. Second, if wind power facilities reduce the value of agricultural land, the impacts on the financial portfolio of farmers could be severe since farm real estate makes up over 80 percent of the value of farm assets in the United States (Bloomendahl et al., 2011).

\section{Methods}

Citing various studies (Colwell and Dilmore, 1999; Rosen, 1974; Brown and Rosen, 1982; Epple, 1987), Freeman et al. (2014) provide a high-level overview of hedonic price theory by beginning with the preferences of a consumer. It is assumed that the utility of a consumer is defined by their consumption of a commodity $z$ and the house in which they live. The characteristics of their house can be broken down into a vector of amenities Q which includes three categories of observations: (1) characteristics of the house (number of bedrooms and bathrooms, size of property, type of furnishings, etc., (2) neighborhood information such as the type of houses nearby, distance to a park, etc., and finally (3) environmental characteristics such as air pollution near the parcel. 
A major assumption in hedonic price theory is that the market is in equilibrium such that all individuals have maximized their own utilities by choosing parcels with the bundle of characteristics which they desire. This leads to the formal expression that the price of the $j$-th

parcel can be reflected as: $=2(3)$, stating that the rental rate is a function of the property

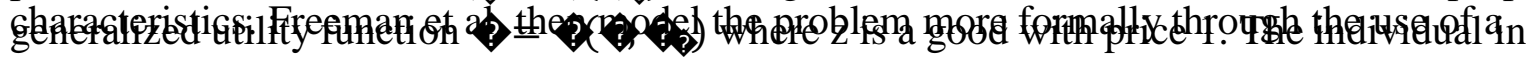

question maximizes $u$ subject to the budget constraint $-2(2)-0$ where $M$ represents the money income of the consumer. Assuming that the individual is a price taker, then that person must face a series of implicit marginal price schedules for the varying characteristics of parcels on the market. Utility is then maximized by moving along each marginal price schedule until a point where marginal willingness to pay for an additional unit of the characteristic in question equals the marginal implicit price of that characteristic (Freeman et al., 2014).

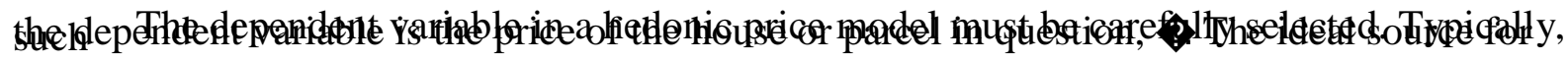
data is real market transactions. However, this brings forth its own set of difficulty. For example, housing property is infrequently traded and sale prices can be skewed by transactions between relatives or which are influenced by outside forces. An additional source of housing value data is that of professional appraisals. According to prior literature, the hedonic price function can be said to be derived from the interaction of individuals' preferences and suppliers' costs. The functional form is not heavily restricted by theory and can be linear, quadratic, log-log, and more.

The utilization of this generalized theory has been extended to numerous applications. For example, Ready and Abdalla (2004) model housing values against the presence of 
agricultural operations on nearby land. The authors find that positive externalities are derived from the presence of nearby agricultural open space. This indicates that buyers are willing to pay more to have open space near a potential property purchase. Alternatively, the presence of largescale animal operations has a negative effect. These types of operations can lead to air and water pollution, animal and waste smell, and are generally unsightly and industrial in appearance.

This paper employs a generalized hedonic regression model, in which the value of a property parcel can be compared to the characteristics of each parcel. This allows for the determination of the intrinsic value of each attribute as well as the prediction of transaction prices (Monson, 2009). Based on general hedonic theory, the model (1) relates the assessed value of a particular parcel to a vector of land characteristics, the distance in miles to the nearest turbine, and a radius variable describing how many turbines exist within one mile of any given property. The inclusion of the radius variable serves as a robustness check, as the estimation of local effects often requires controlling for more than simple linear distance to a landmark (Ross et al., 2011).

\section{1) $A$ रेखे

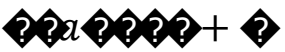

The availability of more extensive data would likely increase the accuracy of this model. However, this paper is concerned with the coefficients for each distance variable, not predicting the determinants of assessment values. It should be noted that this model is not meant to be predictive, but rather, to explain the relationship between the distance variables and the per acre land value.

Somerset County is located in southwestern Pennsylvania in the Laurel Highlands region. It is the seventh largest county in the state with a land area of just over 1,000 square miles. The 
county is settled mostly by farmers and includes 25 townships, 25 boroughs, and only 72.4 persons per square mile compared to the state average of 283.9 (U.S. Census Bureau, 2014). Tourism, manufacturing, coal mining, and agriculture are the major economic forces in the county. The 2013 population estimate is 76,520 , which is a 1.6 percent decline since 2010 .

Agricultural land makes up roughly 312.5 square miles (or about 29\%) of the county land area. Somerset County also has a high concentration of wind energy operations. The area currently has 221 wind energy turbines owned by multiple companies. Figure 3 shows an overview of the spatial relationships between agricultural land and wind turbines in Somerset County.

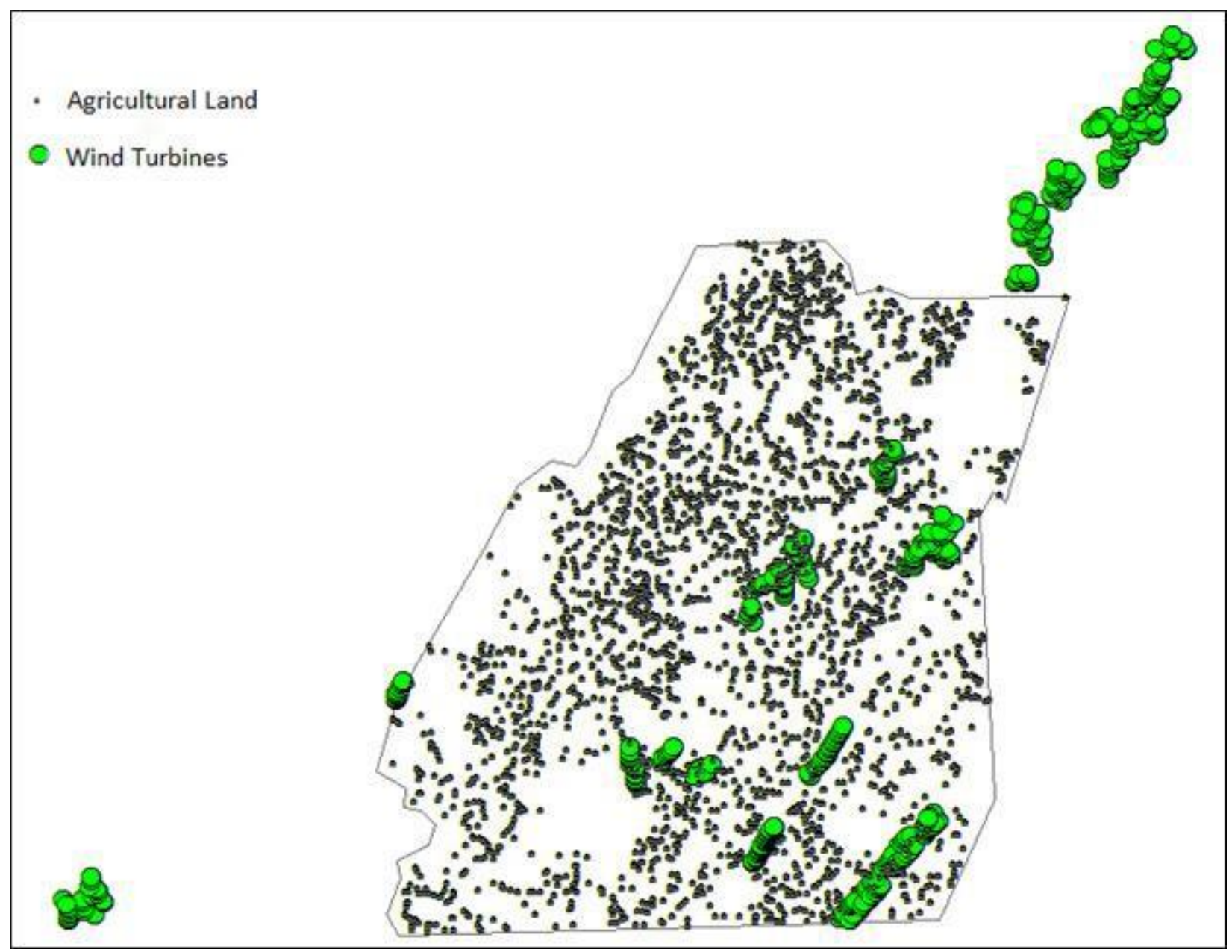

Figure 3: Agricultural Land and Wind Turbines in Somerset County, PA 
The majority of the wind turbines in the county are monopole and range from 90 to 150 feet high. Somerset County has received significant investment and activity in wind energy operations. The amount of electricity generated by Somerset County windmills has more than doubled since it began in 2000 (Stouffer, 2010). The first windmill in southwest PA began generating power in 2000 and wind energy has been growing in Pennsylvania ever since. In 2009, electricity generated by windmills in Pennsylvania more than doubled, adding more than 387 MW of wind power capacity (Stouffer, 2010).

Wind turbine data for the area was obtained through the United States Geological Survey (Diffendorfer et al., 2014), which provides a shape file mapping every documented wind turbine in the United States. This data set was created using the Federal Aviation Administration Digital Obstacle File and ArcGIS Desktop by the Geosciences and Environmental Change Science Center of the United States Geological Survey. This data represents all wind turbines in the area as of July 2013. In the fall of 2014, current assessed values for every agricultural land parcel in Somerset County were obtained through the Somerset County Government website. Descriptive statistics for all non-binary variables in our data set are presented in Table 4.

Table 4: Descriptive Statistics for Non-Binary Variables

\begin{tabular}{|c|c|c|c|c|}
\hline Variable & Mean & $\begin{array}{c}\text { Standard } \\
\text { Deviation }\end{array}$ & Minimum & Maximum \\
\hline Assessed & 52,961 & 35,104 & 280 & 359,860 \\
\hline Acres & 68.8 & 81.9 & 0.6 & 148.7 \\
\hline Miles & 5.26 & 3.43 & 0.03 & 14.55 \\
\hline Radius & 0.45 & 1.83 & 0 & 15 \\
\hline Land Use Codes (Factor) & $\mathrm{n} / \mathrm{a}$ & $\mathrm{n} / \mathrm{a}$ & $\mathrm{n} / \mathrm{a}$ & $\mathrm{n} / \mathrm{a}$ \\
\hline
\end{tabular}

Assessed values were used as very few agricultural parcels in the county have changed owners in the past decade and those that have are not arms-length sales but instead sales between 
family members. Given the lack of arms-length farm sales, assessed value is the best measure for the value of agricultural land given that assessors attempt to approximate market value.

In addition to data on parcel size in acres and assessed value, the only additional data in the file from the Somerset County government are land use codes. For Somerset County there are six different land use codes that are used: AAB (with buildings, tillable and no-till soil, AAO (with buildings, no-till soil), AAT (with buildings, tillable soil), VVB (no buildings, tillable and no-till soil), VVO (no buildings and no-till soil, and VVT (no buildings and tillable soil). As can be seen, the primary distinctions are whether the parcel has buildings and tillable land. These determinations are made as part of the property assessment process, which occurs on an asneeded basis by a professional assessor. The assessor makes observations regarding the specific property characteristics, noting features such as buildings, acreage, topography, soil quality, location, and many more. Neighboring properties are also taken into consideration when determining the value of a land parcel. Assessed value is calculated as one-half of market value, which is defined by the assessor based on property characteristics and the examination of similar sales.

An additional factor that impacts assessed value in Somerset County, Pennsylvania is the Clean and Green program, a state law which allows qualifying agricultural and forest land to be assessed at a value for that use rather than fair market value (Rizzo and Maust, 2001). The purpose of the law (Pennsylvania Farmland and Forest Land Assessment Act, Act 319-amended by Act 156 in 1998 and Act 235 in 2004) is "to encourage property owners to retain their land in agricultural, open space, or forestland use, by providing some real estate tax relief." In our data set this is coded as zero if the property is not part of the Clean and Green program and 1 if it qualifies. Distance variables were computed using ESRI ArcMap. 


\section{Results and Discussion}

For robustness, three specifications were examined (as shown in Table 5). The first column is a parsimonious regression which includes only the distance variables. The second column is the full specification as described in equation (1) above. The third column is the same specification as estimated in column 2 but using generalized least squares to deal with heteroskedasticity related to different categories of properties have different variabilities.

Table 5: Hedonic Regression Results

\begin{tabular}{|c|c|c|c|c|c|c|}
\hline Variable & \multicolumn{2}{|l|}{ (1) } & \multicolumn{2}{|l|}{$(2)$} & \multicolumn{2}{|l|}{ (3) } \\
\hline Acres & & & $\begin{array}{c}137.84 \\
(1614.74)\end{array}$ & $* * *$ & $\begin{array}{c}137.84 \\
(7.8)\end{array}$ & $* * *$ \\
\hline CleanGreen & & & $\begin{array}{l}-16341.52 \\
(1274.48)\end{array}$ & $* * *$ & $\begin{array}{c}- \\
16341.76 \\
(1274.45)\end{array}$ & $* * *$ \\
\hline Miles & $\begin{array}{c}164.9 \\
(202.0) \\
\end{array}$ & & $\begin{array}{c}443.52 \\
(1395.44) \\
\end{array}$ & $*$ & $\begin{array}{c}443.53 \\
(186.87) \\
\end{array}$ & $*$ \\
\hline Radius & $\begin{array}{l}-460.2 \\
(379.0)\end{array}$ & & $\begin{array}{l}-400.94 \\
(348.64) \\
\end{array}$ & & $\begin{array}{l}-400.94 \\
(348.64) \\
\end{array}$ & \\
\hline AAO (with buildings; no-till soil) & & & $\begin{array}{l}-6631.54 \\
(1395.44)\end{array}$ & $* * *$ & $\begin{array}{l}-6631.54 \\
(1395.44)\end{array}$ & $* * *$ \\
\hline AAT (with buildings; tillable soil) & & & $\begin{array}{c}220.68 \\
(2319.03) \\
\end{array}$ & & $\begin{array}{c}220.68 \\
(2319.03) \\
\end{array}$ & \\
\hline $\begin{array}{l}\text { VVB (no buildings; tillable \& no-till } \\
\text { soil) }\end{array}$ & & & $\begin{array}{l}-37332.09 \\
(6642.12)\end{array}$ & $* * *$ & $\begin{array}{c}- \\
37332.09 \\
(6642.11)\end{array}$ & $* * *$ \\
\hline VVO (no buildings; no-till soil) & & & $\begin{array}{l}-45324.7 \\
(5950.59) \\
\end{array}$ & $* * *$ & $\begin{array}{l}-45324.7 \\
(5950.6) \\
\end{array}$ & $* * *$ \\
\hline VVT (no buildings; tillable soil) & & & $\begin{array}{c}-41343.99 \\
(14469.42)\end{array}$ & $* *$ & $\begin{array}{c}- \\
41343.99 \\
(14469.4) \\
\end{array}$ & $* *$ \\
\hline Constant & $\begin{array}{l}52298.8 \\
(1305.0) \\
\end{array}$ & $* * *$ & $\begin{array}{l}54010.56 \\
(1614.74) \\
\end{array}$ & $* * *$ & $\begin{array}{c}54010.56 \\
(1614.7) \\
\end{array}$ & $* * *$ \\
\hline Observations & 2912 & & 2912 & & 2912 & \\
\hline R-squared & 0.001095 & & 0.1573 & & $\mathrm{n} / \mathrm{a}$ & \\
\hline
\end{tabular}


While the parsimonious regression shows no relationship between assessed value of agricultural land and distance variables, both full specifications display positive and statistical significant relationships between the mileage variable and assessed value. While statistically significant at the 10 percent level, this relationship is not economically meaningful. Calculated at the mean assessed value, a parcel moved one mile closer to a turbine can be expected to have their assessed valuation decline by $\$ 443$, or just over one percent of a standard deviation in assessed value.

It is important to note that our data does not allow us to address causality. If turbines are more likely to be sited away from high-quality agricultural land then our results might be picking up that selection effect. This selection effect, however, means that our results are upward estimates. Given how small in economic magnitude the relationship is between the assessed value of agricultural property and distance from wind turbines, policymakers and citizens should be more confident in the results of Vyn and McCullogh (2014).

\section{Conclusions and Policy Implications}

While Heintzelman and Tuttle (2012) did find that wind facilities reduce the value of surrounding land, their study consisted of primarily residential properties. This study, with its sole focus on agricultural land, finds no significant relationship between wind energy operations and the value of surrounding agricultural land. This is in agreement with the studies conducted by Sims and Dent (2007) and Sims et al. (2008) which also looked at only residential land, but found no significant relationship. This study also confirms the findings of Vyn and McCullough (2014) which is the only study containing a significant amount of agricultural property in the hedonic regression. Based on the results of this study, it is not likely that policy makers should 
be concerned with the impact of wind turbines on surrounding agricultural land. The same cannot be said about the relationship between wind turbines and residential property, as studies have shown mixed results. 


\section{References}

Bloomendahl, B., Perrin, R., and Johnson, B. (2011) "The Impact of Ethanol Plants on Surrounding Farmland Values: A Case Study.” Land Economics 87.2: 223-232.

Bohn, C. and Lant, C. (2009) "Welcoming the Wind? Determinants of Wind Power Development among U.S. States.” Professional Geographer 61.1: 87-100.

Brisman, A. (2005). "The Aesthetics of Wind Energy Systems." NYU Environmental Law Journal 13: 1-133.

Brown, J. and Rosen, H. (1982). "On the Estimation of Structural Hedonic Price Models." Econometrica. 50(3): 765-768.

Coleby, A., Miller, D., and Aspinall, P. (2009) "Public Attitudes and Participation In Wind Turbine Development." Journal of Environmental Assessment Policy \& Management 11.1: 6995.

Colwell, P. and Dilmore, G. (1999) "Who Was First? An Examination of an Early Hedonic Study." Land Economics. 75(4): 620-626.

Devine-Wright, P. "Beyond NIMBYism: Towards and Integrated Framework for Understanding Public Perceptions of Wind Energy." Wind Energy 8: 125-139.

Diffendorfer, J., Compton, R., Kramer, L, and Norton, D. (2014). Onshore Industrial Wind Turbine Locations for the United States through July 2013. United States Geological Survey.

Epple, D. (1987) "Hedonic Prices and Implicit Markets: Estimating Demand and Supply Functions for Differentiated Products.” Journal of Political Economy. 95(1):59-80.

Fischel, W. (2001). “Why Are There NIMBYS?” Land Economics 77: 144-152.

Freeman, A.M., Herriges, J. and Kling, C. (2014) The Measurement of Environmental and Resource Values. RFF Press. Resources for the Future. Third Edition.

Good, J. (2006). “The Aesthetics of Wind Energy.” Human Ecology Review 13: 76-89.

Heintzelman, M. and Tuttle, C. (2012) "Values in the Wind: A Hedonic Analysis of Wind Power Facilities." Land Economics 88.3: 571-588.

Monson, M. (2009) "Valuation Using Hedonic Pricing Models." Cornell Real Estate Review. 7:62-73.

Peek, K. (2014) “Is America’s Wind Boom Over?” Popular Science 285: 34. 
Pralle, S. and Boscarino, J. (2011) "Framing Trade-Offs: The Politics of Nuclear Power and Wind Energy in the Age of Global Climate Change." Review of Policy Research 28.4: 323-346.

Rizzo, J. and Maust, D. (2001) "Understanding the Clean \& Green Program.” Somerset County Assessment Office.

Rosen, S. (1974) "Hedonic Prices and Implicit Markets: Product Differentiation in Pure Competition.” Journal of Political Economy. 81(1): 34-55.

Ross, J., Farmer, M., and Lipscomb, C. (2011) "Inconsistency in Welfare Inferences From Distance Variables in Hedonic Regressions.” Journal of Real Estate and Finance Economics 43.3: 385-400.

Siler-Evans, K., Azevedo, I., Morgan, M., and Apt, J. (2013) "Regional Variations in the Health, Environmental and Climate Benefits of Wind and Solar Generation." Proceedings of the National Academy of Sciences of the United States of America1 10.29: 11768-11773.

Sims, S. and Dent, P. (2007) "Property Stigma: Wind Farms and Just the Latest Fashion." Journal of Property Investment and Finance 25.6: 626-651.

Sims, S., Dent, P., and Oskrochi, G. (2008) "Modeling the Impact of Wind Farms on House Prices in the UK." International Journal of Strategic Property Management 12.4: 251-269.

Stouffer, R. (2010) "Wind Power Gains Steam in Pennsylvania." Pittsburgh Tribune Review (PA) 09 Apr. 2010.

Swofford, J. and Slattery, M. (2010) "Public Attitudes of Wind Energy in Texas: Local Communities in Close Proximity to Wind Farms and Their Effect on Decision-Making." Energy Policy. 38.5: 2508-2519.

United States Census Bureau. (2014) "State \& County Quick Facts." Online at: http://quickfacts.census.gov/qfd/index.html. Accessed 02 February.

Velasco, J. (2008) "Welfare Economics and Policy Analysis of U.S. Biofuels Policy: Discussion.” Review of Agricultural Economics 30.3: 422-424.

Vyn, R. and McCullough, R. (2014) “The Effects of Wind Turbines on Property Values in Ontario: Does Public Perception Match Empirical Evidence? Canadian Journal of Agricultural Economics 62.3: 365-392. 


\title{
Chapter 4: Essay 3 - Estimating a Spatially Explicit Production Function for U.S. Agriculture
}

\begin{abstract}
This study uses U.S. county-level agricultural data for 2012 to estimate a spatially explicit production function and analyze the impact of spatial heterogeneity on the input-output relationships in U.S. agriculture. This is an important consideration given that traditional analyses are almost always temporal in nature. Results indicate that significant spatial heterogeneity is present which in turn impacts productivity substantially by reducing the return to inputs in certain areas. Significant clustering is apparent, with high productivity areas concentrated in the Midwest and Southeast and low productivity areas concentrated in the Southwest and Northeast. This is likely due to factors such as land use, geographic characteristics, and water availability. Spillover effects from one region's input use on the net income of a neighboring region are not significant. However, the presence of a spatial lag is clear with regard to net income. The meaning of this finding is not as clear, as it is possible that counties are similar to those around them, thus engaging in similar activity under similar conditions.
\end{abstract}

Keywords: agricultural productivity, spatial heterogeneity, spillovers

JEL Codes: C21, Q10, Q18 


\section{Introduction}

The United States is one of the largest agricultural producers in the world, and has more arable land than any other nation on earth (Environmental Protection Agency, 2015). The global agricultural system is complex, and food is more affordable in the U.S. than any other developed country. Agriculture is a business venture with significantly high start-up costs and a commodity output with low value per unit. Even though the per-unit value of most crops is low, the 2007 Census of Agriculture showed that U.S. farm sales were roughly \$297 billion. Farmers are subject to price fluctuations in many major inputs including — but not limited to — machinery, fertilizer, chemical inputs, seed, fuel, heating and cooling systems, livestock commodities, veterinary care, etc. In addition, inflation has had a quantifiable impact on farmers. In a report from the EPA, it is noted that using the 1910-1914 period as a base, prices received by today's farmers have increased by at least six fold. On the other hand, costs of production have increased by at least sixteen times (Environmental Protection Agency, 2015).

Historically low per-unit value of agricultural commodities and changing price conditions have led to a push for increased efficiency in production. This has resulted in a shift toward large-scale operations in which production can be maintained in high volume. Figure 4 provides a visualization of the agricultural market, showing that over 50 percent of U.S. farms have sales of less than $\$ 10,000$, but that same group of farms only accounts for roughly 10 percent of U.S. agricultural sales. It can be seen that over 30 percent of agricultural sales are made by less than $10 \%$ of agricultural operations. These are a representation of high-sales, large-scale, and highefficiency operations.

The productivity of U.S. agriculture is growing faster than domestic food and fiber demand. Thus, U.S. farmers rely heavily on export markets to sustain income. U.S. agricultural 
exports have been larger than imports since 1960, generating a surplus in agricultural trade (USDA, 2013).

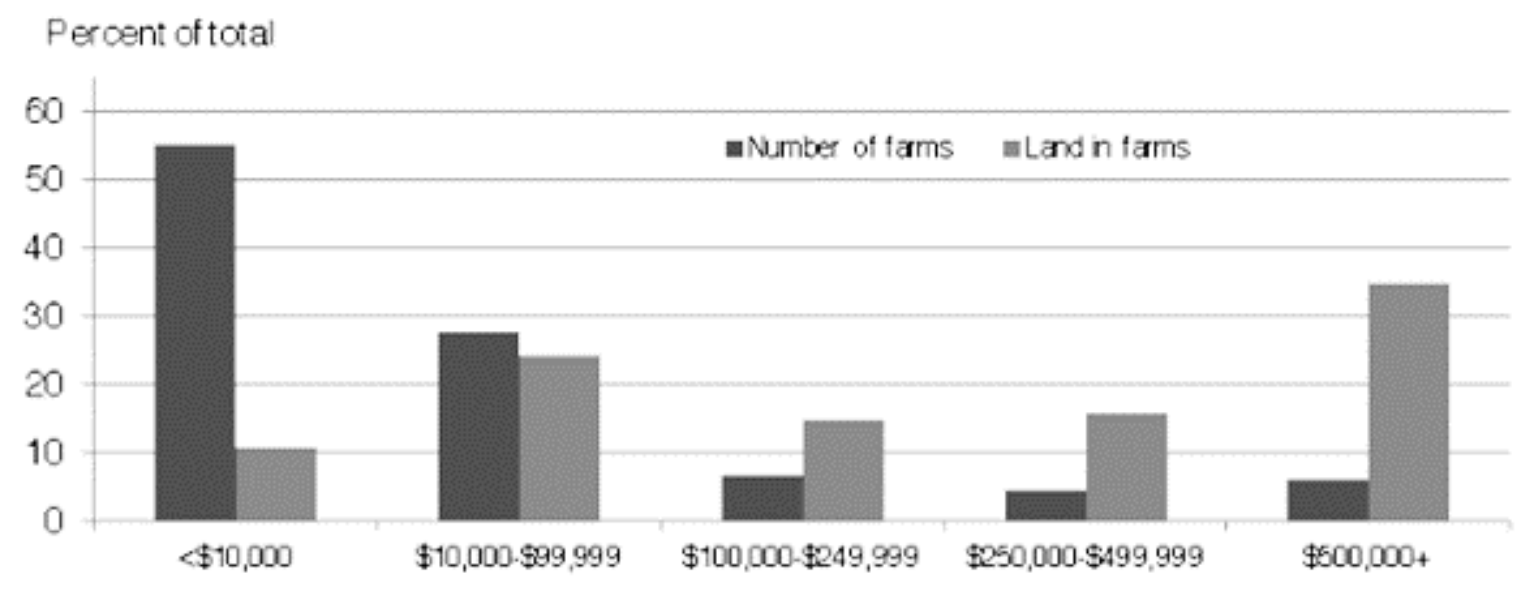

Figure 4: Farms and land in U.S. Farms by Economic Sales Class (2012)

As a result of this increase in productivity, the agricultural sector requires less labor input, leading to a significant decrease in employment in the $20^{\text {th }}$ century. In addition, Torgerson and Shane (2014) show that the value added to GDP by agriculture and related industries is substantial ( $\$ 775.8$ billion or approximately 5 percent of GDP).

Despite evident shifts in the structure of U.S. agriculture, the sector is still dominated by small family farms and relies almost entirely on inputs such as rainfall, sunlight, and temperature (Alston et al., 2010). As a result, variation in these inputs can negatively impact agricultural producers. This provides the motivation for this study which adapts the framework set forth in a recent paper by Yu et al. (2014) in which the authors attempt to evaluate the impact of spatial heterogeneity on the variation of input-output relationships in Turkey's agricultural sector. The idea is that spatial heterogeneity may lead to variation in agricultural productivity.

This type of spatial heterogeneity is apparent in U.S. geography. Different regions have different agricultural conditions in regard to key inputs such as rainfall, soil quality, sunlight, temperature, length of seasons, etc. For example, loss of soil fertility associated with depletion of 
organic matter has been shown to decrease agricultural productivity significantly (Bauer and Black., 1994). Lkupitiya et al. (2012) estimated the spatial and temporal variability in organic matter stocks in U.S. croplands and displayed substantial variation across regions. The Bureau of Economic Analysis delineation of geographic regions divides the U.S. into eight distinct regions: New England, Mideast, Great Lakes, Plains, Southeast, Southwest, Rocky Mountain, and Far West. Each region is defined by different characteristics with regard to climate, land type, and other factors which could influence agricultural productivity. Figure 5 provides a graphical overview of these regions. These regions are arbitrary, but a relevant example of the spatial heterogeneity that exists in the U.S.

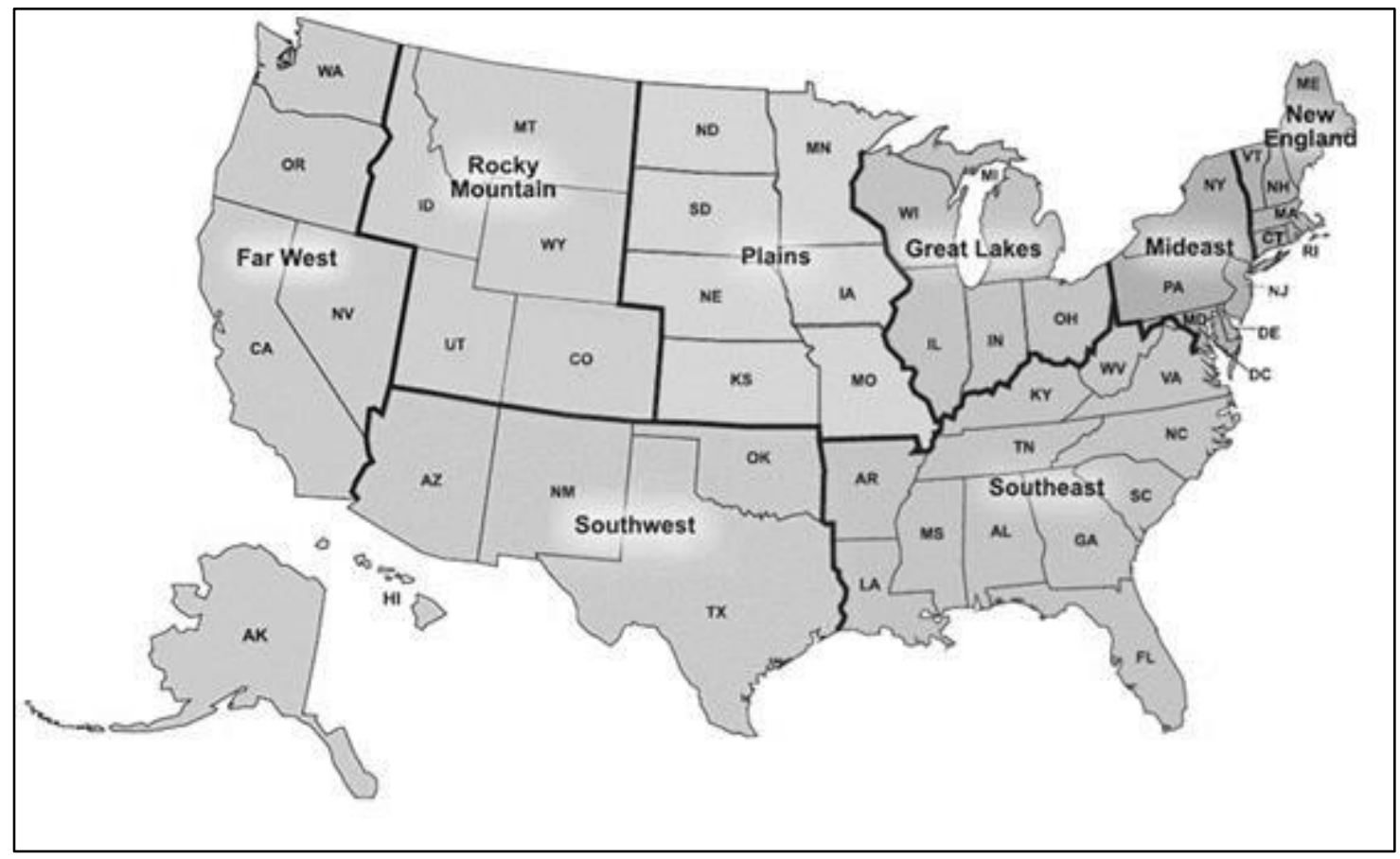

Figure 5: Bureau of Economic Analysis Regions

Agricultural activity in the U.S. is also affected by agricultural policy. For example, the 2014 Farm Bill provides legislation to deal with the dynamic challenges in agricultural production in the U.S. The bill ends direct payments, strengthens crop insurance, and innovates 
in regard to risk management strategies (Stabenow, 2014). Agricultural policy ranges from federal farm bills such as the aforementioned, to narrowly-defined, state-level policies and regulations which address questions or concerns unique to a specific area or type of agriculture (Hamilton, 2013). It is important that such policies are created and implemented in a way that can most efficiently allocate resources and funds. Therefore, the purpose of this study is to provide empirical evidence on the degree to which agricultural output is affected by spatial heterogeneity in the U.S. This provides a valuable resource for agricultural policy makers and researchers as it provides a more complete picture of U.S. agriculture, especially when combined with temporal analyses.

The next section provides a detailed overview of the existing literature beginning with a discussion of agricultural production economics and moving in to an explanation of relevant studies regarding agricultural productivity, production function estimation, and spatial heterogeneity. Sections 3 and 4 describe the methodological procedures which are employed in identifying spatial dependence, spatial econometric modeling framework, and specification testing. Section 5 describes the data and sections 6 and 7 present results and discussion.

\section{Background}

The last century resulted in significant progress in agricultural economics and farm management strategies. Debertin (2012) describes agriculture as the closest real-world example of a traditional purely competitive market. There are clearly some caveats for the case of the United States. Subsidy markets, risk management programs, and many other publicly funded and mandated actions impact the agricultural sector at the federal and state levels. However, despite this consideration, the purely competitive model comes closer to representing farming than any other existing model of economic behavior. 
In a 2010 study, Chavas et al. (2010, pg. 356) provide what they refer to as a "reflection on the path taken by production economics and farm management over the last century." They present a high-level overview of the key considerations, findings, and breakthroughs in agricultural economics, and in doing so, identify 16 major contributions in the areas of applied production analysis, agricultural productivity, risk management and dynamics. Within these broad categories exist major findings such as the identification of the role of diminishing returns in agricultural production (Spillman, 1923; 1924; 1933; Spillman and Lang, 1924). The authors also list three key findings with regard to production economics: (1) economies of scale seem to exist for small firms. (2) There is no strong evidence that diseconomies of scale exist for large firms. (3) There exist a wide range of farm sizes where average cost is roughly constant, which implies that economies of scale may not provide a strong incentive for farms to increase in size. This helps to explain the remaining prevalence of the small family farm in America. It is not the objective of this study to summarize the findings of Chavas et al., but rather to allude to their work as an introduction and supporting factor in the discussion of the changing landscape of agricultural production economics.

In a study which discusses the implications of the push toward sustainable agriculture on the current agricultural paradigm, Lyson and Welsh (1993) compare the current agricultural system to that of the mass production model of manufacturing in which efficiency and profit maximization is the ultimate aim. The level of U.S. farm output and input use from 1948-2011 grew at an average rate of 1.49 and 0.07 percent, respectively. The significant difference between these two numbers implies substantial growth in agricultural productivity. Despite this fact, analysis of the individual states shows considerable variance in these growth rates across space (Ball et al., 2014). Figure 6 provides a visual demonstration, which provides motivation for the 
examination of spatial dependence and spillovers in the estimation of an agricultural production function. It should be noted that it is possible for productivity measures to be influenced by factors not relating to spatial heterogeneity. For example, Dettori et al. (2012) find that total factor productivity differences across Europe are partially explained by disparities in intangible assets such as human capital, social capital, and technological capital.

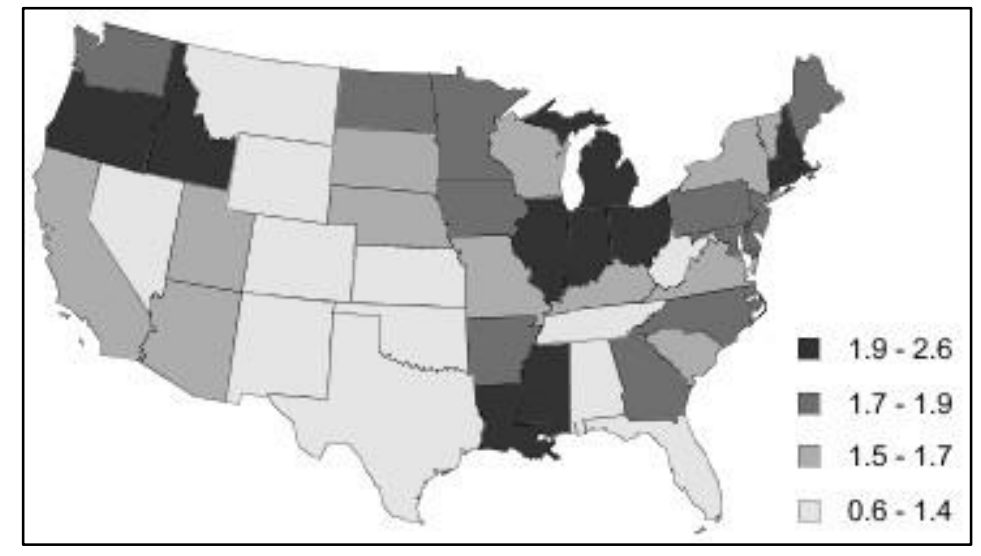

Figure 6: Change in Agricultural Productivity by State, percent, 1960-2004

Many studies exist in regard to the estimation of production functions. In a recent study, Shaik (2014) shows using quantile-regression methods that traditional measures of returns to scale and technology are under and overestimated in states at upper and lower quantiles of the distribution, respectively. The discussion of recent developments in production function estimation could be a paper in and of itself. Rather, this paper will focus on production function estimation with a spatial component. Nearly twenty years ago, Weiss (1996) presented an overview of the emerging role of spatial analysis in agricultural economics and defined the core opportunity of agricultural economists' as the need to quantify the costs and benefits of detecting and exploring spatial variability. Yu et al. (2014) refer to multiple other studies which have examined the role of space in regard to production functions (Anselin et al., 1997; Cavailhes and Wavresky, 2003; Fingleton and Mccombie, 2006; Lambert, and Cho, 2008; Vaya et al., 2004). 
Despite this fairly wide application of the methodology, the use of spatial econometrics to estimate agricultural production functions is limited.

In one such paper, Cho et al. (2007) estimate an agricultural production function using a Chinese county-level dataset and geographically weighted regression methods. They also compute county specific input-output elasticities and provide a visual representation using geographic information system (GIS) techniques. Their results are found by comparing GWR and OLS estimates and confirm that allowing for spatial variation within the regression consistently improves the fit of the agricultural production function. This spatial information provides insight into the relative importance of inputs in different regions of the country, and provides valuable information for policy makers in China. In a similar paper titled "Evaluating Spatial and Temporal Variation in Agricultural Output Elasticities in Turkey," Yu et al. (2014) provide a unique evaluation of the spatial variation that exists in the Turkish agricultural sector and how it impacts the input-output elasticities across the country. Their results indicate that disparities in agricultural activities and geographic conditions affected the return from input factors, and that policy makers should consider this regional heterogeneity and potential comparative advantage when creating new legislation. The authors break the process down in to four steps: (1) identifying spatial dependence, (2) generalizing a spatial production function, (3) comparing and selecting appropriate models, and (4) estimation and results. These four steps provide the generalized framework for this study.

\section{Identifying Spatial Dependence}

Before considering the application of a spatial econometric model, it is important to explore the concept of spatial dependence, also referred to as spatial autocorrelation. LeSage and Pace (2009, pg. 2) provide an excellent overview of the concept in which they describe spatial 
dependence as "a situation where values observed at one location depend on the values observed at nearby locations." Whether or not a location is nearby can be determined through the use of various mathematical criteria such as Euclidean distance, touching borders, etc. The authors provide a generalized mathematical example for which observations $i$ and $j$ represent neighbors as defined by some criteria. Then a data generating process may take the form:

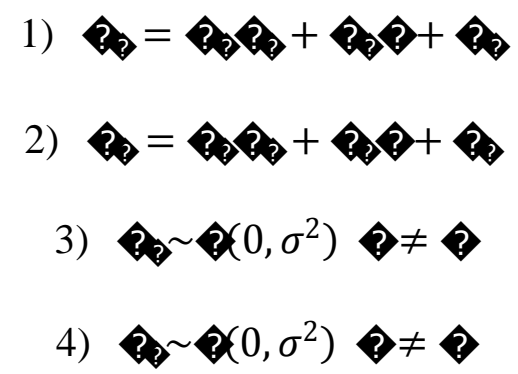

Such that the value of depends on the value of $>$ and vice versa. This system represents a generalized example of spatial dependence, but does not necessarily define all cases or situations. There are three types of spatial autocorrelation: (1) positive - nearby observations are likely to be similar to one another; (2) negative - nearby observations are likely to be opposite one another; and (3) non - no spatial effect is discernible. It is important to note that in most any data set with a spatial component, everything is related to everything else. However, things which are close together are 'more' related than things which are far away (Tobler, 1970). Yu et al. (2014) cite many other recent examples which have been discussed in the spatial econometrics literature (Anselin, 1995; Can, 1990, 1992; Cliff and Ord, 1973; Dubin, 1992; Kilkenny and Thisse, 1999; LeSage, 1997; Leung et al., 2000; McMillen, 1992, 2003).

In testing for the presence of spatial autocorrelation, the Moran's I statistic is a generally recognized starting point. Moran's I is a global statistic which provides an indication of the presence (or lack thereof) of a pattern of spatial dependence that is true for the entire dataset (Anselin, 1993). The Moran's I statistic is defined by equation (5) where $\mathrm{N}$ is the number of 
spatial units, $\mathrm{X}$ is the variable of interest, ${ }^{-}$the mean of $\mathrm{X}$, and the spatial weight matrix (Moran, 1948). Values of the Moran's I statistic can range from -1 to +1 in which a value of -1 corresponds to perfect negative autocorrelation, a value 0 corresponds to no autocorrelation, and a value of +1 represents perfect positive autocorrelation.

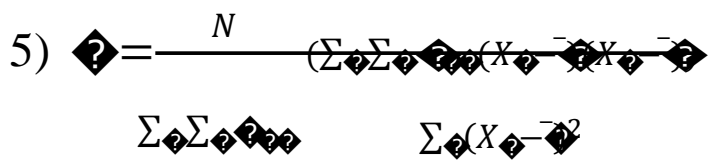

While it is important to consider the values of the Moran's I statistic, given its global nature, it is not without its flaws. When data sets become large, the degree of spatial autocorrelation between observations becomes more likely to show instability in the form of non-stationarity at the local level, spatial regimes, or spatial drift (Anselin, 1993). As a potential solution to this problem, Anselin (1995) proposed a general class of 'local indicators of spatial association' (LISA) which allow for the decomposition of global indicators such as the Moran's I into the contribution of each observation. This technique lends itself readily to visualization and can provide insight into the spatial distribution of spatially associated effects.

\section{Empirical Model}

The generalized framework described here draws its process heavily from Yu et al. (2014). However, it varies in its method of model selection, estimation and interpretation. The empirical methodology begins by considering a Cobb-Douglas functional form. The CobbDouglas function has been widely used in agricultural studies since 1928 and its appeal rests largely with its simplicity (Debertin, 2012). The generalized form is represented by equation (6)

in which represents net agricultural income for county i; represents total factor productivity; represents input $\mathrm{k}$ for state and areprents the return of each input $\mathrm{k}$ to output. 


\section{6) $\vec{\theta}=\vec{\nabla}$}

If production is assumed to be stochastic, a random shock can be incorporated, also referred to as a Solow residual.

7)

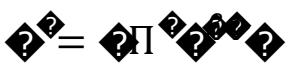

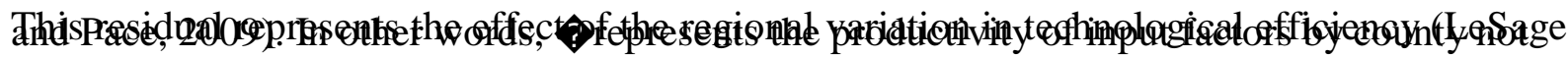

included in the aggregated total factor productivity (TFP) (2). This provides a clear window into the degree of spatial heterogeneity that may exist in U.S. agricultural production. In order to linearize the relationship, the natural log of both sides can be taken and converted to matrix form.

8)

In order to include a spatial component in this model, multiple spatial econometric models are considered. The most common models in spatial econometrics are the (SAR) Spatial Autoregressive Model, the (SDM) Spatial Durbin Model, and the (SEM) Spatial Error Model (LeSage and Pace, 2009). The SAR model's only deviation from equation (8) is its inclusion of a spatial lag on the dependent variable. The SAR model is represented by equation (9) in which $\rho$ is the spatial lag coefficient value and $W y$ acts as a weighted average of the dependent variable values of the surrounding parcels, or counties in this case.

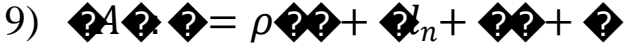

It is important to consider the choice of a spatial weight matrix. There has been much debate in the econometrics literature regarding the particular specification of weights matrices, with concern that various specifications may produce varying and/or biased estimates. LeSage and Pace (2014) find no theoretical basis for this belief and conclude that weight-matrix specification is not likely to significantly impact estimates. The Spatial Durbin Model (10) 
expands our framework further by including spatial lags of explanatory variables as well as the dependent variable. Finally, the spatial error model (11) uses lags to reflect dependence in the error process (LeSage and Pace, 2009).

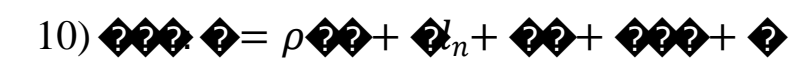

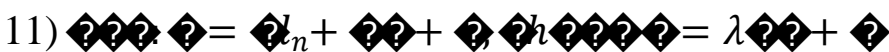

Various specifications of these three models (and three other similar models) are considered through a rigorous model selection process. The use of OLS in the estimation of spatial models can lead to inconsistent estimates, incorrect standard errors, and more. Maximum likelihood, however, is consistent for spatial models. Much of the historical literature has focused on ways to avoid MLE due to computational difficulties. Despite this, many computational advances have occurred since the time of Anselin's 1988 text, and MLE provides a consistent and reliable estimation method for spatial models (LeSage and Pace, 2009). It should be noted that the interpretation of estimation results in spatial models is not as straightforward as that of a linear model. For example, in the simple linear regression model (12), the interpretation of is that for a one unit increase in $\mathrm{X}$, y should increase by 2 . This does not hold true for models such as the SAR (9) or SDM (10).

\section{2) $2=20+2$}

This discrepancy comes as a result of the functional form, whereas the partial derivative - is not simply equal to as a result of the spatially lagged dependent variable. A change in an explanatory variable in one region will affect the region itself (direct effect) and potentially all other regions (indirect effect). These effects are combined to generate the 'total effect' of a marginal change. In order to determine the value of the derivative for an equation with a spatially lagged dependent variable, the equation must be algebraically manipulated (i.e. the 
model must be written in reduced form) which is described in detail in LeSage and Pace (2009, pg. 34).

In the estimation of such models, the ideal data transformation is that of a log-log specification. This is because of the scaling effect that occurs and also because coefficients of this type of model can be interpreted as the input-output elasticity for the given variable. Given that this data includes various negative net income values which yield complex numbers when logged, the data is transformed through the use of studentization. This process consists of subtracting the mean from each observation and dividing by the standard deviation. Coefficients (in the case of models with spatially lagged dependent variables, effects estimates) should then be interpreted as changes in standard deviation.

Model specification is assessed using the procedure defined by Elhorst (2010) in an article which provides a broad perspective on some key issues in regard to the 2009 LeSage and Pace text. Elhorst begins with the testing procedure defined by Florax et al. (2003) which allows for testing of the significance of the spatially lagged dependent variable and spatially lagged error term. Using this as a starting point, he proposes a generalized testing procedure which can help the econometrician determine the best model specification for the data. The main problem with the testing procedure suggested by Florax et al. is that it provides only a limited model space in which $M=\{$ OLS, SAR, SEM $\}$. However, this does not allow for the consideration of SDM, SLX, or SDEM specifications. The Spatial Lag of X (SLX) model in equation (13) is simply a standard normal linear model with an additional term consisting of spatially lagged independent variables. In this model, ordinary least squares can be used and coefficient interpretation is straightforward. The Spatial Durbin Error Model (SDEM) in equation (14) augments the SEM model with a spatial lag of the explanatory variables. 


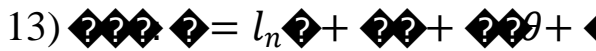

$\begin{aligned} &14) 2 ? \\ & \text { By implementing a likelihood-ratio test and Wald test, Elhorst is able to develop a }\end{aligned}$ procedure which expands the model space to $M=\{$ OLS, SAR, SEM, SDM, SLX, SDEM $\}$ providing expanded possibility for global, local, and OLS models. A step-by-step overview of the Elhorst testing procedure can be found in appendix 2. For a more thorough overview, see the Elhorst (2010) article.

\section{Data}

Data for this analysis is derived from the USDA's NASS Quick Stats 2.0 web portal and USDA Census of Agriculture for 3,109 counties in 2012. Net income (\$) serves as a proxy for output. Input variables include labor (number of workers employed), fertilizer expense (\$), fuel expense (\$), acres of land harvested, machinery asset value (\$) and inventory of tractors and trucks. Many studies are fairly limited in their choice of input variables for the agricultural production function. The inclusion of this wide array of variables allows a vast overview of relationships and spatial dependence to be examined. Descriptive statistics are provided in Table 6. Data is not transformed in Table 6 in order to facilitate easy understanding of the magnitude of values. For example, the maximum net income for 2012 occurred in Fresno, CA at \$1.079 billion. The minimum for 2012 was $-\$ 47.5$ million in Marion, FL. It should also be noted that the state with the largest agricultural net income (California) is also one of the largest states by land area. Conversely, the state with the lowest agricultural net income (Rhode Island) is the smallest state by land area. 
Table 6: Descriptive Statistics of U.S. Agricultural Data (2012)

\begin{tabular}{|c|c|c|c|c|}
\hline Variable & Mean & Std. Deviation & Minimum & Maximum \\
\hline Net Income & $\$ 30,287,095.00$ & $\$ 55,216,631.07$ & $\$-47,500,000.00$ & $\$ 1,079,176,000.00$ \\
\hline Labor & 902.03 & 2587.96 & 1 & 63626 \\
\hline Land & 105368.42 & 121651.67 & 28 & 995781 \\
\hline Machinery & 79475708.76 & 75737857.91 & 59000 & 917856000 \\
\hline Fertilizer & 9414748.40 & 13511341.26 & 1000 & 216341000 \\
\hline Fuel & 5407973.75 & 7985353.08 & 1000 & 181428000 \\
\hline Tractors & 1363.14 & 1114.60 & 4 & 15086 \\
\hline Trucks & 1076.50 & 810.92 & 5 & 10758 \\
\hline
\end{tabular}

\section{Results}

Table 7: Global Moran's I Statistics for U.S. Agriculture (2012)

\begin{tabular}{|c|c|}
\hline & Moran's I \\
\hline Net Income & 0.539503 \\
\hline Labor & 0.456022 \\
\hline Land & 0.703358 \\
\hline Machinery & 0.58096 \\
\hline Fertilizer & 0.584869 \\
\hline Fuel & 0.522674 \\
\hline Tractors & 0.434724 \\
\hline Trucks & 0.882502 \\
\hline
\end{tabular}

Considering net income and various input variables for U.S. agriculture, a Moran's I statistic is displayed in Table 7. These results were computed using GeoDa and a rook contiguity

weight matrix in which the value of $=1$ if states $i$ and $j$ share a border and $=0$ if they do not. The degree of spatial autocorrelation is positive and relatively high for all variables, ranging from approximately 0.43 to 0.88 .

This provides sufficient justification for further exploration of the impact of space on agricultural production. In examination of local spatial autocorrelation, the LISA method of analysis was employed through GeoDa, mapping results across 3,109 mainland counties for each 
variable in Figure 7. This provides a visual overview of the presence of local spatial association in the data set. Within each section, shading represents significance of at least $95 \%$. Darker portions represent higher significance. It is clear that significant clustering exists, with the location of that clustering varying with each variable. Given that this represents positive spatial autocorrelation, counties which are highly significant tend to be surrounded by other similarly valued counties.

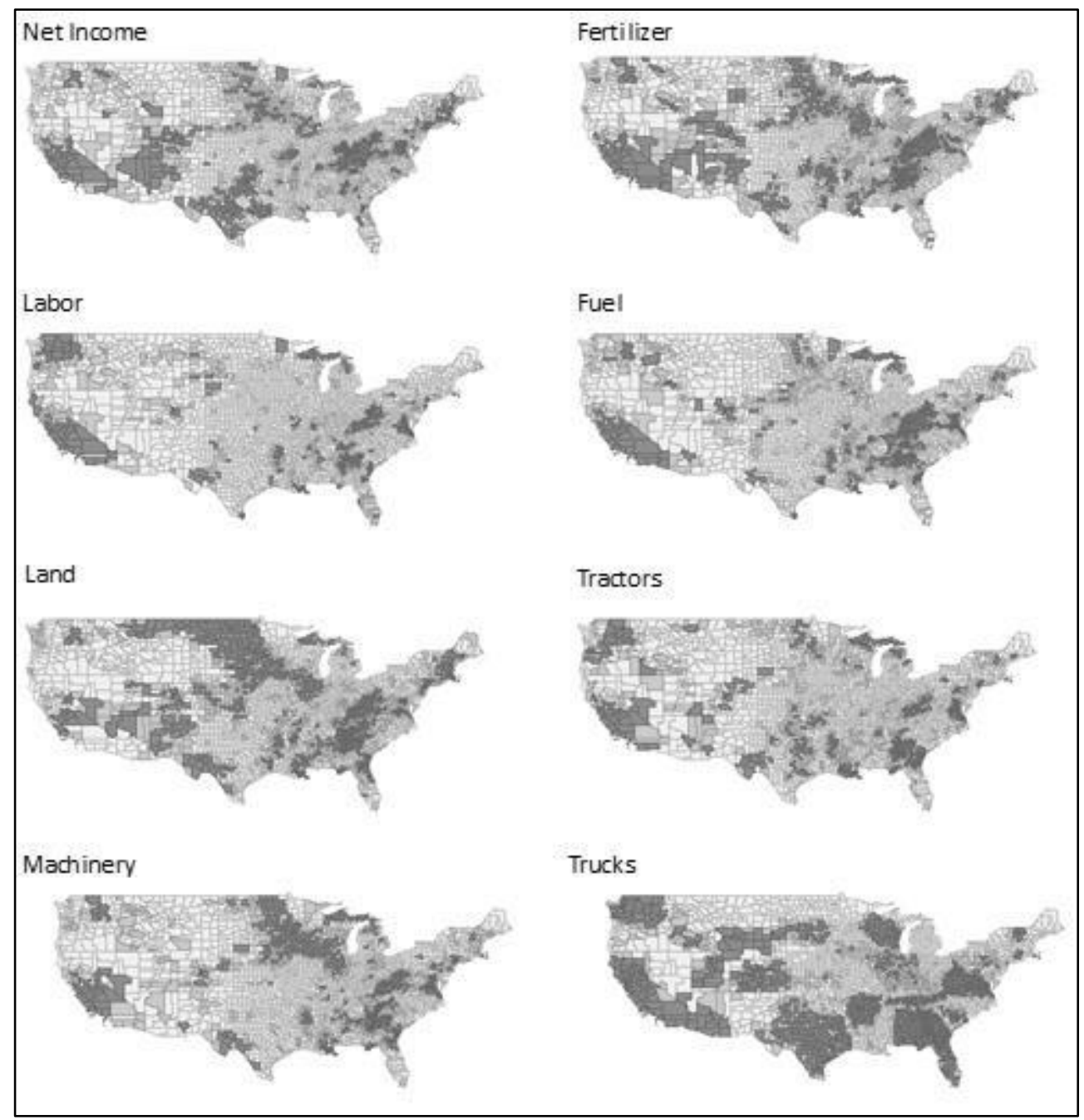

Figure 7: Local Indicators of Spatial Association (LISA) on U.S. Agricultural Data (2012)

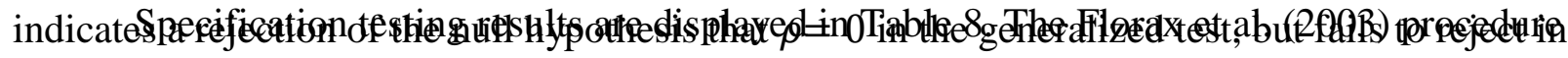


the robust variety. Also, the procedure rejects the null that $\lambda=0$ in both the generalized and robust varieties. Using the steps laid out by Elhorst (2010), this points us toward the SDM model. Moving forward with the likelihood ratio test to determine whether the SDM model can be reduced to the SAR model, results indicate a rejection of the restricted (SAR) model. The same is true for the restricted SEM model. This implies that spatially lagged dependent variables and spatially lagged error terms are likely to play a role in the data generating process.

Consequently, OLS can be rejected in favor of the Spatial Durbin Model (SDM). In support of this conclusion, LeSage and Pace often argue that the SDM model is the best place to start when considering spatial model specification.

Table 8: Model Specification Testing Results

\begin{tabular}{|c|c|c|}
\hline & Marginal Probability & Result \\
\hline LM Lag & 0.0000000 & Reject the null that rho $=0$. \\
\hline LM Error & 0.0000000 & Reject the null that lambda $=0$. \\
\hline LM Lag Robust & 0.21603582 & Fail to reject the null that rho $=0$. \\
\hline LM Error Robust & 0.0000000 & Reject the null that lambda $=0$. \\
\hline LR (SDM vs. SAR) & 0.0000000 & Reject the restricted (SAR) model. \\
\hline LR (SDM vs. SEM) & 0.0302000 & Reject the restricted (SEM) model. \\
\hline Wald (SLX vs. OLS) & $\mathrm{n} / \mathrm{a}$ & Testing points to SDM model. \\
\hline
\end{tabular}

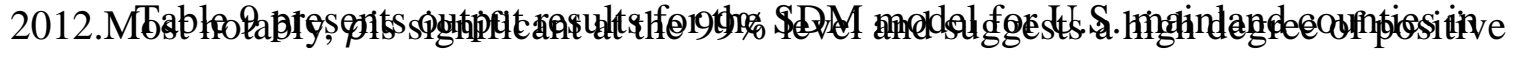
spatial autocorrelation. This implies that counties with a high agricultural net income are likely to be surrounded by counties with a similarly high agricultural income. The opposite is also true in that low agricultural income counties are likely to be surrounded by those with a similar status. It is important to recall that when interpreting output from a regression model with a spatially lagged dependent variable, attention must be paid to effects estimates rather than coefficients. Effects estimates of an independent variable in county $i$ can be interpreted such that 


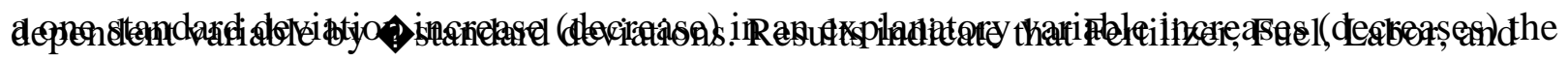

Machinery all have a positive impact with direct effects of $0.1073,0.5452,0.0997$, and 0.5855 , respectively. The magnitude of these effects is worth noting. As previously discussed, the growth of agricultural productivity and the use of efficient technology has significantly reduced the need for labor. Results indicate that labor plays a small role when compared to other inputs. For example, a one standard deviation increase in labor use results in only a 0.1073 standard deviation increase in net income.

Conversely, a one standard deviation increase in machinery results in a 0.5855 standard deviation increase in net income. This provides an empirical demonstration of the relative importance of machinery to labor in today's agricultural production system. Land, Tractors and Trucks have a negative effect on net income, which can be explained by the plausible hypothesis that these are essentially assets held by the owner which may or may not be directly adding to the value of net income, at least after a certain threshold.

In consideration of spillovers, the indirect effect is the change in standard deviations of net income (dependent variable) in county i that can be attributed to a one standard deviation change in the independent variable for the weighted average of surrounding counties $(j=1,2, \ldots, J)$. See LeSage and Pace (2009) for further explanation. The presence of spillovers in this analysis is minimal and only shows significance in the land variable. The land variable is an explicit representation of the number of acres of agricultural land harvested in a given county. It is important to consider the possibility that spatially significant variables may be explained by the fact that counties near one another have similar characteristics, and thus engage in similar agricultural activity with similar resources. These results align with those found by Yu et al. 
(2014) in that indirect effects are not shown to be statistically significant in agricultural

production. While indirect effects are not statistically significant, their direction is still worth noting. For example, bidding up the price of labor in county $i$ has a negative effect on the net income of neighboring counties.

Table 9: Spatial Durbin Model Output

\begin{tabular}{|c|c|c|c|c|}
\hline Variable & Coefficient & Direct Effect & Indirect Effect & Total Effect \\
\hline Constant & $\begin{array}{c}0.000295 \\
(0.993140)\end{array}$ & - & - & \\
\hline Fertilizer & $\begin{array}{c}0.104337 * * * \\
(0.000000)\end{array}$ & $\begin{array}{c}0.107260 * * * \\
(0.000000)\end{array}$ & $\begin{array}{c}0.052494 \\
(0.174635)\end{array}$ & $\begin{array}{r}0.159754 * * * \\
(0.000226)\end{array}$ \\
\hline Fuel & $\begin{array}{c}0.546217 * * * \\
(0.000000)\end{array}$ & $\begin{array}{r}0.545158 * * * \\
(0.000000)\end{array}$ & $\begin{array}{c}-0.024699 \\
(0.747334)\end{array}$ & $\begin{array}{r}0.520459 * * * \\
(0.000000)\end{array}$ \\
\hline Labor & $\begin{array}{c}0.100978 * * * \\
(0.000030)\end{array}$ & $\begin{array}{r}0.099711^{* * *} * \\
(0.000017)\end{array}$ & $\begin{array}{c}-0.024863 \\
(0.659424)\end{array}$ & $\begin{array}{c}0.074848 \\
(0.172128)\end{array}$ \\
\hline Land & $\begin{array}{c}-0.137000 * * * \\
(0.000000)\end{array}$ & $\begin{array}{c}-0.131848 * * * \\
(0.000000)\end{array}$ & $\begin{array}{c}0.082089 * * \\
(0.034006)\end{array}$ & $\begin{array}{l}-0.049759 \\
(0236298)\end{array}$ \\
\hline Machinery & $\begin{array}{c}0.590612 * * * \\
(0.000000)\end{array}$ & $\begin{array}{r}0.585549 * * * \\
(0.000000)\end{array}$ & $\begin{array}{c}-0.059293 \\
(0.219882)\end{array}$ & $\begin{array}{r}0.526256^{* * * *} \\
(0.000000)\end{array}$ \\
\hline Tractors & $\begin{array}{c}-0.068166^{*} \\
(0.074296)\end{array}$ & $\begin{array}{c}-0.067591^{*} \\
(0.069200)\end{array}$ & $\begin{array}{c}-0.001534 \\
(0.987224)\end{array}$ & $\begin{array}{c}-0.069125 \\
(0.491164)\end{array}$ \\
\hline Trucks & $\begin{array}{c}-0.223171 * * * \\
(0.000000)\end{array}$ & $\begin{array}{c}-0.223543^{* * * *} \\
(0.000000)\end{array}$ & $\begin{array}{c}-0.005240 \\
(0.924952)\end{array}$ & $\begin{array}{r}-0.228783 * * * \\
(0.000032)\end{array}$ \\
\hline W-Fertilizer & $\begin{array}{l}-0.028486 \\
(0.160108)\end{array}$ & - & - & - \\
\hline W-Fuel & $\begin{array}{c}-0.301798 * * * \\
(0.000000)\end{array}$ & - & - & - \\
\hline W-Labor & $\begin{array}{c}-0.066015^{*} \\
(0.063610)\end{array}$ & - & - & - \\
\hline W-Land & $\begin{array}{c}0.113981^{* * * *} \\
(0.000000)\end{array}$ & - & R-squared & 0.8734 \\
\hline W-Machinery & $\begin{array}{c}-0.342602 * * * \\
(0.000000)\end{array}$ & - & Rbar-squared & 0.8728 \\
\hline W-Tractors & $\begin{array}{c}0.035869 \\
(0.521736)\end{array}$ & - & $\operatorname{Sigma}^{\wedge} 2$ & 0.1014 \\
\hline W-Trucks & $\begin{array}{c}0.115463 * * * \\
(0.000234)\end{array}$ & - & Log-likelihood & 135.34741 \\
\hline rho & $\begin{array}{c}0.527960 * * * \\
(0.000000)\end{array}$ & - & $\mathbf{n}$ & 3109 \\
\hline
\end{tabular}

Note: Significance of $99 \%, 95 \%$ and $90 \%$ represented by $* * *, * *$, and *, respectively. P-values are in parentheses. 


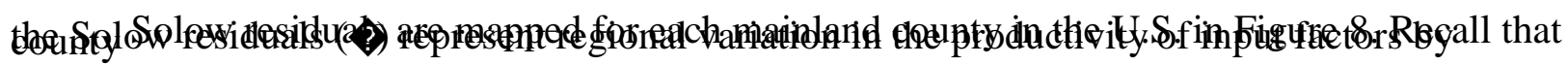

not included in the total factor productivity (?). Clusters of high productivity occur in the Midwestern regions as well as the Southeast. Particularly low-productivity regions are scattered throughout areas such as southwest and northeast. This reveals significant impacts of spatial heterogeneity on the input-output relationships in U.S. agricultural production. It appears that the Midwest, Southeast, and parts of California and Idaho are quite productive. In contrast, parts of the Northeast, and Southwest are suffering in this regard. This makes intuitive sense as regions such as the Midwest and Southeast have been shown to exhibit favorable conditions for agricultural production and production tends to be focused around crops that perform well in the conditions of the local environment. One important factor is water availability. While irrigation systems are available to mitigate risk, their existence does not entirely offset water concerns in dry areas such as the southwestern U.S. The plains of the Midwest lend themselves readily to production of fields of crops and the utilization of large machinery which is shown to increase productivity significantly. In addition, land use in the northeast is significantly forested and this extends to agricultural land parcels. Comparing this to a highly productive region such as the 
Midwest reveals that highly productive regions tend to be less forested and more conducive to mass-scale row crops and animal agriculture.

Results display some significance in total effects and these values are worth noting. The total effect is the combination of direct and indirect effects and represents the effect of a marginal change in input use on agricultural net income across the country. Total effects for fertilizer, fuel, machinery, and trucks are significant at the $99 \%$ level and amount to 0.159754 , $0.520459,0.526256$, and -0.228783 , respectively. A marginal increase in the use of fertilizer, fuel, or machinery in county i leads to an increase in net income not only in county $\mathrm{i}$, but in surrounding counties as well. It is worth mentioning that direct effects make up roughly 94 percent of total effects for these three inputs. Thus, indirect effects are not only statistically insignificant, but small. The significance of total effects can be derived from this dominance of the direct effects, which are highly significant and with substantially greater magnitude.

\section{Conclusion}

This study used U.S. county-level agricultural data for 2012 to estimate a spatially

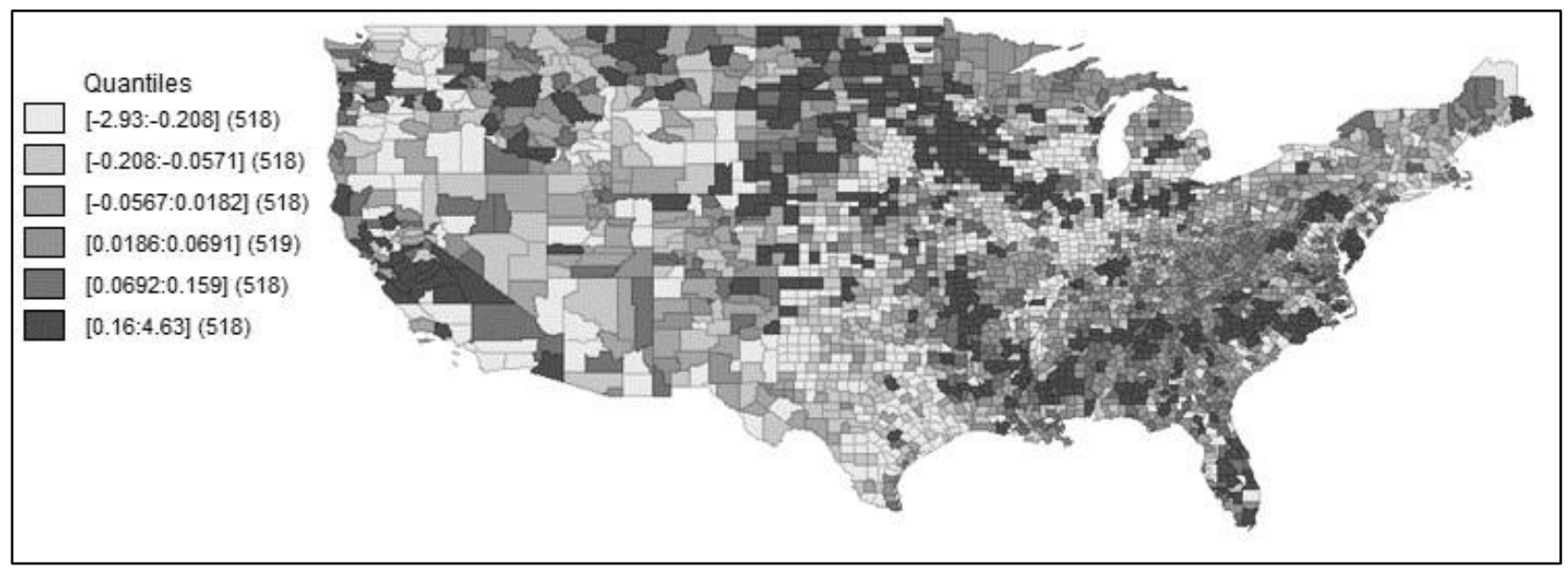

Figure 8: Quantile Map of Solow Residuals

relationships in U.S. agriculture. This allows for an expanded version of the traditional non- 
spatial and largely temporal framework of estimation. Results indicate that significant spatial heterogeneity is present and impacts productivity substantially by reducing the degree of return to inputs in certain areas. Significant clustering is apparent, with high productivity areas concentrated in the Midwest and Southeast and low productivity areas concentrated in the Southwest and Northeast. This is likely a result of a combination of various factors such as land use, geographic characteristics, water availability, and local policy actions. The use of this spatial econometric estimation technique provides value by allowing for the separation of the effects of generalized productivity increases and those derived from spatial heterogeneity, which has been clearly demonstrated through the use of a Solow residual. Spillover effects from one region's input use on the net income of a neighboring region are not significant, confirming the results of a similar study by Yu et al (2014). The presence of a spatial lag is significant with regard to net income. The meaning of this finding is not well-defined, as it is possible that counties are similar to those around them with regard to economics, geography, and climate resulting in similar activity under similar conditions. This brings back the idea that within any spatially referenced data set, everything is related to everything else, but things which are close together are 'more' related than things which are far apart. Policymakers should consider the costs and benefits of subsidizing agricultural activity in areas with less productivity, as a more efficient economic scenario likely exists. This may result in more fragmented policies which encourage agricultural activity in productive areas and make it less appealing in less productive areas. Alternatively, policy makers could focus on ways to improve productivity and efficiency in low-productivity areas. 


\section{References}

Alston, J., Andersen, M., James, J. and P. Pardey. 2010. "A Brief History of U.S. Agriculture." In Persistence Pays: U.S. Agricultural Productivity Growth and the Benefits from Public R\&D Spending. Natural Resource Management and Policy 34, Springer Science \& Business Media.

Anselin, L. 1988. Spatial Econometrics: Methods and Models. Springer Science \& Business Media.

Anselin, L. 1993. "The Moran Scatterplot as an ESDA Tool to Assess Local Instability in Spatial Association." Spatial Analytical Perspectives on GIS. 111-125.

Anselin, L. 1995. "Local Indicators of Spatial Association-LISA.” Geographical Analysis. 27(2):93-115.

Anselin, L. 1998 Spatial Econometrics: Methods and Models. Kluwer Academic Publishers, Dordrecht.

Anselin, L., Varga, A., and Z. Acs. 1997. "Local Geographic Spillovers between University Research and High Technology Innovations." Journal of Urban Economics. 42:422-448.

Bauer, A. and A. Black. 1994. "Quantification of the Effect of Soil Organic Matter Content on Soil Productivity." Soil Science Society of America Journal 58:185-193.

Ball, E., Wang, S., and R. Nehring. 2014. Agricultural Productivity in the U.S. ERS, U.S. Department of Agriculture, Washington, D.C.

Can, A. 1990. "The Measurement of Neighborhood Dynamics in Urban House Prices." Economic Geography. 66:254-272.

Can, A. 1992. "Specification and Estimation of Hedonic Housing Price Models." Regional Science and Urban Economics. 22:453-474

Cavailhes, J. and P. Wavresky. 2003. "Urban Influences in Periurban Farmland Prices." European Review of Agricultural Economics. 30:333-357.

Chavas, J, Chambers, R, and R. Pope. 2010. "Production Economics and Farm Management: a Century of Contributions." American Journal of Agricultural Economics. 92(2):356-375.

Cho, S., Chen, Z., Yen, S. and B. English. 2007. "Spatial Variation of Output-Input Elasticities: Evidence from Chinese County-Level Agricultural Production Data." Papers in Regional Science. 86:139-157.

Cliff, A and J. Ord. 1973. Spatial Autocorrelation. Pion Limited, London. 
Debertin, D.L. (2012) Agricultural Production Economics. 2nd ed. Pearson Education, Upper Saddle River.

Dettori, B., Marrocu, E., and R. Paci. 2012. "Total Factor Productivity, Intangible Assets and Spatial Dependence in the European Regions." Regional Studies. 46:1401-1416.

Dubin, R.A. 1992. "Spatial Autocorrelation and Neighborhood Quality." Regional Science and Urban Economics. 22:433-452

Elhorst, J.P. 2010. “Applied Spatial Econometrics: Raising the Bar." Spatial Economic Analysis. 5(1):9-28.

Environmental Protection Agency. 2015. "Economic Overview." Washington, D.C. http://www.epa.gov/agriculture/ag101/printeconomics.html

Environmental Protection Agency. 2015. "Land Use Overview." Washington, D.C. http://www.epa.gov/agriculture/ag101/landuse.html

Food and Agricultural Organization of the United Nations. 2015. "Agricultural Outlook 20142023." http://www.agri-outlook.org

Fingleton, B. and J. Mccombie. 2006. "Empirical Growth Models With Spatial Effects." Papers in Regional Science. 85:177-198.

Florax, R., Folmer, H. and S. Rey. 2003. "Specification Searches in Spatial Econometrics: the Relevance of Hendry's Methodology." Regional Science and Urban Economics. 33:557-579.

Kilkenny, M. and J. Thisse. 1999. "Economics of Location: A Selective Survey." Computers \& Operations Research 26:1369-1394.

Lambert, D. and S. Cho. 2008. "Forecasting Input Demand Shocks on China's Gross Value of Agricultural Output." Review of Regional Studies. 38:343-359.

LeSage J.P. 1997. "Regression Analysis of Spatial Data." Journal of Regional Analysis and Policy. 27:83-94.

LeSage, J. and R. Pace. 2009. Introduction to Spatial Econometrics. CRC Press, Boca Raton, FL.

LeSage, J. and R. Pace. 2014. "The Biggest Myth in Spatial Econometrics." Econometrics. 2:217-249.

Leung, Y., Mei, C., and W. Zhang. 2000. "Testing for Spatial Autocorrelation Among the Residuals of the Geographically Weighted Regression." Environment and Planning A. 32:871890 
Lokupitiya, E., Paustian, K., Easter, M., Williams, S., Andren, O., and T. Katterer. 2012. "Carbon Balances in US Croplands During the Last Two Decades of the Twentieth Century." Biogeochemstry. 107:207-225.

Lyson, T. and R. Welsh. 1993. "The Production Function, Crop Diversity, And The Debate Between Conventional And Sustainable Agriculture." Rural Sociology. 58(3):424-439.

McMillen, D. 1992. "Probit with Spatial Autocorrelation.” Journal of Regional Science 3:335348

McMillen, D. 2003. "Spatial Autocorrelation or Model Misspecification?" International Regional Science Review. 26:208-217.

Moran, P. 1948. "The Interpretation of Statistical Maps." Journal of the Royal Statistical Society B. 10(2):243-251.

Moran, P. 1950. "Notes on Continuous Stochastic Phenomena.” Biometrika. 37(1/2):17-23.

Shaik, S. 2014. "Re-Examination of Production, Cost, and Restricted Profit Functions Using Quantile Regression Approach.” Agricultural Economics. 45(2):199-212.

Solow, R. 1957. "Technical Change and the Aggregate Production Function." Review of Economics and Statistics. 39:312-320.

Spillman, W. 1923. "Applications of the Law of Diminishing Returns to Some Fertilizer and Feed Data.” Journal of Farm Economics. 5:36-52.

Spillman, W. 1924. "Law of Diminishing Increment in the Fattening of Steers and Hogs." Journal of Farm Economics. 6:166-178.

Spillman, W. 1933. "Use of the Exponential Yield Curve in Fertilizer Experiments." United States Department of Agriculture Technical Bulletin 348.

Spillman, W. and E. Lang. 1924. The Law of Diminishing Returns. Yonkers-on-Hudson, NY. World Book Company.

Stabenow, D. 2014. "Agriculture Reform, Food and Jobs Act of 2013." United States Senate Committee on Agriculture, Nutrition and Forestry.

http://www.ag.senate.gov/download/?id=dfe429ca-4069-4119-a8ee-359dfb29e9c3

Tobler, W. 1970. "A Computer Movie Simulating Urban Growth in the Detroit Region." Economic Geography. 46:234-240.

Torgerson, D. and M. Shane. 2014. "What is Agriculture's Share of the Overall U.S. Economy?" USDA Economic Research Service.

http://www.ers.usda.gov/data-products/ag-and-food-statistics-charting-the-essentials.aspx 
United States Department of Agriculture Economic Research Service. "Agricultural Trade Overview." http://www.ers.usda.gov/topics/international-markets-trade/us-agriculturaltrade.aspx

Vaya, E., Lopez-Bazo, E., Moreno, R. and J. Surinach. 2004. "Growth and Externalities Across Economies: An Empirical Analysis Using Spatial Econometrics” In: Anselin, L., Florax, R., Rey, S. (Eds.). Advances in Spatial Econometrics: Methodology, Tools and Applications. Springer Verlag, 433-455.

Weiss, M. 1996. "Precision Farming and Spatial Economic Analysis: Research Challenges and Opportunities." American Journal of Agricultural Economics. 78(5):1275-1280.

Yu, T., Cho, S., Koc, A., Boluk, G., Kim, S. and D. Lambert. 2014. "Evaluating Spatial and Temporal Variation in Agricultural Output Elasticities in Turkey. Agricultural Economics. 45:279-290. 


\section{Chapter 5: Conclusion}

Without a doubt, the energy mix is changing and this brings forth a variety of new challenges. Standards such as the Energy Independence and Security Act of 2007 and the Clean Power Plan implement aggressive targets with regard to renewable energy production. In an industry which has been dominated by nonrenewable sources such as coal and petroleum, a sizable shift toward renewables has the potential to be a major disruption. This disruption primarily affects the energy sector, but also indirectly affects a wide variety of industries. One industry which is indirectly affected by the push toward renewable energy sources is the agricultural sector. Consider the production of ethanol which relies heavily on corn as a primary input. This new source of demand for corn increases the overall demand for corn-already a highly in-demand product involved in the production of most feedstock and processed foods. Ethanol is only one example in an overwhelmingly dynamic problem. For example-and the subject of one chapter of this dissertation — what about the impact that renewable energy technologies may have in the form of externalities? The analysis of these multifaceted problems provides significant job security for economists and policy analysts. Economists are widely active in forecasting prices, allocating resources, and trying to achieve the ever-elusive ideal of efficiency. The dynamic nature of the market makes this a challenging affair. It is the role of economists to determine how this changing energy mix — driven by nonmarket objectives—is likely to affect the overall economy and its various sub-sectors. Policy makers should then use the findings of economists and other researchers to formulate effective policy which is informed by good science. As chapter 2 of this document shows, policy makers are not always engaged in decision making purely for the people, but the ideal remains. 
This dissertation contributes to the academic literature by providing three independent studies on various aspects of the dynamic and ever changing relationship between energy and agricultural policy. Various econometric techniques are employed such as logistic, hedonic, and spatial econometric regression. In addition, a variety of software packages were utilized in the empirical analysis. These include R (http://www.r-project.com), MATLAB (http://www.mathworks.com/products/matlab/), GeoDa (https://geodacenter.asu.edu/) and ArcGIS (http://www.arcgis.com/). Each of the three studies provides a unique insight into a narrowly defined aspect of the economics and policy of energy and/or agriculture in the United States.

First, consideration is made into the process of policy creation. The main objective of Chapter 2 is to examine what factors influence policy makers in their voting behavior. This is accomplished through a review and synthesis of the literature combined with an econometric regression model. Using a series of legislator-specific, constituent specific, and agricultural finance indicators, voting behavior on the 2014 Farm Bill is analyzed through the use of a simple binary logit regression model. This provides insight into the role of campaign finance, demographics, and constituent desires in the voting decisions of legislators. Results indicate (along with the results of many other studies) that policy makers do not always act in a way that supports the desires of their constituency, and are often influenced significantly by campaign finance and lobbying. To be more specific, legislators did vote in favor of their constituency, but campaign finance and the state of the agricultural sector played the largest role in their decision making. This—while not a surprising result—is a telling way to begin a dissertation on energy and agricultural policy economics. Despite strong (and repeated) evidence that legislators are significantly influenced by funding, the discussion on campaign finance reform has not 
developed to the point that any significant change has taken place. It may be a tall order to ask policy makers to vote on a measure that limits - and likely decreases - their own utility attainment.

Chapter 3 provides a unique look at one type of externality that may occur as a result of the changing energy mix. As a result of the push toward renewables, wind is the fastest growing energy source in the United States. However, wind energy development has faced multiple forms of resistance with opponents citing issues such as bird deaths, noise, and aesthetics. Many studies have been published which examine the potential impact of wind turbines on surrounding residential land values. Research has shown that wind turbines can significantly reduce the value of homes nearby. This study adds to a sparse body of literature which examines the relationship between wind turbines and agricultural land. Given that agricultural landowners' portfolios are comprised heavily of land assets, a significant reduction in value due to wind energy development is of significant concern.

Chapter 3 examines that possibility using a hedonic regression model on the relatively small study area of Somerset County, PA. The model compares assessed land value to a series of land characteristics and other variables which represent the proximity and intensity of surrounding wind turbines. Somerset County is an ideal study area given that it is mostly rural with a high concentration of agricultural land. In addition, the area has undergone significant development of wind energy which tends to run along mountain ridgelines. Results indicate that no significant relationship exists between the value of agricultural land and the presence of wind turbines nearby. This is likely due to the fact that many agricultural land parcels are nonresidential. Individuals tend to have aesthetics as a dominant complaint. As a result, it is predictable that residential land near wind turbines may lose value. On the other hand, non- 
residential land which is primarily for work and not enjoyment is not as likely to face the same perils. This result is not necessarily generalizable to all areas in which agricultural land and wind turbines are present. Given its small area of one county, the findings are quite likely representative of characteristics in nearby counties, but the same is not necessarily true for counties further away. This implies that results should be interpreted with caution and further research would help in solidifying this finding.

Finally, Chapter 4 presents the most methodologically involved study of the dissertation in which agricultural production statistics are examined at the county level for the entire United States in 2012. The goal of this chapter is to consider the role of spatial heterogeneity in agricultural productivity levels across the U.S. This impact is analyzed by estimating a spatially explicit production function for U.S. agriculture. Productivity in this case is not defined by quantity of output, but net income generated. This is because net income is often the bottom line for any business, and productivity does not always mean 'more product.' This study adds to the literature in that traditional studies which estimate production functions are almost always temporal in nature. By considering the role of space, additional information reveals itself.

Results indicate that significant spatial heterogeneity is present which in turn impacts productivity in the form of reduced (and sometimes increased) return to inputs. For example, an apple farm in Arizona is likely to perform quite differently than an Apple farm in Maine. These two regions are defined by intensely different seasons, temperatures, rainfall, soil quality, etc. Clustering of productivity areas is apparent, with high productivity areas concentrated in the Midwest and Southeast, and low productivity areas concentrated in the Northeast and Southwest. This is quite likely due to factors such as land use, geographic characteristics and water availability. No significant spillovers from one region's input use on the net income of 
neighboring regions are observed. Despite this, the presence of a spatial lag is clear. This implies that high net income areas are typically surrounded by other high net income areas. The interpretation of this finding is less clear. It could simply be that counties are similar in characteristics to those around them, thus engaging in similar activity under similar conditions. This study reveals that space plays an important role in the productivity of agricultural operations. One way to utilize this information is to consider the costs and benefits of subsidizing agricultural operations in low productivity areas. Consideration should also be made toward increasing subsidization to high productivity areas, assuming the capacity and demand for goods.

The findings of this study contribute to the current body of academic literature in a variety of ways. First and foremost, it would be naïve to view the role of science in policy as a process in which scientific discovery through empirical research leads to public recognition and ultimately appropriate policy reform. Chapter 2 reveals this and supports many other studies which do the same. While policy makers are voted into office as representatives of a constituency, they are also influenced by their own self-interest. As a result, their behavior can be swayed by the two things that political parties want/need: votes and resources. This leads to the ability of industry to manipulate the political process in order to benefit through the power of coercion. Politicians supply the ability to manipulate the market which is demanded by industry. Industry can supply resources such as funds and sometimes votes. This creates a situation where a mutually beneficial transaction can occur. Despite the rationale of such a scenario, it is not always beneficial with regard to efficiency and deviates from the pure concept of a democratic representative.

Second, space is an important consideration in the analysis of economic and political data. Chapters 3 and 4 reveal this quite clearly. Advances in technology and software provide an 
increasingly useful platform for the analysis of spatial data. Spatially referenced datasets are a Google search away and the tools required to analyze them are often open source and easily accessible. This provides a unique opportunity for the next generation of researchers in which the role of space can be further developed. Techniques such as spatial econometrics and geographical mapping are by no means recent advances, but in the long scale of scientific discovery, they are relatively new. This provides the potential to unearth new discoveries as well as consider the validity of previously accepted paradigms in economic thought. 


\section{Appendix 1: Long-term Energy Projections}

Using data from the EIA Annual Energy Outlook 2015, total energy production is expected to rise (see Figure 9). Despite this trend, it is helpful to break the growth down into various categories.

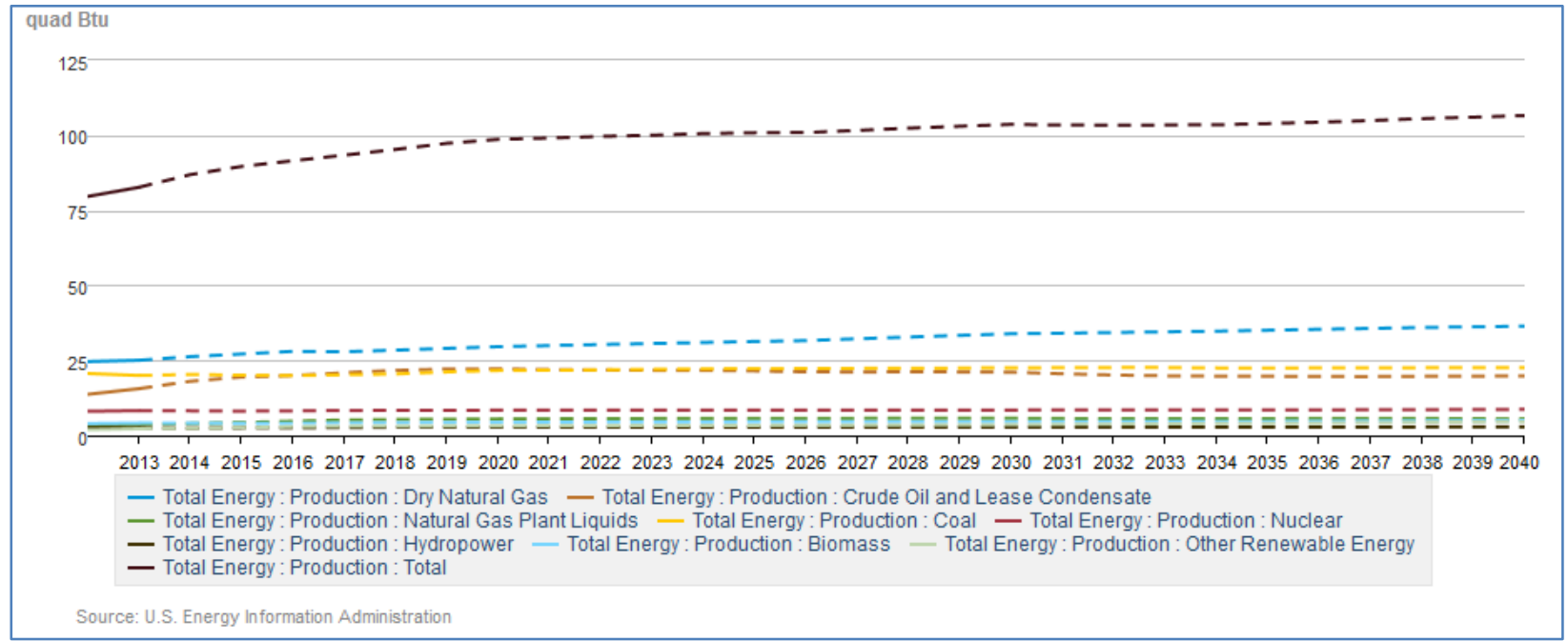

Figure 9: Total Energy Production Projections

Fossil fuels continue to dominate the energy mix in the United States, but various other sources are projected to grow. See Table 10 for a detailed description of growth rates over the next 25 years. While all sources (except 'other') are exhibiting growth, the variation in this growth is significant. It is important to note that this growth is derived from data on quadrillion Btu's of energy production. Total energy production is expected to rise from 89.64 quadrillion Btu in 2015 to 106.58 quadrillion Btu by 2040. Renewable sources exhibit the strongest growth rate at 2.7 percent, while other sources exhibit the weakest growth rates. Other sources are defined as non-biogenic municipal waste, liquid hydrogen, methanol, and some domestic inputs to refineries. 
Table 10: Growth Rates of Energy Production by Source (2015-2040)

\begin{tabular}{|c|c|}
\hline Energy Production & $\begin{array}{c}\text { Growth } \\
\text { Rate }\end{array}$ \\
\hline Crude Oil & $0.9 \%$ \\
\hline $\begin{array}{c}\text { Natural Gas Plant } \\
\text { Liquids }\end{array}$ & $1.7 \%$ \\
\hline Dry Natural Gas & $1.4 \%$ \\
\hline Coal & $0.5 \%$ \\
\hline Nuclear & $0.2 \%$ \\
\hline Conventional Hydro & $0.4 \%$ \\
\hline Biomass & $0.7 \%$ \\
\hline $\begin{array}{c}\text { Other Renewable } \\
\text { Energy }\end{array}$ & $2.7 \%$ \\
\hline Other & $-1.0 \%$ \\
\hline Total & $0.9 \%$ \\
\hline
\end{tabular}

While the differences in these growth rates are substantial, they could potentially be confused with regard to magnitude. For example, the 1.4 percent rate of growth in dry natural gas corresponds to an additional 9.77 quadrillion Btu's of energy production. In contrast, the 2.7 percent growth in 'other renewable energy' corresponds to only 2.7 quadrillion Btu's of energy production. This is an important consideration.

The EIA defines Other Renewable Energy as "grid connected electricity from landfill gas; biogenic municipal waste; wind; photovoltaic and solar thermal sources; and non-electric energy from renewable sources such as active and passive solar systems. Excludes electricity imports using renewable sources and nonmarket renewable energy." This category then refers to the two main sources which are discussed as being renewable (i.e. wind and solar). The EIA makes a distinction and provides a unique category for Nuclear, Hydroelectric Power, and Biomass. It is worth discussing each of these in detail.

Nuclear energy is derived from the core of atoms. When the bonds that hold the nucleus together are broken, energy is released. Thus, energy can be used for the production of 
electricity, but it must first be released. This is accomplished through nuclear fusion and nuclear fission. Nuclear fusion is the process of forming atoms together to form a larger atom. This is not a commonly used technology as research is ongoing regarding its effectiveness and feasibility. Most nuclear energy operations use nuclear fission in which atoms are split to form smaller atoms. Most nuclear plants use Uranium—a common metal found in rocks—as fuel for nuclear fission (EIA, 2014). In 2012, nuclear power plants provided nearly 11 percent of the world's electricity while in 2014, 13 countries derived at least 25 percent of their electricity supply from nuclear (NEI, 2015). At the peak of this trend was France, bringing in 76.9 percent of their electricity from nuclear. Slovakia was a close second at 56.8 percent. The other 11 countries with significantly high nuclear energy production are Hungary, Ukraine, Belgium, Sweden, Switzerland, Slovenia, Czech Republic, Finland, Bulgaria, Armenia and South Korea. The EIA projects that nuclear energy consumption will increase, albeit slowly and steadily.

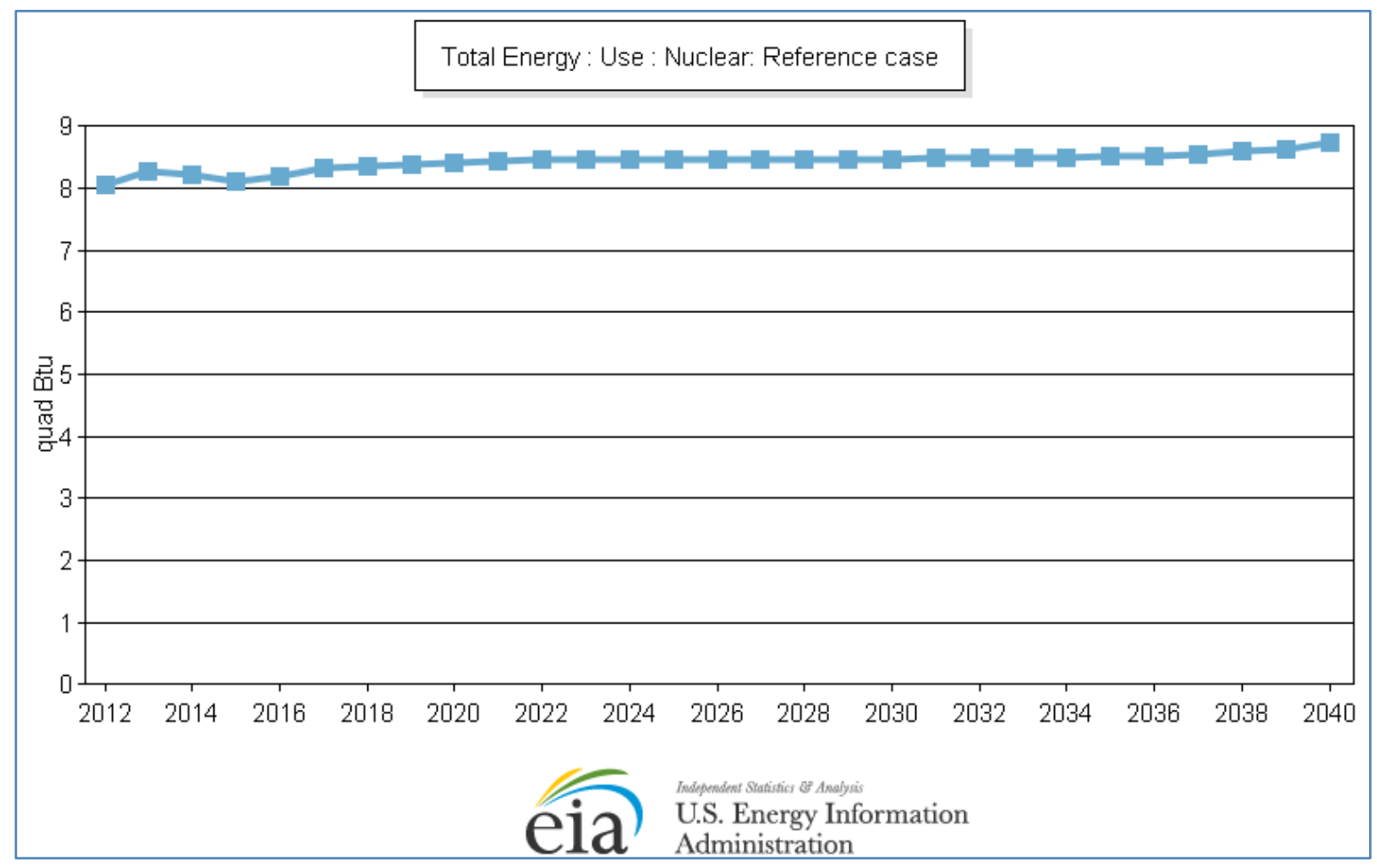

Figure 10: Nuclear Energy Consumption Projections 
Hydroelectric power is another renewable source and the largest renewable source in the U.S. In 2013, hydropower accounted for about 6 percent of electricity generation and 6 percent of total renewable electricity generation. Typically, hydroelectric power plants are located on or near a water source in the form of a dam. It has been used for thousands of years, originally to grind grain. The first U.S. hydroelectric power plant opened in Appleton, WI in 1882. The movement of water pushes a turbine and spins a generator in order to create electricity. Figure 11 shows the historical utilization of hydroelectricity. It is clear that hydroelectricity has been a key renewable

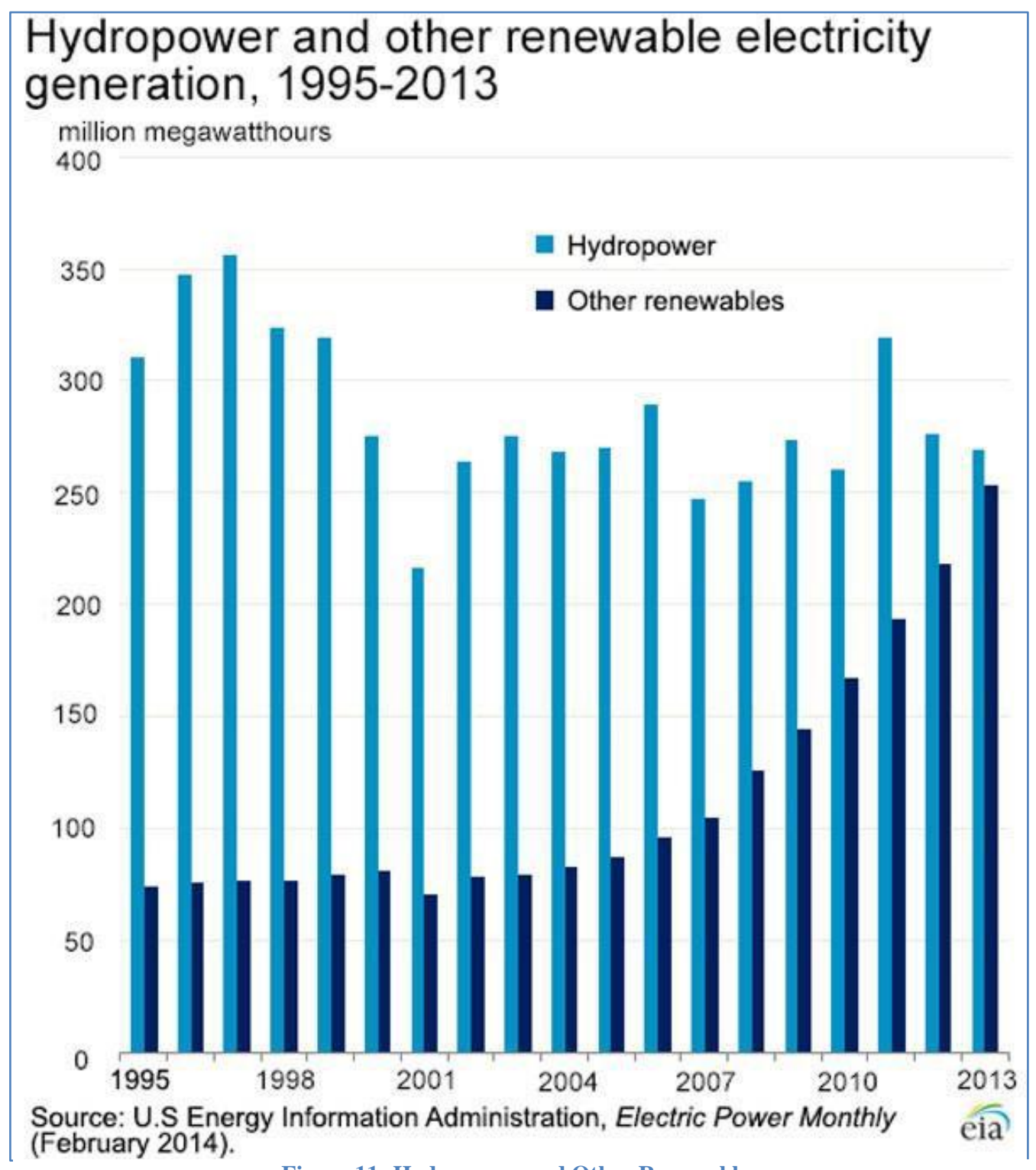

Figure 11: Hydropower and Other Renewables 
energy source for decades, with other sources coming into prominence slowly over time. In the United States specifically, the top hydroelectricity producing states are Washington, Oregon, New York, California, and Alabama. Most hydroelectricity is produced by the federal government. For example, the Bonneville Power Administration is a federal agency which operates in the Pacific Northwest. Managing 31 hydroelectric power plants and various other sources, they supply roughly $35 \%$ of electricity to the Pacific Northwest.

Biomass is derived from wood, crops, garbage, landfill gas, and alcohol fuels. It is organic material that contains stored energy from the sun. Animal manure is a commonly used source. When burned, chemical energy is released and this heat can be used to create electricity. Projections for biomass utilization are particularly interesting. Figure 12 shows an increase of 0.7 percent over the next 25 years. It is important to remember that scale is an issue here. While this seems like a relatively sharp increase, the quantity involved is not large.

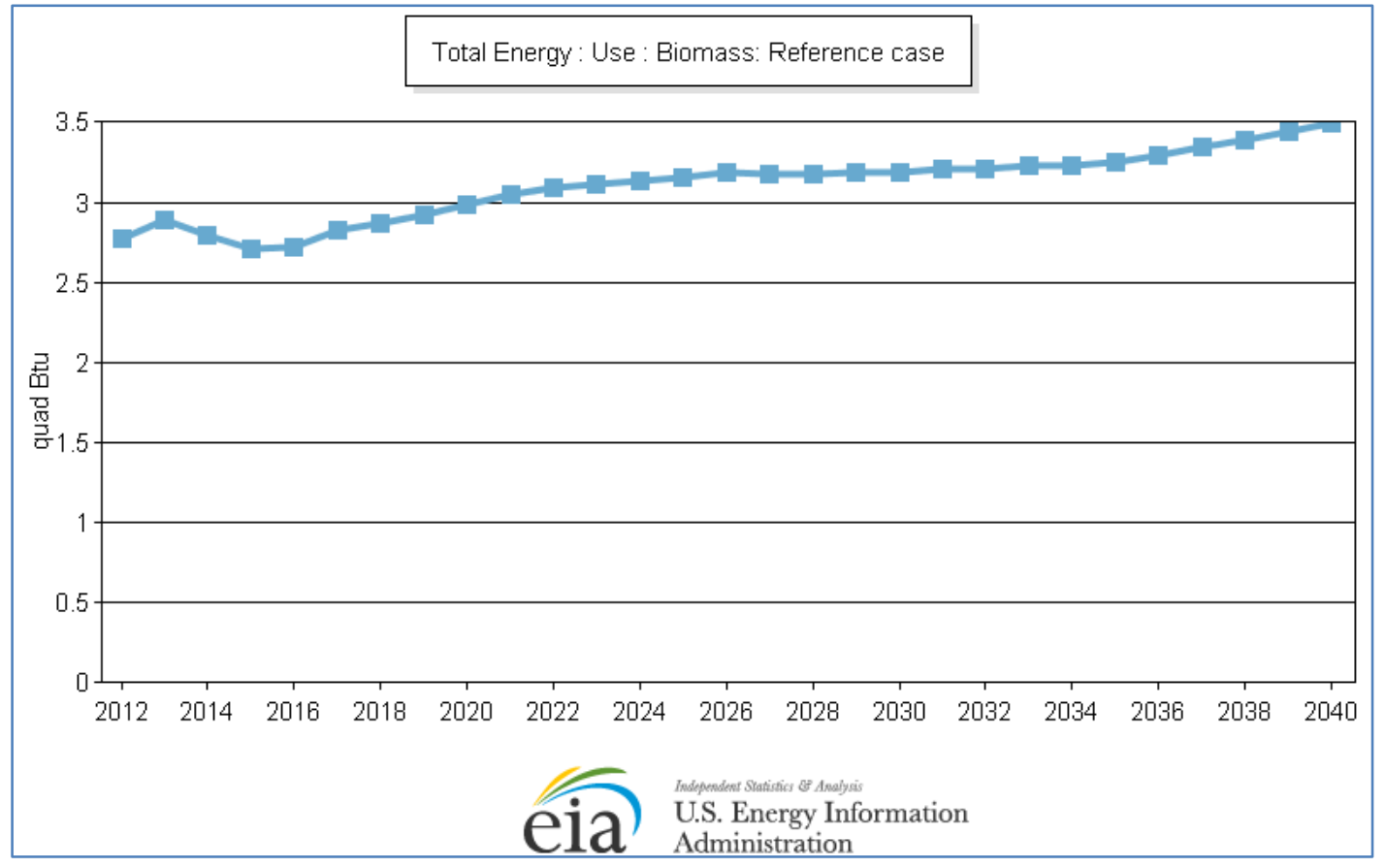

Figure 12: Biomass Consumption Projections 
Other renewable energy consists mostly of wind and solar power. Wind turbines convert energy from the wind into electrical power. Wind is related to solar because wind is actually a form of solar energy. Winds are a result of uneven heating of the atmosphere and rotation of the earth. The spinning turbines can and have been used for grinding grain, pumping water, or most commonly, converting power to electricity by connection to a generator. Solar energy is derived from light and heat from the sun. The most common form of solar energy capture device is the solar panel. Both wind and solar energy are growing as new technology emerges to reduce the cost of their use. This category shows substantial growth and is projected to rise significantly over the next 25 years.

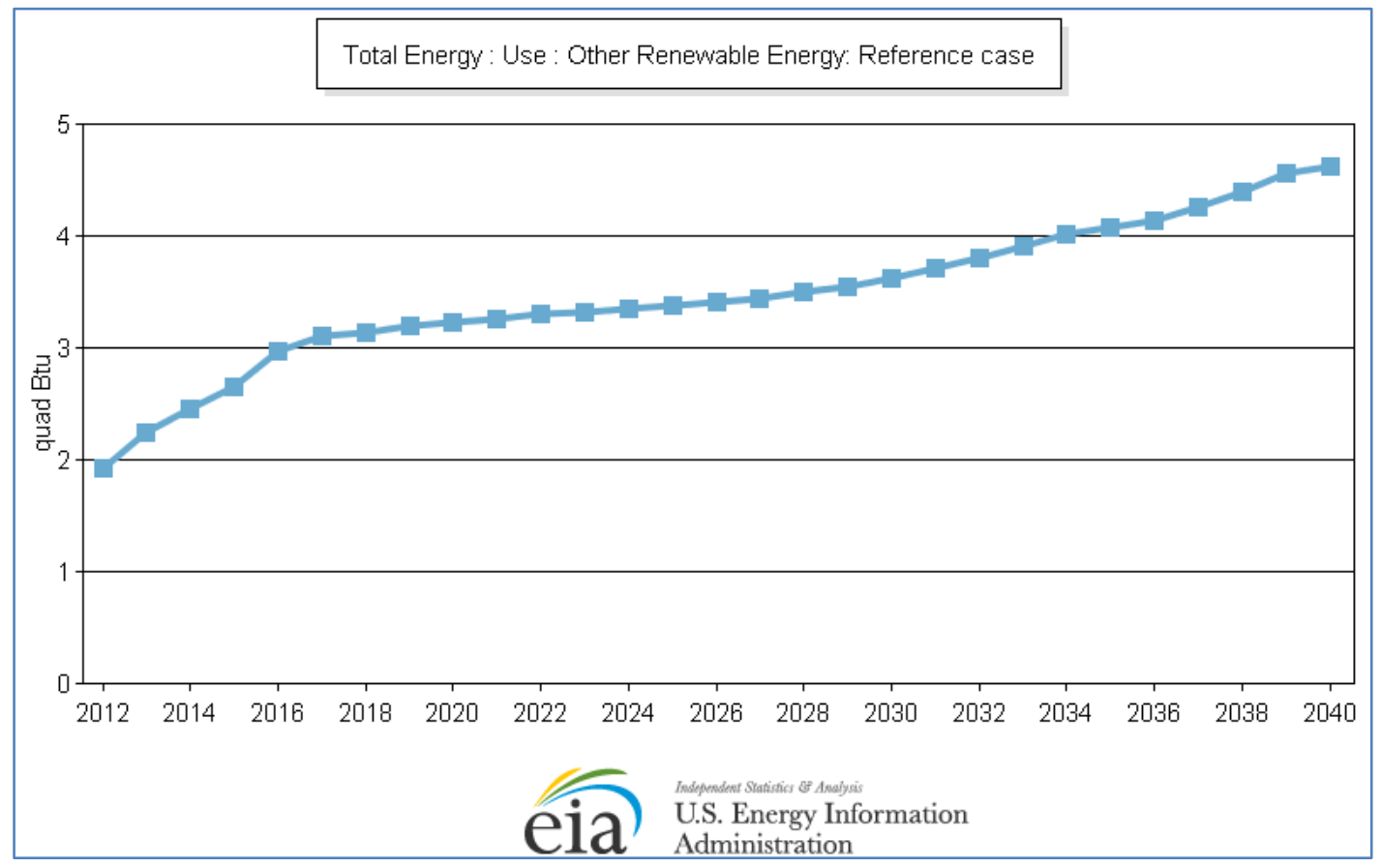

Figure 13: Other Renewable Energy Growth 


\section{References}

EIA. (2014) "Nuclear Explained." U.S. Energy Information Administration. http://www.eia.gov/energyexplained/index.cfm?page=nuclear_home

EIA. (2015) “Annual Energy Outlook 2015” U.S. Energy Information Administration. http://www.eia.gov/forecasts/aeo/

NEI. (2015) "World Statistics: Nuclear Energy around the World.” Nuclear Energy Institute. http://www.nei.org/Knowledge-Center/Nuclear-Statistics/World-Statistics 


\section{Appendix 2: Elhorst Testing Procedure}

Model Space $M=\{$ OLS, SAR, SEM, SDM, SLX, SDEM $\}$ : This is a clear improvement over

Florax et al. The model space contains three global spatial models, two local spatial models, and one ordinary least squares model.

\section{Elhorst Testing Procedure:}

1. Estimate model via OLS \& use the various LM tests to determine the proper model. (Go through the Florax et al. procedure)

2. If OLS is rejected in favor of SAR, SEM, or both, estimate the SDM model.

3. Use the LR test to test the following hypotheses:

a. 9 : $\theta=0$. Testing whether SDM can be reduced to SAR.

b. $\vartheta: \theta+\rho ?=0$. Testing whether SDM can be reduced to SEM.

4. If $?$ 9: $\theta=0$ can't be rejected, use SAR as long as robust LM test stats point to the SAR model.

5. If $\theta=\theta+\rho=0$ can't be rejected, use SEM as long as the $P \curvearrowright \lambda *$ test points to SEM.

6 . If one of the conditions in $4 \& 5$ are not satisfied, use the SDM model.

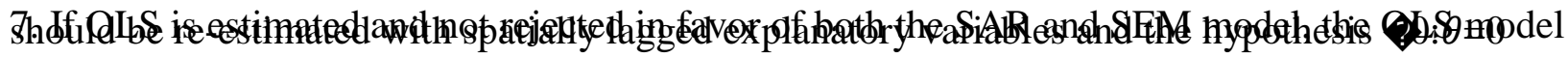 tested.}

8. If $९: \theta=0$ can't be rejected, use OLS.

9. If $\vartheta: \theta=0$ is rejected, the SDM model should be estimated and $\vartheta 9: \rho=0$ should be tested.

10. If $29: \rho=0$ is rejected, use SDM. If $29: \rho=0$ is not rejected, use SLX (OLS with spatially lagged explanatory variables.) 


\section{List of All References}

Abetti, P. (2008) "Congressional Voting on DR-CAFTA: Ineffectiveness of Environmental Lobbying." Journal of Economic Policy Reform, 11:11-20.

Abler, D. (1991) "Campaign Contributions and House Voting on Sugar and Dairy Legislation." American Journal of Agricultural Economics. 73:11-17.

Alston, J., Andersen, M., James, J. and P. Pardey. 2010. “A Brief History of U.S. Agriculture." In Persistence Pays: U.S. Agricultural Productivity Growth and the Benefits from Public R\&D Spending. Natural Resource Management and Policy 34, Springer Science \& Business Media.

Anselin, L. 1988. Spatial Econometrics: Methods and Models. Springer Science \& Business Media.

Anselin, L. 1993. "The Moran Scatterplot as an ESDA Tool to Assess Local Instability in Spatial Association." Spatial Analytical Perspectives on GIS. 111-125.

Anselin, L. 1995. "Local Indicators of Spatial Association-LISA.” Geographical Analysis. 27(2):93-115.

Anselin, L. 1998 Spatial Econometrics: Methods and Models. Kluwer Academic Publishers, Dordrecht.

Anselin, L., Varga, A., and Z. Acs. 1997. "Local Geographic Spillovers between University Research and High Technology Innovations." Journal of Urban Economics. 42:422-448.

Ansolabehere, S., de Figueiredo, J., and Snyder, J. (2003) "Why is There So Little Money in U.S. Politics?” Journal of Economic Perspectives. 17(1):105-130.

Ball, E., Wang, S., and R. Nehring. 2014. Agricultural Productivity in the U.S. ERS, U.S. Department of Agriculture, Washington, D.C.

Bauer, A. and A. Black. 1994. "Quantification of the Effect of Soil Organic Matter Content on Soil Productivity." Soil Science Society of America Journal 58:185-193.

Bender, B. (1991) "The Influence of Ideology on Congressional Voting." Economic Inquiry. 29:416-428.

Bessou, C., Ferchaud, F., Gabrielle, B. and Mary, B. (2011) "Biofuels, Greenhouse Gases and Climate Change. A Review.” Agronomy for Sustainable Development. 31(1):1-79.

Bloomendahl, B., Perrin, R., and Johnson, B. (2011) "The Impact of Ethanol Plants on Surrounding Farmland Values: A Case Study.” Land Economics 87.2: 223-232. 
Bohn, C. and Lant, C. (2009) "Welcoming the Wind? Determinants of Wind Power Development among U.S. States.” Professional Geographer 61.1: 87-100.

Brisman, A. (2005). "The Aesthetics of Wind Energy Systems." NYU Environmental Law Journal 13: 1-133.

Brooks, J. (1997) "Congressional Voting on Farm Payment Limitations: Political Pressure or Ideological Conviction?” Journal of Agriculture and Resource Economics. 22(2):281-295.

Brown, J. and Rosen, H. (1982). "On the Estimation of Structural Hedonic Price Models." Econometrica. 50(3): 765-768.

Can, A. 1990. "The Measurement of Neighborhood Dynamics in Urban House Prices." Economic Geography. 66:254-272.

Can, A. 1992. "Specification and Estimation of Hedonic Housing Price Models." Regional Science and Urban Economics. 22:453-474

Cavailhes, J. and P. Wavresky. 2003. "Urban Influences in Periurban Farmland Prices." European Review of Agricultural Economics. 30:333-357.

Chappell, H. (1982) "Campaign Contributions and Congressional Voting: A Simultaneous ProbitTobit Model." Review of Economics and Statistics. 64:77-83.

Chavas, J, Chambers, R, and R. Pope. 2010. "Production Economics and Farm Management: a Century of Contributions.” American Journal of Agricultural Economics. 92(2):356-375.

Chel, A. and Kaushik, G. (2011) "Renewable Energy for Sustainable Agriculture." Agronomy for Sustainable Development. 31(1): 91-118.

Cho, S., Chen, Z., Yen, S. and B. English. 2007. "Spatial Variation of Output-Input Elasticities: Evidence from Chinese County-Level Agricultural Production Data." Papers in Regional Science. 86:139-157.

Chressanthis, G., Gilbert, K. and Grimes, P. (1991) "Ideology, Constituent Interests, and Senatorial Voting: The Case of Abortion.” Social Science Quarterly. 72:588-600.

Chupp, B. (2011) "Environmental Constituent Interest, Green Electricity Policies, and Legislative Voting." Journal of Environmental Economics and Management. 62:254-266.

Chupp, B. (2014) "Political Interaction in the Senate: Estimating A Political 'Spatial' Weights Matrix And An Application To Lobbying Behavior." Public Choice. 160(3):521-538.

Cliff, A and J. Ord. 1973. Spatial Autocorrelation. Pion Limited, London. 
Coleby, A., Miller, D., and Aspinall, P. (2009) "Public Attitudes and Participation In Wind Turbine Development." Journal of Environmental Assessment Policy \& Management 11.1: 6995.

Colwell, P. and Dilmore, G. (1999) "Who Was First? An Examination of an Early Hedonic Study." Land Economics. 75(4): 620-626.

Congleton, R. (2002) “The Median Voter Model.” In C.K. Rowley and F. Schneider, The Encyclopedia of Public Choice. Kluwer Academic Press.

Constant, L. (2006) "When Money Matters: Campaign Contributions, Roll Call Votes, and School Choice in Florida.” State Politics \& Policy Quarterly. 6(2):195-219.

De Gorter, H. and Just, D. (2010) "The Social Costs and Benefits of Biofuels: The Intersection of Environmental, Energy and Agricultural Policy." Applied Economic Perspectives and Policy. 31(1): 4-32.

Debertin, D.L. (2012) Agricultural Production Economics. 2nd ed. Pearson Education, Upper Saddle River.

Dettori, B., Marrocu, E., and R. Paci. 2012. "Total Factor Productivity, Intangible Assets and Spatial Dependence in the European Regions.” Regional Studies. 46:1401-1416.

Devault, J. (2010) "CAFTA, Campaign Contributions, and the Role of Special Interests." Economics \& Politics. 22(3):282-297.

Devine-Wright, P. "Beyond NIMBYism: Towards and Integrated Framework for Understanding Public Perceptions of Wind Energy." Wind Energy 8: 125-139.

Diffendorfer, J., Compton, R., Kramer, L, and Norton, D. (2014). Onshore Industrial Wind Turbine Locations for the United States through July 2013. United States Geological Survey.

Downs, A. (1957) An Economic Theory of Democracy. New York: Harper and Row.

Dubin, R.A. 1992. "Spatial Autocorrelation and Neighborhood Quality." Regional Science and Urban Economics. 22:433-452

EIA. (2014) "Nuclear Explained.” U.S. Energy Information Administration. http://www.eia.gov/energyexplained/index.cfm?page=nuclear_home

EIA. (2015) “Annual Energy Outlook 2015” U.S. Energy Information Administration. http://www.eia.gov/forecasts/aeo/

Elhorst, J.P. 2010. “Applied Spatial Econometrics: Raising the Bar.” Spatial Economic Analysis. 5(1):9-28. 
Ellison, S. and Mullin, W. (1995) "Economics and Politics - the Case of Sugar Tariff Reform." Journal of Law and Economics. 38(2):335-366.

Environmental Protection Agency. 2015. "Economic Overview." Washington, D.C. http://www.epa.gov/agriculture/ag101/printeconomics.html

Environmental Protection Agency. 2015. "Land Use Overview.” Washington, D.C. http://www.epa.gov/agriculture/ag101/landuse.html

Epple, D. (1987) "Hedonic Prices and Implicit Markets: Estimating Demand and Supply Functions for Differentiated Products." Journal of Political Economy. 95(1):59-80.

ERS (Economic Research Service). (2013) “Corn Overview.” USDA Economic Research Service. http://www.ers.usda.gov/topics/crops/corn.aspx

ERS (Economic Research Service). (2013). "U.S. Agricultural Trade Overview." USDA Economic Research Service. http://www.ers.usda.gov/topics/international-markets-trade/usagricultural-trade.aspx\#.U5h_IyiPW71

FEC (Federal Elections Commission). (2012) "Federal Elections 2012: Election Results for the U.S. President, the U.S. Senate, and the U.S. House of Representatives." http://www.fec.gov/pubrec/fe2012/federalelections2012.shtml

Fingleton, B. and J. Mccombie. 2006. "Empirical Growth Models With Spatial Effects." Papers in Regional Science. 85:177-198.

Fischel, W. (2001). “Why Are There NIMBYS?” Land Economics 77: 144-152.

Florax, R., Folmer, H. and S. Rey. 2003. "Specification Searches in Spatial Econometrics: the Relevance of Hendry's Methodology.” Regional Science and Urban Economics. 33:557-579.

Food and Agricultural Organization of the United Nations. 2015. "Agricultural Outlook 20142023." http://www.agri-outlook.org

Fordham, B. and McKeown, T. (2003) "Selection and Influence: Interest Groups and Congressional Voting on Trade Policy." International Organization. 57:519-549.

Freeman, A.M., Herriges, J. and Kling, C. (2014) The Measurement of Environmental and Resource Values. RFF Press. Resources for the Future. Third Edition.

Gawandde, K. and Hoekman, B. (2006) "Lobbying and Agricultural Trade Policy in the United States." International Organization. 60(3):527-561.

Good, J. (2006). "The Aesthetics of Wind Energy." Human Ecology Review 13: 76-89. 
Goodwin, B. and Smith, V. (2014) "Theme Overview: The 2014 Farm Bill—An Economic Welfare Disaster or Triumph?" Choices: The Magazine of Food, Farm \& Resource Issues. 29(3):1.

Hamilton, N. (2014) "The 2014 Farm Bill: Lessons in Patience, Politics, and Persuasion." Drake Journal of Agricultural Law 19.1:1-37.

Heintzelman, M. and Tuttle, C. (2012) "Values in the Wind: A Hedonic Analysis of Wind Power Facilities." Land Economics. 88(3): 571-588.

Kahane, L. (1996) "Congressional Voting Patterns on NAFTA.” American Journal of Economics and Sociology. 55:4.

Kalt, J. and Zupan, M. (1984) "Capture and Ideology in the Economic Theory of Politics." The American Economic Review. 74:279-300.

Kalt, J. and Zupan, M. (1990) "The Apparent Ideological Behavior of Legislators: Testing for Principal-Agent Slack in Political Institutions.” The Journal of Law \& Economics. 33:103-131.

Kau, J., Kennan, D., and Rubin, P. (1982) “A General Equilibrium Model of Congressional Voting." Quarterly Journal of Economics. 97:271-293.

Kilkenny, M. and J. Thisse. 1999. "Economics of Location: A Selective Survey." Computers \& Operations Research 26:1369-1394.

Ladha, K. (1994) “Coalitions in Congressional Voting.” Public Choice. 76:43-63.

Lambert, D. and S. Cho. 2008. "Forecasting Input Demand Shocks on China's Gross Value of Agricultural Output." Review of Regional Studies. 38:343-359.

Lee, D. and Tkachyk, S. (1987) "An Empirical Analysis of Congressional Voting on Farm Bill Legislation.” Cornell Agricultural Economics Staff Paper. 87(21).

LeSage J.P. 1997. "Regression Analysis of Spatial Data.” Journal of Regional Analysis and Policy. 27:83-94.

LeSage, J. and R. Pace. 2009. Introduction to Spatial Econometrics. CRC Press, Boca Raton, FL.

LeSage, J. and R. Pace. 2014. "The Biggest Myth in Spatial Econometrics.” Econometrics. 2:217-249.

Leung, Y., Mei, C., and W. Zhang. 2000. "Testing for Spatial Autocorrelation Among the Residuals of the Geographically Weighted Regression." Environment and Planning A. 32:871890 
Lokupitiya, E., Paustian, K., Easter, M., Williams, S., Andren, O., and T. Katterer. 2012. "Carbon Balances in US Croplands During the Last Two Decades of the Twentieth Century." Biogeochemstry. 107:207-225.

Lyson, T. and R. Welsh. 1993. "The Production Function, Crop Diversity, And The Debate Between Conventional And Sustainable Agriculture." Rural Sociology. 58(3):424-439.

Maniadis, Z. (2009) “Campaign Contributions as a Commitment Device.” Public Choice. 139:301-315.

McArther, J. and Marks, S. (1988) "Constituent Interest vs. Legislator Ideology: The Role of Political Opportunity Cost.” Economic Inquiry. 26(3):461-470.

McMillen, D. 1992. "Probit with Spatial Autocorrelation.” Journal of Regional Science 3:335348

McMillen, D. 2003. "Spatial Autocorrelation or Model Misspecification?” International Regional Science Review. 26:208-217.

Moran, P. 1948. "The Interpretation of Statistical Maps." Journal of the Royal Statistical Society B. 10(2):243-251.

Moran, P. 1950. “Notes on Continuous Stochastic Phenomena.” Biometrika. 37(1/2):17-23.

Monson, M. (2009) "Valuation Using Hedonic Pricing Models." Cornell Real Estate Review. 7:62-73.

NEI. (2015) "World Statistics: Nuclear Energy around the World.” Nuclear Energy Institute. http://www.nei.org/Knowledge-Center/Nuclear-Statistics/World-Statistics

O'Roark, J. and Wood, W. (2010) "Determinants of Congressional Minimum Wage Support: The Role of Economic Education.” Public Choice. 147:209-225.

Peek, K. (2014) “Is America’s Wind Boom Over?” Popular Science 285: 34.

Peltzman, S. (1976) “Toward a More General Theory of Regulation.” Journal of Law and Economics. 19:211-240.

Powell, L. (2014) "The Influence of Campaign Contributions on the Legislative Process." Duke Journal of Constitutional Law \& Public Policy. 9(1):75-101.

Pralle, S. and Boscarino, J. (2011) "Framing Trade-Offs: The Politics of Nuclear Power and Wind Energy in the Age of Global Climate Change." Review of Policy Research 28.4: 323-346.

Rizzo, J. and Maust, D. (2001) "Understanding the Clean \& Green Program.” Somerset County Assessment Office. 
Rosen, S. (1974) "Hedonic Prices and Implicit Markets: Product Differentiation in Pure Competition." Journal of Political Economy. 81(1): 34-55.

Roscoe, D. and Jenkins, S. (2005) “A Meta-Analysis of Campaign Contributions' Impact on Roll Call Voting.” Social Science Quarterly. 86(1):52-68.

Ross, J., Farmer, M., and Lipscomb, C. (2011) "Inconsistency in Welfare Inferences From Distance Variables in Hedonic Regressions.” Journal of Real Estate and Finance Economics 43.3: 385-400.

Shaik, S. 2014. "Re-Examination of Production, Cost, and Restricted Profit Functions Using Quantile Regression Approach.” Agricultural Economics. 45(2):199-212.

Siler-Evans, K., Azevedo, I., Morgan, M., and Apt, J. (2013) "Regional Variations in the Health, Environmental and Climate Benefits of Wind and Solar Generation." Proceedings of the National Academy of Sciences of the United States of America1 10.29: 11768-11773.

Sims, S. and Dent, P. (2007) "Property Stigma: Wind Farms and Just the Latest Fashion." Journal of Property Investment and Finance 25.6: 626-651.

Sims, S., Dent, P., and Oskrochi, G. (2008) "Modeling the Impact of Wind Farms on House Prices in the UK." International Journal of Strategic Property Management 12.4: 251-269.

Solow, R. 1957. "Technical Change and the Aggregate Production Function." Review of Economics and Statistics. 39:312-320.

Spillman, W. 1923. "Applications of the Law of Diminishing Returns to Some Fertilizer and Feed Data." Journal of Farm Economics. 5:36-52.

Spillman, W. 1924. "Law of Diminishing Increment in the Fattening of Steers and Hogs." Journal of Farm Economics. 6:166-178.

Spillman, W. 1933. "Use of the Exponential Yield Curve in Fertilizer Experiments." United States Department of Agriculture Technical Bulletin 348.

Spillman, W. and E. Lang. 1924. The Law of Diminishing Returns. Yonkers-on-Hudson, NY. World Book Company.

Stabenow, D. (2014) “Agriculture Reform, Food and Jobs Act of 2013." United States Senate Committee on Agriculture, Nutrition, and Forestry.

http://www.ag.senate.gov/download/?id=dfe429ca-4069-4119-a8ee-359dfb29e9c3

Stigler, G. (1971) “The Theory of Economic Regulation.” Bell Journal of Economics. 2:3-21.

Stouffer, R. (2010) "Wind Power Gains Steam in Pennsylvania.” Pittsburgh Tribune Review 09 Apr. 2010. 
Stratmann, T. (1991) "What Do Campaign Contributions Buy? Deciphering Causal Effects of Money and Votes.” Southern Economic Journal. 57(3):606-620.

Stratmann, T. (1992) "The Effects of Logrolling on Congressional Voting." The American Economic Review. 82:1162-1176.

Stratmann, T. (1995) "Logrolling in the U.S. Congress.” Economic Inquiry, 33:441-456.

Swofford, J. and Slattery, M. (2010) "Public Attitudes of Wind Energy in Texas: Local Communities in Close Proximity to Wind Farms and Their Effect on Decision-Making." Energy Policy. 38.5: 2508-2519.

Tobler, W. 1970. "A Computer Movie Simulating Urban Growth in the Detroit Region." Economic Geography. 46:234-240.

Torgerson, D. and M. Shane. 2014. "What is Agriculture's Share of the Overall U.S. Economy?" USDA Economic Research Service. http://www.ers.usda.gov/data-products/ag-and-food-statistics-charting-the-essentials.aspx United States Department of Agriculture Economic Research Service. "Agricultural Trade Overview.” http://www.ers.usda.gov/topics/international-markets-trade/us-agriculturaltrade.aspx

Tosini, S. and Tower, E. (1987) "The Textile Bill of 1985: The Determinants of Congressional Voting Patterns.” Public Choice. 54:19-25.

Tyner, W. (2010) "The Integration of Energy and Agricultural Markets." Agricultural Economics. 41(6): 193-201.

Tyner, W., Dooley, F. and Viteri, D. (2011) "Alternative Pathways for Fulfilling the RFS Mandate.” American Journal of Agricultural Economics. 93(2): 465-472.

United States Census Bureau. (2014) "State \& County Quick Facts.” Online at: http://quickfacts.census.gov/qfd/index.html. Accessed 02 February.

U.S. Senate. (2014) "2014 Farm Bill." United States Senate Committee on Agriculture, Nutrition, and Forestry. http://www.ag.senate.gov/issues/farm-bill

U.S.D.A. (United States Department of Agriculture). (2014) "Farm Bill Highlights." http://www.usda.gov/documents/usda-2014-farm-bill-highlights.pdf

Vaya, E., Lopez-Bazo, E., Moreno, R. and J. Surinach. 2004. "Growth and Externalities Across Economies: An Empirical Analysis Using Spatial Econometrics” In: Anselin, L., Florax, R., Rey, S. (Eds.). Advances in Spatial Econometrics: Methodology, Tools and Applications. Springer Verlag, 433-455. 
Velasco, J. (2008) "Welfare Economics and Policy Analysis of U.S. Biofuels Policy:

Discussion." Review of Agricultural Economics 30.3: 422-424.

Vesenka, M. (1989) "Economic Interests and Ideological Conviction: A Note on PACs and Agricultural Acts.” Journal of Economic Behavior and Organization. 12:259-263.

Vyn, R. and McCullough, R. (2014) “The Effects of Wind Turbines on Property Values in Ontario: Does Public Perception Match Empirical Evidence? Canadian Journal of Agricultural Economics 62.3: 365-392.

Weiss, M. 1996. "Precision Farming and Spatial Economic Analysis: Research Challenges and Opportunities.” American Journal of Agricultural Economics. 78(5):1275-1280.

Welch, W. (1982) "Campaign Contributions and Legislative Voting: Milk Money and Dairy Price Supports.” Western Political Quarterly. 35:478-495.

The White House. (2015) "Fact Sheet: President Obama to Announce Historic Carbon Pollution Standards for Power Plants." The White House. Office of the Press Secretary. https://www.whitehouse.gov/the-press-office/2015/08/03/fact-sheet-president-obama-announcehistoric-carbon-pollution-standards

Yeung, I. (2008) "The Influence of Campaign Contributions on Legislative Voting: A Case Study of the 1996 Farm Bill." Thesis. Department of Economics, Amherst College.

Yu, T., Cho, S., Koc, A., Boluk, G., Kim, S. and D. Lambert. 2014. "Evaluating Spatial and Temporal Variation in Agricultural Output Elasticities in Turkey. Agricultural Economics. 45:279-290. 


\section{Education}

West Virginia University

Ph.D. in Resource Economics (3.8/4.0 GPA)

Morgantown, WV

Dec 2015

Three Essays on the Economics of Agricultural and Energy Policy (Defended 10/23/2015)

M.S. in Agricultural \& Resource Economics

May 2014

B.S. in Economics

May 2012

Employment

State Street Corporation | Model Validation Group

Quantitative Analyst | Asst. Vice-President

- Responsible for rigorous validation of financial models (i.e. LGD, PD, etc.) through examination of theoretical specification, methodological/statistical approach, and model performance

- Assisted in the development of a quantitative model risk scoring system for enterprise risk management

- Co-lead initiatives to enhance compliance with federal regulation (i.e. SR 11-7, Volcker Rule, etc.)

West Virginia University | Division of Resource Mgmt.

Aug 2013 - June 2015

Economic Research Assistant

Morgantown, WV

- $\quad$ Engaged in the development and publication of academic research in applied and regional economics

- $\quad$ Published in a variety of journals related to economic theory, public policy, and natural resources

- $\quad$ Assisted with course materials and delivery for two undergraduate economics courses

Public Consulting Group | Public Partnerships, LLC

Business Analyst

Dec 2012 - June 2013

Morgantown, WV

- Responsible for monitoring and resolving issues with timesheets, spending plans, and payroll

- Assisted with the creation of project proposals, technical documents and policy materials

- Acted as a liaison between clients, consultants, and corporate departments

\section{Qualifications}

General: Applied Microeconomics, Political Economy, Natural Resources and Environment, Spatial Econometrics, Policy Analysis, Quantitative Analytics \& Validation, Risk Management

PhD Coursework: Economic Theory, Econometrics (Time Series, Spatial, Panel), Environmental Economics, Natural Resource Economics, Linear Programming, Public Economics

Computer: R, Matlab, Javascript, ArcGIS, GeoDa, MS Office, Blackboard

\section{Publications}

Shultz, C., Hall, J. and M. Strager. "Production of Wind Energy and Agricultural Land Values: Evidence from Pennsylvania." Oil, Gas, and Energy Quarterly. Forthcoming.

Hall, J. and C. Shultz. "Determinants of Voting Behavior on the Keystone XL Pipeline." Applied Economics Letters. Forthcoming.

Shultz, C. (2015) "Changing Economic Conditions and Why People Work: An Update of Gallaway et al. (1991)." The Empirical Economics Letters. 14(5): 451-459.

Shultz, C. (2015) "Madmen, Intellectuals, and Academic Scribblers: The Economic Engine of Political Change" Journal of Entrepreneurship and Public Policy. 4(3): 394-396.

Shultz, C. "Congressional Voting on the 2014 Farm Bill and the Role of Campaign Finance." Submitted.

Shultz, C., Lacombe, D. and G. D’Souza. "Estimating a Spatially Explicit Production Function for U.S. Agriculture." Submitted.

Hall, J., Shultz, C. and E.F. Stephenson. “A Public Choice Analysis of Local Fracking Bans.” Submitted. 


\section{Teaching}

West Virginia University (TA)

ARE 150 | Introduction to Agribusiness Economics. 3 cr. (68 students)

$A R E 220 \mid$ Introduction to Environmental \& Resource Economics. 3 cr. (35 students)

- Assisted with development of presentations, assignments, and other course materials

- Full responsibility for grading and use of Blackboard system

\section{Presentations}

Shultz, C., Hall, J. and M. Strager. (2015) "Harnessing the Wind: a Win-Win for Energy and Agriculture?" West Virginia University $19^{\text {th }}$ Student Research and Creative Scholarship Day. Morgantown, WV. April 7.

Shultz, C. and G. D’Souza. (2014) "Effect of Climate Change on Fresh Water in the Coming Years." Invited paper (presented by D'Souza). $4^{\text {th }}$ International Congress on Economics, Administration, and Public Accounting. Universidad Nacional de Asuncion. Asuncion, Paraguay. Oct 14-16.

Shultz, C. (2014) "Introduction to Economic Notation and Theory for New Doctoral Students." West Virginia University Division of Resource Management. Morgantown, WV. Aug 18.

\section{Honors}

Grand Awards Judge. Intel Int'l Science and Engineering Fair. Pittsburgh, PA. May 12-13, 2015.

Invited Attendee. U.S. Advanced Research Projects Agency-Energy (ARPA-E) Energy Innovation Summit. Washington, D.C. Feb 9-11, 2015.

President. West Virginia University Graduate Resource Economics Club. Oct 2014 - May 2015.

Recipient. West Virginia Promise Scholarship. 2008 - 2010.

\section{Refereeing}

Land Economics - January 2015

Contemporary Economic Policy - September 2015

\section{References}

\section{Dr. Gerard D'Souza}

Director and Professor of Agricultural \& Resource Economics

West Virginia University

304-293-5490

GDSouza@wvu.edu

\section{Dr. Joshua Hall}

Associate Professor of Economics

West Virginia University

304-293-7870

Joshua.Hall@mail.wvu.edu

\section{Dr. Donald Lacombe}

Associate Professor of Agricultural \& Resource Economics \& Economics

Regional Research Institute

West Virginia University

304-293-8543

Donald.Lacombe@mail.wvu.edu 